\title{
International Union of Basic and Clinical Pharmacology. LXXXVII. Complement Peptide C5a, C4a, and C3a Receptors
}

\author{
Andreas Klos, Elisabeth Wende, Kathryn J. Wareham, and Peter N. Monk \\ Department for Medical Microbiology, Medical School Hannover, Hannover, Germany (A.K., E.W.); and the Department \\ of Infection and Immunity, University of Sheffield Medical School, Sheffield, United Kingdom (K.J.W., P.N.M.)
}

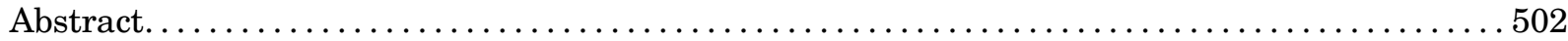

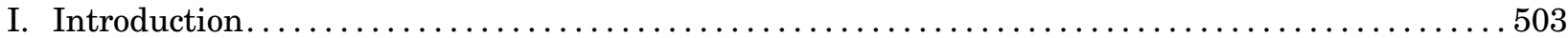

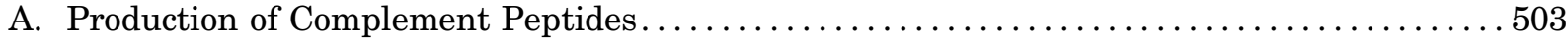

B. Concentrations of Complement Peptides in Health and Disease.................... 503

C. C3a and C5a Generation outside the Complement Cascade ...................... 504

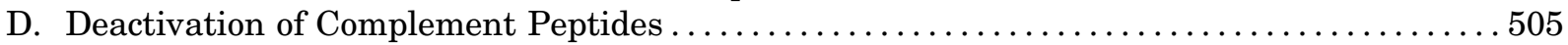

II. The Role of Complement Peptides in Pathophysiology .......................... 505

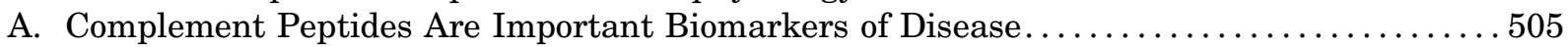

B. Functions of the Complement Peptides beyond Innate Immunity $\ldots \ldots \ldots \ldots \ldots \ldots \ldots \ldots 6$

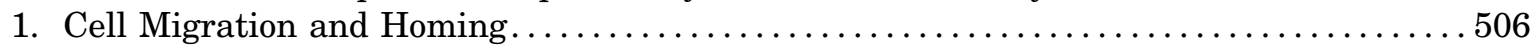

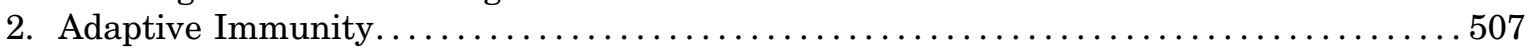

3. Hemopoiesis. ................................................ 508

4. Regeneration and Other Functions..................................... 508

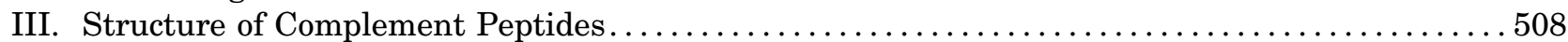

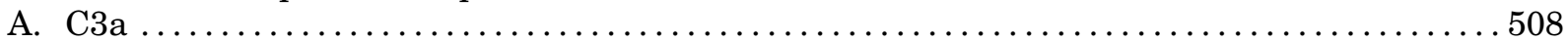

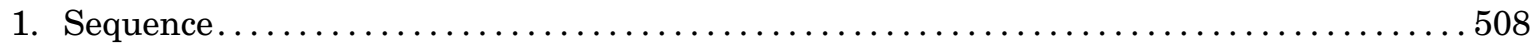

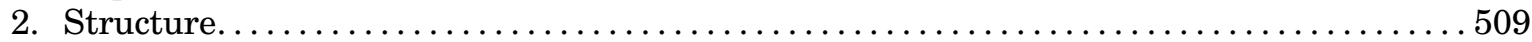

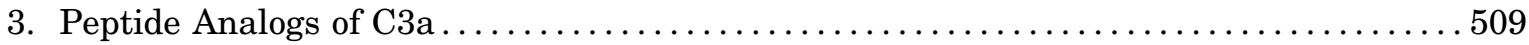

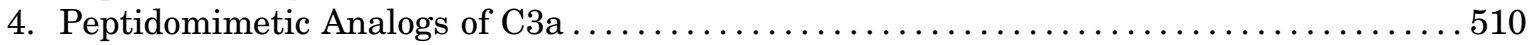

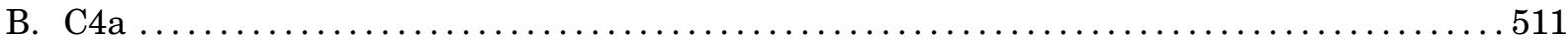

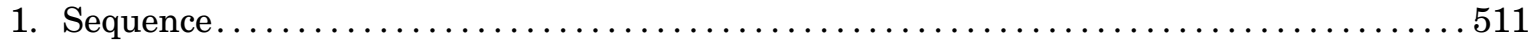

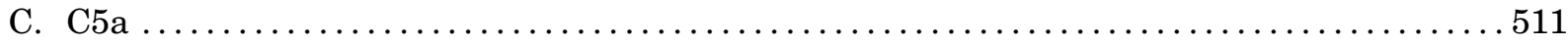

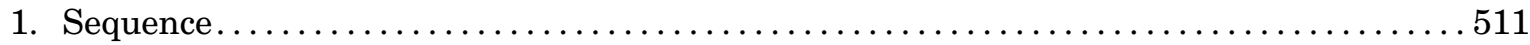

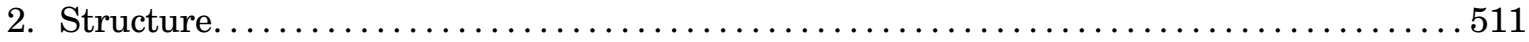

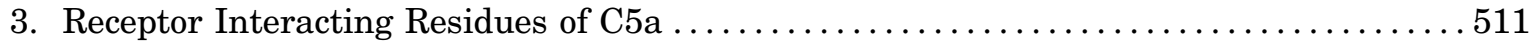

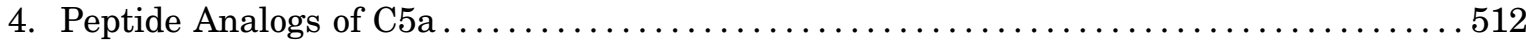

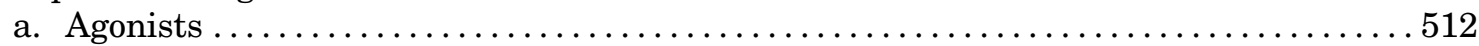

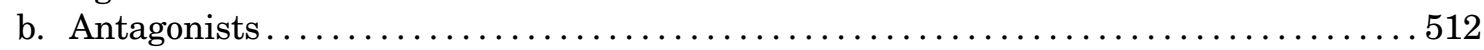

5. Naturally Occurring Non-Complement-Derived Analogs of C5a .............. 513

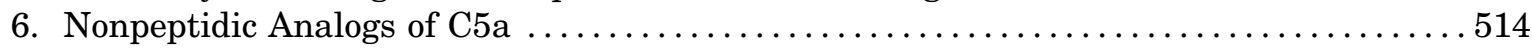

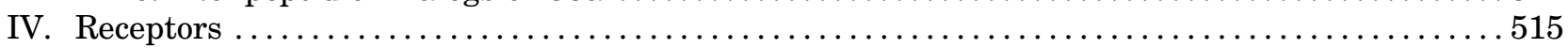

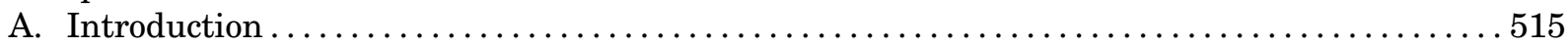

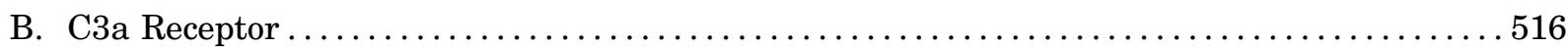

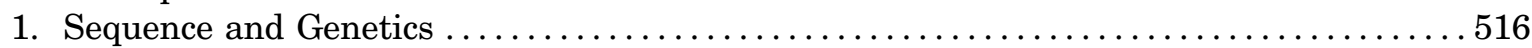

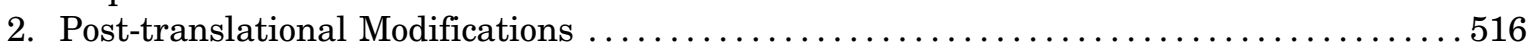

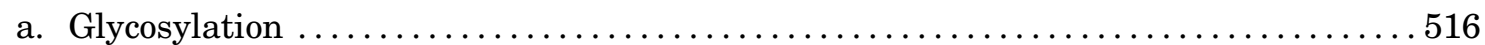

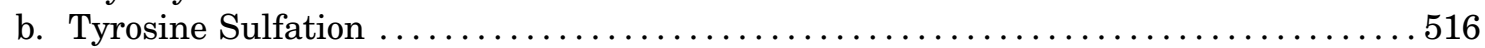

This study was funded in part by the British Heart Foundation [Project Grant PG/09/018/25279] (to P.N.M., for K.J.W.); by the Hannover Biomedical Research School (HBRS/ZIB) (to E.W.); the Helmholtz International Research School for Infection Biology (HIRSIB) (to E.W.); and BMBF Verbund Zoonotischer Chlamydien, TP9 [Project Grants 01 Kl 1011F] (to E.W.), SFB587, TP A16 (to A.K.)].

Address correspondence to: Peter N. Monk, Department of Infection and Immunity, University of Sheffield Medical School, Beech Hill Road, Sheffield S10 2RX, United Kingdom. E-mail: p.monk@shef.ac.uk

dx.doi.org/10.1124/pr.111.005223. 


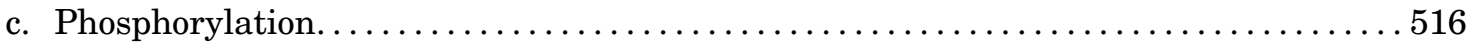

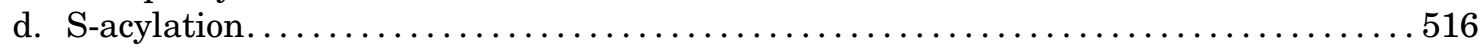

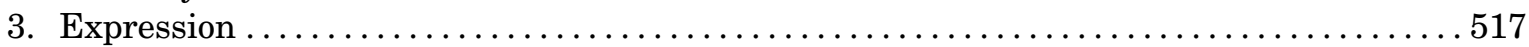

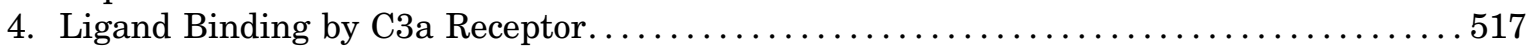

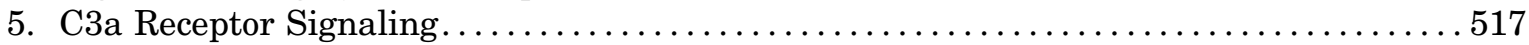

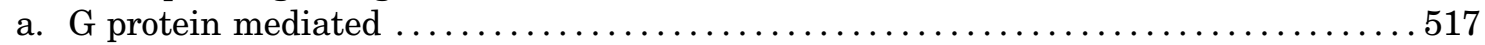

b. Arrestin mediated.................................................. 517

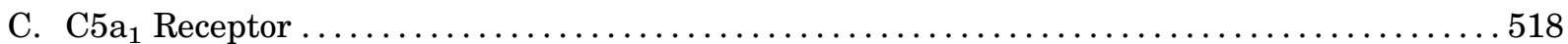

1. Sequence and Genetics ............................................. 518

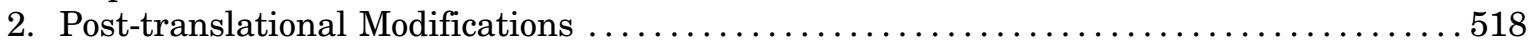

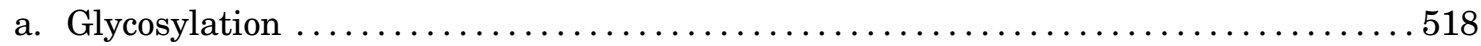

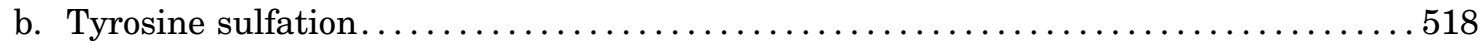

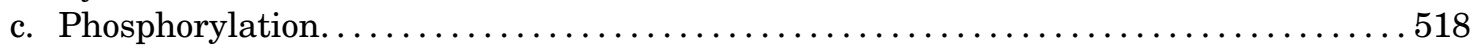

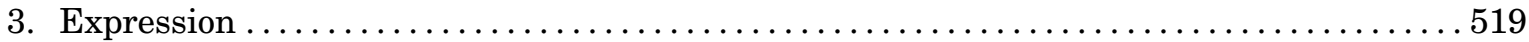

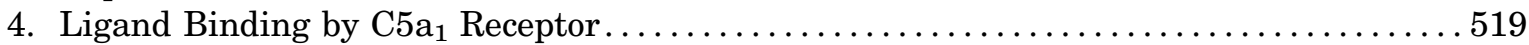

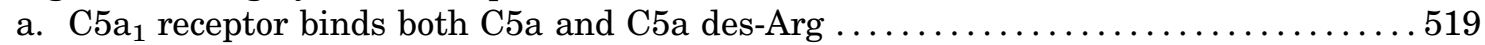

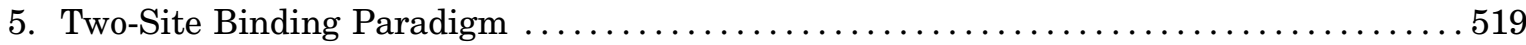

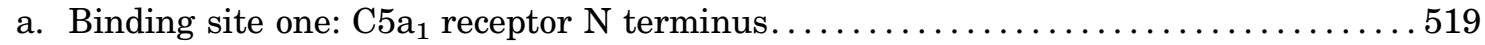

b. Binding site two: transmembrane/extracellular loop regions of $\mathrm{C}^{2} \mathrm{a}_{1}$ receptor $\ldots \ldots 520$

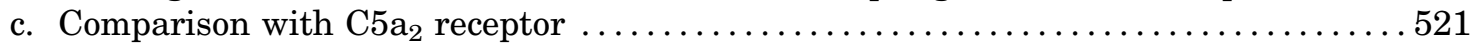

6. ${\mathrm{C} 5 \mathrm{a}_{1} \text { Receptor Signaling } \ldots \ldots \ldots \ldots \ldots \ldots \ldots \ldots \ldots \ldots \ldots \ldots \ldots \ldots \ldots \ldots \ldots \ldots \ldots \ldots \ldots \ldots \ldots \ldots \ldots \ldots \ldots \ldots \ldots \ldots}$

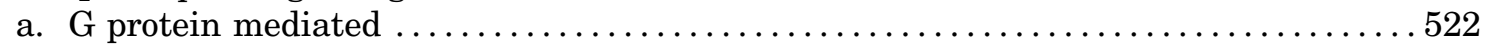

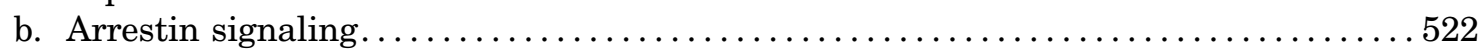

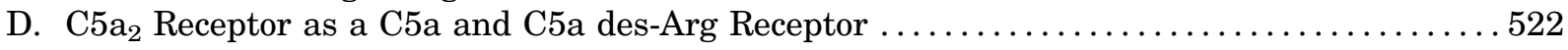

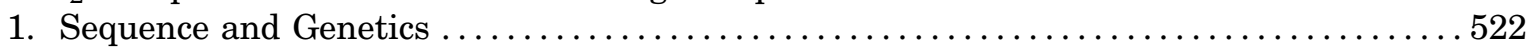

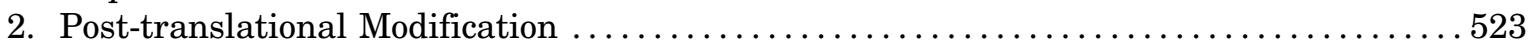

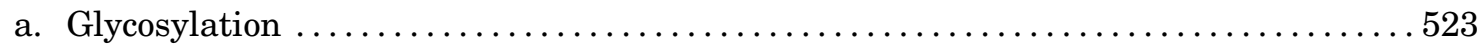

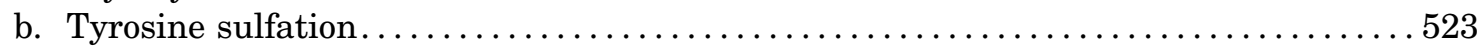

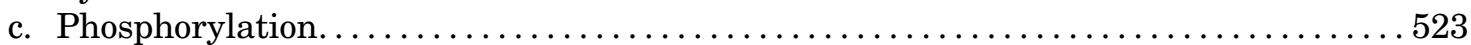

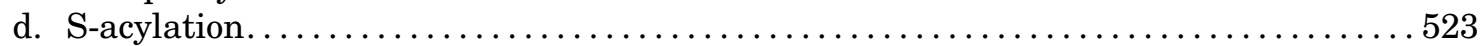

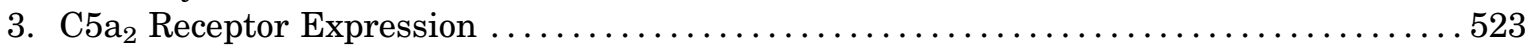

a. Intracellular or extracellular localization for $\mathrm{C}^{2} \mathrm{a}_{2}$ receptor $\ldots \ldots \ldots \ldots \ldots \ldots \ldots 23$

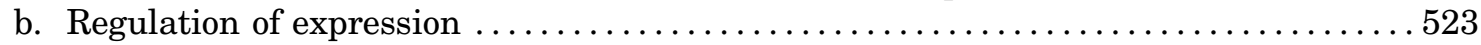

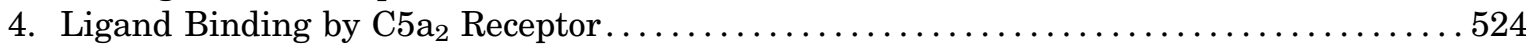

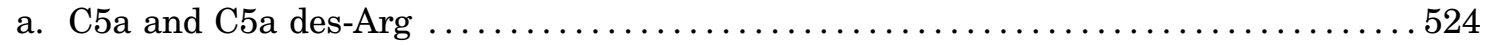

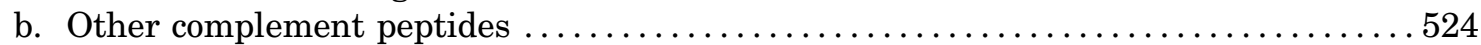

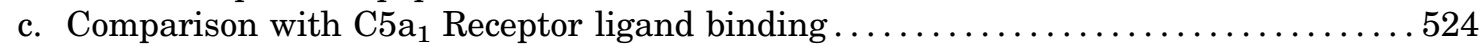

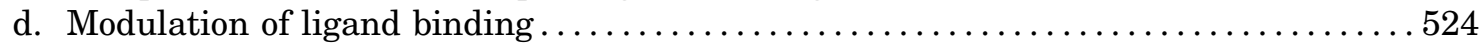

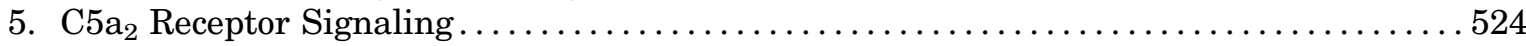

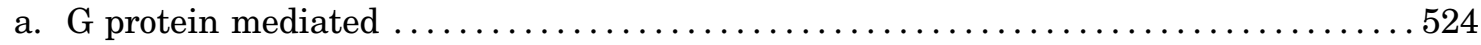

\begin{abstract}
ABBREVIATIONS: ALS, amyotrophic lateral sclerosis; AMD, age-related macular degeneration; AMPK, adenosine monophosphateactivated protein kinase; AP-1, activator protein 1; apoB, apolipoprotein B; apoE, apolipoprotein E; ASP, acylation-stimulating protein; AUrich, adenylate-uridylate-rich; BMI, body mass index; Cha, cyclohexylalanine; CHIPS, chemotaxis inhibitory protein of Staphylococcus aureus; $\mathrm{CHO}$, Chinese hamster ovary; CLP, cecal ligation and puncture; CPB, carboxypeptidase B; CPN, carboxypeptidase N; CPR, carboxypeptidase R; CRP, C-reactive protein; DC, dendritic cell; DMSO, dimethyl sulfoxide; EC, extracellular domain; EDTA, ethylenediaminetetraacetic acid; ELISA, enzyme-linked immunosorbent assay; ERK, extracellular signal-regulated kinase; FEV1, forced expiratory volume in 1 second; FL, fluorescence labeled; FPR, formyl peptide receptor; GPCR, G-protein-coupled receptor; HEK, human embryonic kidney; HMGB1, highmobility group box 1; Hoo, hydroxyorotic acid; HSF, human skin fibroblast; IC, inhibitory concentration; IFN, interferon; IL, interleukin; JPE1375, Hoo-Phe-Orn-Pro-(d-HLeu)-Phe4F-Phe; LDL, low-density lipoprotein; LPL, lipoprotein lipase; LPS, lipopolysaccharide; MAC, membrane attack complex; MAPK, mitogen-activated protein kinase; MeLeu, methyl-leucine; NDT 9513727, N,N-bis(1,3-benzodioxol-5ylmethyl)-1-butyl-2,4-diphenyl-1H-imidazole-5-methanamine; NF- $\mathrm{B}$, nuclear factor $\kappa \mathrm{B}$; NMR, nuclear magnetic resonance; MSC, mesenchymal stem cells; NDT 9513727, $N, N$-bis(1,3-benzodioxol-5-ylmethyl)-1-butyl-2,4-diphenyl-1H-imidazole-5-methanamine; OmpH, outer-membrane protein H; OVA, ovalbumin; PBMC, peripheral blood mononuclear cell; PLC, phospholipase C; PMN, polymorphonuclear neutrophilic granulocyte; PMX53, (3D53) (Ac)Phe-[Orn-Pro-dCha-Trp-Arg]; PT, pertussis toxin; RBL, rat basophilic leukemia; RSM, random saturation mutagenesis; S-1-P, sphingosine-1-phosphate; SB290157, N(2)-[(2,2-diphenylethoxy)acetyl]-L-arginine; SLE, systemic lupus erythematosus; SNP, single-nucleotide polymorphism; TAFI, thrombin-activatable fibrinolysis inhibitor; TG, triglyceride; TGC, thioglycolate; TLR, Toll-like receptor, TM, transmembrane domain; TNF- $\alpha$, tumor-necrosis factor $\alpha$; UTR, untranslated region; VLDL, very low-density lipoprotein; W54011, $N$-[(4-dimethylaminophenyl)methyl]- $N$-(4-isopropylphenyl)-7-methoxy-1,2,3,4-tetrahydronaphthalen-1-carboxamide hydrochloride.
\end{abstract}




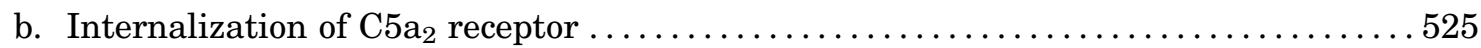

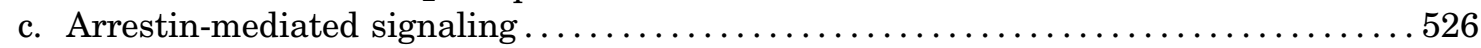

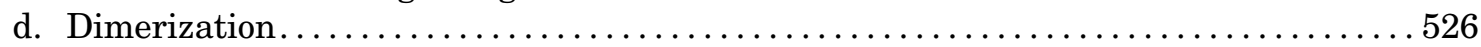

e. Cross-talk with Toll-like receptors ................................ 526

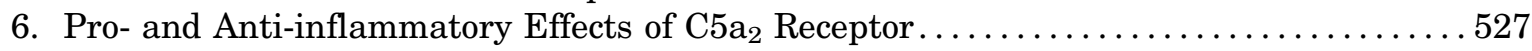

E. C5 $\mathrm{a}_{2}$ Receptor as a Possible Receptor for C3a des-Arg /Acylation Stimulating Protein ..... 527

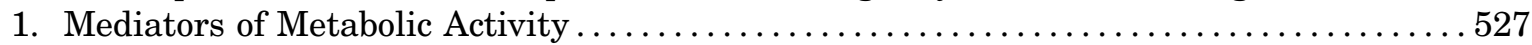

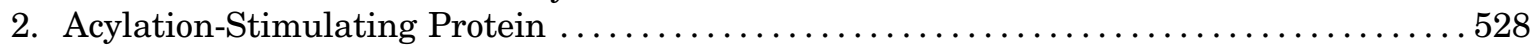

3. The Challenges in Designing Studies Involving Acylation-Stimulating Protein . . . . . 528

a. Lack of an acylation-stimulating protein knockout model. .................. 528

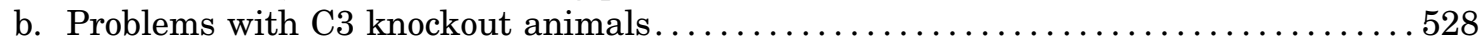

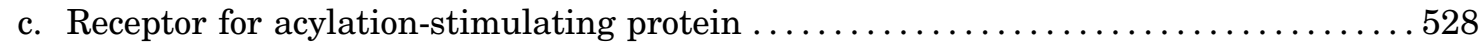

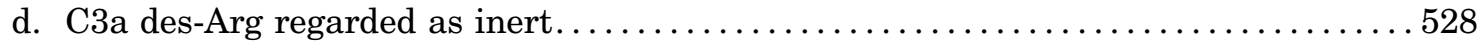

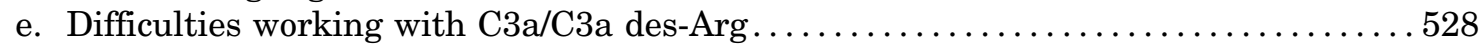

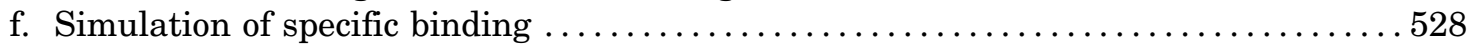

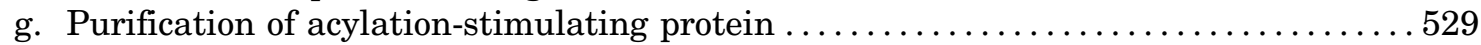

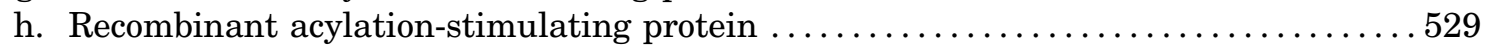

4. Review of Evidence for ${\mathrm{C} 5 \mathrm{a}_{2}}_{2}$ Receptor as the Receptor for Acylation-Stimulating

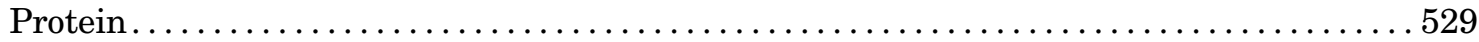

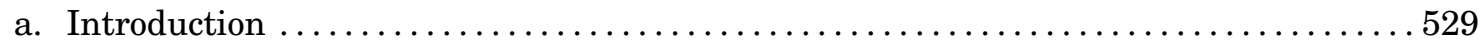

b. Changes after application of an oral fat load in diets..................... 529

c. Modified acylation-stimulating protein levels in various diseases and during a modified hormonal status ..................................... 529

d. Animal models, complement factor C3, acylation-stimulating protein, and

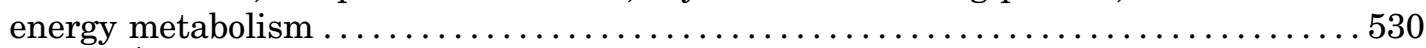

e. $C 5 a r 2^{-1-}$ mice and blockade of $\mathrm{C}^{2} \mathrm{a}_{2}$ receptor by antibodies $\ldots \ldots \ldots \ldots \ldots \ldots \ldots 50$

f. Systemic application of purified acylation-stimulating protein or recombinant

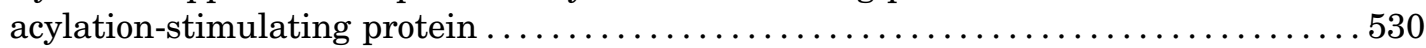

g. In vitro data using purified acylation-stimulating protein, synthetic C3a-related peptides, or recombinant acylation-stimulating protein .................. 531

h. Summary and assessment of the role of C3a des-Arg /ASP and C5a $\mathrm{a}_{2}$ receptor ....532

V. Complement Peptide Functions Not Mediated by the Three Known Receptors .............552

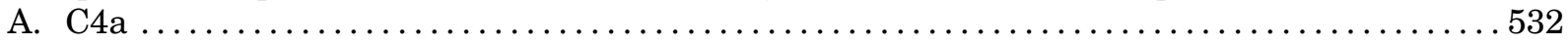

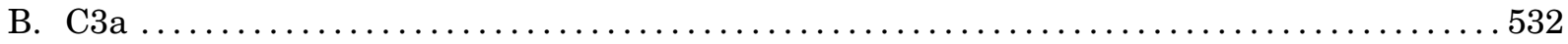

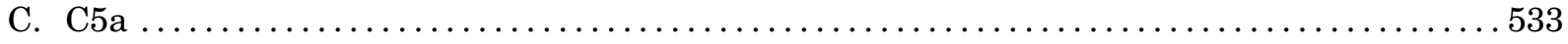

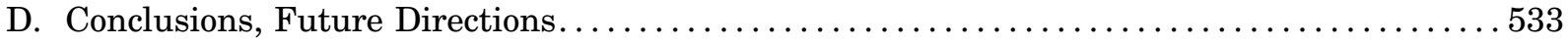

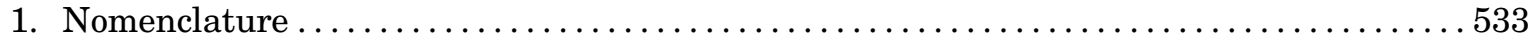

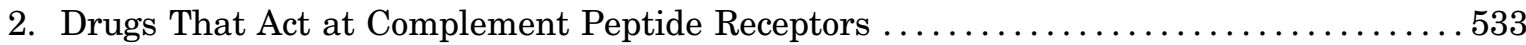

3. Signaling by Complement Peptide Receptors $\ldots \ldots \ldots \ldots \ldots \ldots \ldots \ldots \ldots \ldots \ldots \ldots \ldots 33$

References .................................................... 533

Abstract-The activation of the complement cascade, a cornerstone of the innate immune response, produces a number of small (74-77 amino acid) fragments, originally termed anaphylatoxins, that are potent chemoattractants and secretagogues that act on a wide variety of cell types. These fragments, C5a, C4a, and C3a, participate at all levels of the immune response and are also involved in other processes such as neural development and organ regeneration. Their primary function, however, is in inflammation, so they are important targets for the development of antiinflammatory therapies. Only three receptors for complement peptides have been found, but there are no satisfactory antagonists as yet, despite intensive investigation. In humans, there is a single receptor for C3a (C3a receptor), no known receptor for $\mathrm{C4a}$, and two receptors for $\mathrm{C5a}\left(\mathrm{C5a}_{1}\right.$ receptor and $\mathrm{C5a}_{2}$ receptor). The most recently characterized receptor, the $\mathrm{C5a}_{2}$ receptor (previously known as C5L2 or GPR77), has been regarded as a passive binding protein, but signaling activities are now ascribed to it, so we propose that it be formally identified as a receptor and be given a name to reflect this. Here, we describe the complex biology of the complement peptides, introduce a new suggested nomenclature, and review our current knowledge of receptor pharmacology. 


\section{Introduction}

\section{A. Production of Complement Peptides}

Complement is a vital part of the host defense system, capable of reacting to foreign material and damaged or altered host tissues (Carroll and Sim, 2011). Complement-like genes are present in organisms that diverged more than 1.3 billion years ago (reviewed in Pinto et al., 2007); animals that are incapable of mounting an adaptive immune response possess complement, including the sea-squirt Ciona intestinalis (Pinto et al., 2003) and the "living fossil" horseshoe crab, Carcinoscorpius rotundica (Zarkadis et al., 2001). The complement system consists of a network of soluble and cell-surface proteins that can recognize potential threats and then undergo an amplification phase to produce a response of sufficient proportions to neutralize the perceived danger. The overall response is a balance between positive and negative regulators that allows very fine control of what is a potentially hazardous system: misdirected or excessive activation of complement can be rapidly lethal to the host.

There are three major pathways for the initiation of a complement response (Fig. 1). The first or classic pathway usually requires the formation of immune complexes of IgM or IgG1 antibodies. The closely related second or lectin pathway relies on the direct recognition of foreign material by a series of soluble pattern-recognition receptors. The third or alternative pathway depends on the continual turnover of one component, C3. When complement activation occurs in the fluid phase or proximal to host tissues, inhibitory factors such as CD59 or decay-accelerating factor ensure that no further complement response happens. However, on a receptive surface lacking the appropriate control factors (microbes or xenografts, for example), complement activation is greatly magnified to become a full-blown response even in the absence of any positive triggers.

The complement cascade is based on a series of proteolytic events, with inactive complement proteins successively cleaved to form the next active protease in the chain. The terminal event is the formation of the membrane attack complex (MAC), a lytic pore in the membrane that can cause the death of some cell types. The MAC is inefficient at the cytolysis of nucleated cells, primarily because of defense mechanisms that prevent MAC formation or remove MAC from the cell surface (Tegla et al., 2011). Sublytic MAC, however, is a proinflammatory stimulus for some cell types (reviewed in Dobrina et al., 2002) that has also been linked with the control of hemopoiesis (Ratajczak et al., 2010). The large pool of precursor complement proteins allows a rapid and sizeable response to detected threats; conversely, any failure to control the complement system can lead to inflammatory disease. As

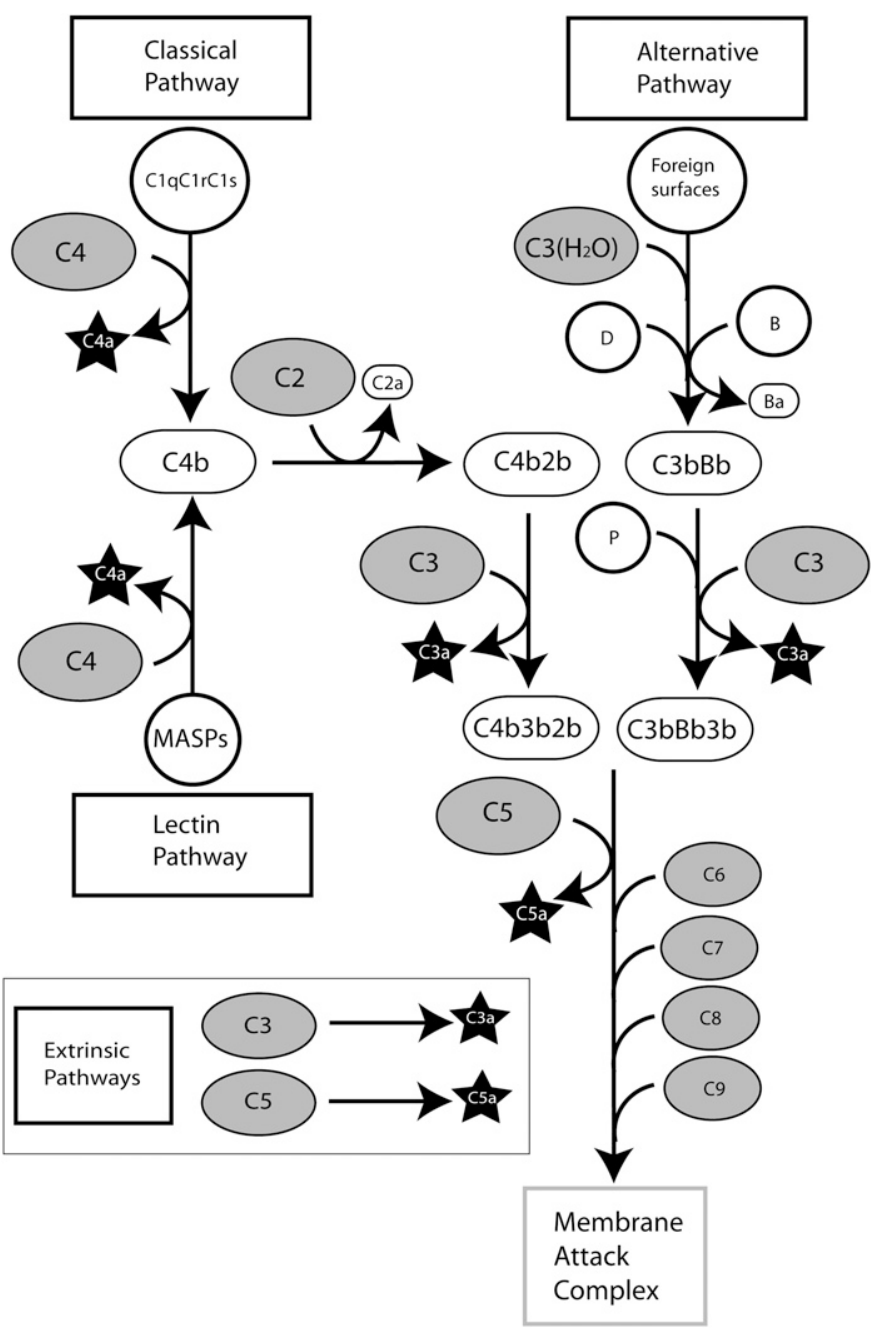

Fig. 1. Pathways for the production of complement peptides. The three major routes of complement activation and the extrinsic pathways for the direct production of complement peptides by protease activities are shown.

a result of proteolysis, a series of small, biologically active protein fragments are produced: C3a and C5a from all three pathways and $\mathrm{C} 4 \mathrm{a}$ primarily from the classic pathway. These protein fragments are rapidly metabolized by carboxypeptidases (Section I.D), forming des-arginated fragments (Burger and Zilow, 1993). Other fragments-for example, derived from the cleavage of $\mathrm{C} 2$ or factor $\mathrm{B}$-are also produced, but these are structurally unrelated to C3a, C4a, and C5a (Krishnan et al., 2009) and are outside the scope of this review.

\section{B. Concentrations of Complement Peptides in Health and Disease}

Determining the "physiologic" levels of complement peptides is problematic, with wide variations in the reported values (Table 1). This is due in part to the different assay techniques and in part to the nature of the biologic sample tested. Serum, obtained after clotting of plasma, generally contains higher levels of 
TABLE 1

Complement peptide concentrations in normal and diseased states

Reported concentrations of complement peptides are shown as nanogram per milliliter.

\begin{tabular}{|c|c|c|c|c|}
\hline \multirow{2}{*}{ Source } & \multicolumn{3}{|c|}{ Peptide } & \multirow{2}{*}{ Reference } \\
\hline & C3a & $\mathrm{C} 4 \mathrm{a}$ & C5a & \\
\hline \multicolumn{5}{|l|}{ Normal } \\
\hline Plasma & 98 & 342 & ND & Lee et al., $2006 \mathrm{~b}$ \\
\hline Serum & 4800 & 1000 & $\sim 0$ & Langone et al., 1984 \\
\hline Pregnancy, plasma & 2393 & 7827 & 20 & Richani et al., 2005 \\
\hline Plasma & 125 & 160 & ND & Terui et al., 1987 \\
\hline Serum & 10,000 & 2000 & 110 & Ohta et al., 2011 \\
\hline Vitreous humor & 98 & 77 & $\sim 0$ & Mondino et al., 1988 \\
\hline Plasma/serum & $152 / 1597$ & $155 / 580$ & $5.4 / 312$ & Wagner and Hugli, 1984 \\
\hline Plasma & 86 & ND & ND & Stove et al., 1996 \\
\hline Plasma & 156 & ND & 5 & Bengtson et al., 1987 \\
\hline Plasma & 20 & 40 & 5 & Strey et al., 2009 \\
\hline \multicolumn{5}{|l|}{ Disease } \\
\hline Aspirin-induced asthma, plasma & 148 & 815 & ND & Lee et al., 2006b \\
\hline Psoriasis, plasma & 253 & 428 & ND & Terui et al., 1987 \\
\hline Colorectal carcinoma, serum & 43,646 & ND & ND & Habermann et al., 2006 \\
\hline Influenza serum & 24,000 & 10,300 & 129 & Ohta et al., 2011 \\
\hline Sepsis, plasma & 976 & ND & ND & Stove et al., 1996 \\
\hline Sepsis, serum, nonsurviving & 1092 & 2385 & 10 & Nakae et al., 1996 \\
\hline Sepsis, serum, surviving & 629 & 631 & 12.3 & Nakae et al., 1996 \\
\hline Acute ischemia, plasma & 630 & - & 12.1 & Bengtson et al., 1987 \\
\hline Liver resection, plasma & 42 & 34 & 6 & Strey et al., 2009 \\
\hline Chronic hepatitis $\mathrm{C}$ virus infection, serum & - & 12,200 & - & Imakiire et al., 2012 \\
\hline
\end{tabular}

ND, not determined.

the fragments due to the actions of the proteases in the clotting cascade on C3, C4, and C5 (Amara et al., 2008) (see Section I.C). Thus, plasma is a more reliable indicator of circulating complement peptide levels, particularly where EDTA has been used, effectively blocking all three major routes of complement activation. Plasma concentrations in healthy human subjects have been reported to be 119,219 , and $5.2 \mathrm{ng} / \mathrm{ml}$ for C3a, C4a, and C5a, respectively (Table 1). It is likely that all these studies are reporting the des-arginated forms of the fragments because the assay methods cannot discriminate between the two forms. In addition, neoepitope-specific antibodies, which can discriminate between $\mathrm{C} 3$ and its cleavage product, detect usually the des-arginated form of C3a with higher sensitivity. Complement peptide levels are clearly elevated in inflammatory diseases and even in pregnancy (Table 1). Elevation of C3a but not C4a suggests activation of the alternative pathway, which does not involve the proteolysis of $\mathrm{C} 4$, whereas very high levels of both $\mathrm{C} 4 \mathrm{a}$ and C3a suggest that both the classic/lectin and alternative pathways are constantly in operation. Both C5a and C5a des-Arg can be rapidly cleared by receptor-mediated endocytosis (Oppermann and Gotze, 1994), unlike C4a des-Arg and C3a des-Arg, which therefore accumulate to much higher levels.

\section{C3a and C5a Generation outside the Complement Cascade}

Although the production of complement peptides is usually linked to the activation of the complement cascade, biologically relevant amounts are also generated by the so-called extrinsic pathways. This was first reported in 1968, when proteolysis of C5 by trypsin was observed to produce anaphylatoxic activity (Cochrane and Muller-Eberhard, 1968). This type of activation is now known to be widespread. Gingipain-1, a cysteine proteinase from Porphyromonas gingivalis, cleaves C3 and C5 to produce leukocyte chemoattractant activities that strongly resemble C3a and C5a (Wingrove et al., 1992), albeit with higher molecular weights than predicted for these fragments. Extrinsic pathway activation may be a common feature of many pathogenic bacteria, being exploited by unrelated organisms such as Tanarella forsythia (Jusko et al., 2012) and Aeromonas sobria (Nitta et al., 2008). For P. gingivalis, the production of $\mathrm{C} 5 \mathrm{a}$ has been proposed to inhibit production mediated by Toll-like receptor 2 (TLR2) interleukin-12 (IL-12), allowing escape from immune clearance (Liang et al., 2011). The feces of the house dust mite Dermatophagoides farinae contain a protease, DerP1, which can generate active complement peptides from C3 and C5 (Maruo et al., 1997). Asbestos and silica can also cause the cleavage of C5 (Governa et al., 2000, 2002, 2005). More recently, cross-talk between the complement and the coagulation cascades has been demonstrated to result in the robust generation of $\mathrm{C} 3 \mathrm{a}$ and $\mathrm{C5a}$, through the actions of factors $\mathrm{Xa} / \mathrm{XIa}$, plasmin, and thrombin (Amara et al., 2010). Factor VII-activating protease can also activate C3 and C5 (Kanse et al., 2012), producing C3a identical to that formed by complement cascade activation but with the N-terminal 4 residues missing from C5a. Enzymes released by activated or damaged host cells can also cause C3a and C5a generation: the proapoptotic aspartic acid protease cathepsin $\mathrm{D}$, elevated 
in trauma (Huber-Lang et al., 2012); $\beta$-tryptase, secreted by mast cells (Fukuoka et al., 2008); and granzyme B, produced by leukocytes (Perl et al., 2012). The relative importance of these fragment-generation systems that lie outside the complement cascade is not yet clear. The increasing availability of inhibitors of complement peptide generation $(\mathrm{Qu}$ et al., 2009; Woodruff et al., 2011) that inhibit either common pathways (e.g., compstatin, which acts on C3) or more specific pathways (e.g., eculizumab, which acts on C5 proteolysis) will help to answer this question.

\section{Deactivation of Complement Peptides}

Human serum contains a potent deactivator of complement peptides, shown to be a carboxypeptidase B-like activity that removes the C-terminal Arg residues of C3a and C5a (Bokisch et al., 1969; Bokisch and Muller-Eberhard, 1970). Inhibition by a carboxypeptidase inhibitor, DL-2-mercaptomethyl-3guanidinoethylthiopropanoic acid, made administration of ordinarily survivable doses of cobra venom factor (CVF) or C3a lethal (Huey et al., 1983). Two major carboxypeptidases control the activity of the fragments. The zinc metalloprotease carboxypeptidase $\mathrm{N}(\mathrm{CPN})$ is released in an active form (Levin et al., 1982), and carboxypeptidase R (CPR) is an acute-phase protein, up-regulated in inflammation and secreted in an inactive form, proCPR (reviewed in Campbell et al., 2001). ProCPR is bound to plasminogen and activated by plasmin or thrombin (Wang et al., 1994; Sato et al., 2000; Nishimura et al., 2007; Leung et al., 2008). It preferentially degrades C5a over C3a (Campbell et al., 2002) and can remove Lys residues from fibrin clots, preventing plasminogen binding (Bajzar et al., 1995). CPR is also known as plasma carboxypeptidase B, activated thrombin-activatable fibrinolysis inhibitor (TAFI), and carboxypeptidase U (Campbell et al., 2001). CPB is a more active carboxypeptidase than CPN and also acts on bradykinin and osteopontin as substrates. TAFI carboxypeptidase is protective in allergic asthma (Fujiwara et al., 2012) and downregulates inflammation in rheumatoid arthritis (RA) (Song et al., 2011). Both CPR and CPN can also inactivate C3a and C5a octapeptides (Section III.C.4) (Campbell et al., 2002).

Defense against host responses by microorganisms can also involve complement peptide degradation. Brugia malayi and Trichinella spiralis, parasitic nematodes, release a metallocarboxypeptidase that inactivates C5a (Rees-Roberts et al., 2010), presumably to prevent eosinophil chemotaxis and activation. Streptococcus pyogenes produces a C5a peptidase (Wexler et al., 1985) that cleaves between His67 and Lys68 (Cleary et al., 1992). This peptidase, ScpA, is a cell wall-anchored serine protease that is important for virulence (Husmann et al., 1997). The virulence of the enterobacterium Serratia marcescens, depends in part on the activity of a $56-\mathrm{kDa}$ protease that can inactivate $\mathrm{C} 5 \mathrm{a}$, thus inhibiting neutrophil influx (Oda et al., 1990).

\section{The Role of Complement Peptides in Pathophysiology}

There is a very fine balance that must be maintained whenever the complement cascade is activated because of the destructive nature of the effector systems: too little may result in incomplete clearance of immune complexes, leading to autoimmune diseases such as systemic lupus erythematosus (SLE) and failure to control infections, but too much causes damage to healthy tissues (Carroll and Sim, 2011). The uncontrolled or inappropriate production of complement peptides has been implicated in many inflammatory disorders, and, although it is beyond the scope of this review to discuss the roles of C3a and C5a in any detail, a list of these disorders is shown in Tables 2 and 3. It should also be noted that C3a and C5a do not always act as partners in crime, both promoting inflammation. In the development of asthma, the generation of C5a during sensitization appears to inhibit the further development of lung disease whereas C3a promotes disease progression, through skewing of the subsequent T-cell response. However, both fragments have deleterious effects at later stages (reviewed in Wills-Karp, 2007). C4a has no known role in human disease.

\section{A. Complement Peptides Are Important Biomarkers of Disease}

The stability of C3a des-Arg and C4a des-Arg has made these complement peptides in particular potentially useful as biomarkers in a number of disorders, even those not traditionally seen as inflammatory in nature such as cancer. Examples are the increased serum levels of $\mathrm{C} 3 \mathrm{a}$ that indicate the presence of colorectal tumors (Habermann et al., 2006), hepatitis C virus-related hepatocellular carcinoma (Lee et al., 2006a; Kanmura et al., 2010), benign prostatic hyperplasia (Xie et al., 2011), and ductal carcinoma in situ of the breast (Solassol et al., 2010). C4a has recently been shown to be elevated in patients with chronic hepatitis $\mathrm{C}$ infection and active disease but is even higher in infected but asymptomatic individuals (Imakiire et al., 2012). Both C4a and C3a levels are predictive of the responses of esophageal cancer patients to chemoradiation (Maher et al., 2011). In more obviously inflammatory disorders, C3a (and to a lesser extent C4a) have been shown to be potentially useful markers in dermatomyositis (Campo et al., 2007), aneurysmal subarachnoid hemorrhage (Mack et al., 2007), acute Lyme disease in tick-bite patients (Shoemaker et al., 2008; Stricker et al., 2009), the exudative form of agerelated macular degeneration (Machalinska et al., 
TABLE 2

Pathologic conditions involving complement peptide C3a

Pathologic Condition

Cardiovascular

Atherosclerotic coronary plaques

Myocardial ischemia and reperfusion injury

Cardiometabolic risk

Resistant hypertension

Spontaneous hypertension

Hepatic

Hepatic function after steatotic liver transplantation

Renal

Renal ischemia/reperfusion

Proteinuric nephropathy

Renal injury in the MRL/lpr mouse

$\beta$-Catenin in renal tubular cells

Complement-induced tubulointerstitial injury

Lupus nephritis

Infection

Gram-negative bacteremia and endotoxic shock

$P$. aeruginosa -induced pneumonia

Arthritis

Chemotactic activity in synovial fluid

Immune complex induced arthritis

Antigen-induced arthritis

Rheumatoid arthritis

Juvenile-onset arthritis

Antibody-induced arthritis

Nervous system

Intracerebral hemorrhage

Demyelination severity

Focal cerebral ischemia

Nociceptive sensitization

Neurodegeneration in experimental lupus

Brain injury after intracerebral hemorrhage

Granulocyte infiltration after focal cerebral ischemia

Asthma

Mucin expression by airway Clara cells

Late asthmatic response and airway hyperresponsiveness Late-stage asthma
Reference

Oksjoki et al., 2007

Busche and Stahl, 2010

Onat et al., 2011

Magen et al., 2010

Xie et al., 2011a

$\mathrm{Xu}$ et al., 2010b

Thurman et al., 2007

Tang et al., 2009

Wenderfer et al., 2009

Liu et al., 2011b

Bao et al., 2011

Mizuno et al., 2007

Hollmann et al., 2008

Mueller-Ortiz et al., 2006

Ward and Zvaifler, 1971

Banda et al., 2010

Banda et al., 2012

Moxley and Ruddy, 1985

Prokopec et al., 2012

Hutamekalin et al., 2010

Garrett et al., 2009

Ingersoll et al., 2010

Mocco et al., 2006

Jang et al., 2010

Jacob et al., 2010a

Rynkowski et al., 2009

Ducruet et al., 2008

Dillard et al., 2007

Mizutani et al., 2009

Mizutani et al., 2012
2009), endometriosis (Fassbender et al., 2009), adverse pregnancy outcomes (Lynch et al., 2011), chronic obstructive pulmonary disease (Marc et al., 2004; Zhang et al., 2011), cryptogenic and large-vessel disease subtypes of stroke (Stokowska et al., 2011), heart failure (Gombos et al., 2012), cerebral arteriovenous malformations (Haque et al., 2011), asthma (Joks et al., 2008), gestational diabetes mellitus (Lappas, 2011), SLE (Wild et al., 1990), acute relapses in multiple sclerosis (Ingram et al., 2010), IgA nephropathy/Henoch-Schonlein nephritis (Abou-Ragheb et al., 1992) and impaired renal function (Abou-Ragheb et al., 1991), atopic dermatitis (Sergeev Iu et al., 1989), psoriasis (Takematsu et al., 1986) and psoriatic arthritis (Muto et al., 1991), idiopathic pulmonary arterial hypertension (Abdul-Salam et al., 2006), postexercise malaise in myalgic encephalomyelitis/chronic fatigue syndrome (Nijs et al., 2010), AIDS-associated retinitis (Mondino et al., 1990), and grafted corneas (Mondino and Sumner, 1990). In addition, C4a and C5a levels decrease after liver resection whereas C3a levels increase (Strey et al., 2009); and C3a and C4a are elevated in liver transplant recipients (Pfeifer et al., 2000). Finally, elevated C3a and C4a in sepsis are associated with a fatal outcome, whereas C5a levels are not correlated (Hack et al., 1989).

\section{B. Functions of the Complement Peptides beyond Innate Immunity}

The complement system has evolved a number of nonimmunologic functions. Homeostasis is maintained by the action of complement on cellular debris, which is important in the prevention of autoimmune responses. In development, complement has roles in bone metabolism, hemopoiesis, angiogenesis, and tissue repair. Complement is also involved in liver and lens regeneration (reviewed in Rutkowski et al., 2010a). This range of activities makes the complement system and its fragments important players in neoplasia (Rutkowski et al., 2010b) and a wide variety of other functions, some of which we will detail.

1. Cell Migration and Homing. In the central nervous system, C3a (and to a lesser extent C5a) is active during the development of the rat cerebellum (Benard et al., 2008) and the in vitro differentiation and migration of neural progenitor cells (Shinjyo et al., 2009). C3a is known to be the coattractant that organizes neural crest cells when they migrate during 
TABLE 3

Pathologic conditions involving complement peptide C5a

Pathologic Condition

Reference

Cardiovascular

Fibrosis in hypertension

Atherosclerosis in $\mathrm{ApoE}^{-1-}$ mice

Preclinical atherosclerosis associated with systemic lupus erythematosus

Arterial injury in atherosclerosis-prone mice

Hemodialysis-associated thrombosis

Human coronary lesions

Complement and coagulation cascades

Pancreatic islet cells express $\mathrm{C}_{5} \mathrm{a}_{1}$ receptor, $\mathrm{C}^{2} \mathrm{a}_{2}$ receptor

Arthritis

Inflammation in autoimmune arthritis

Inflammatory arthritis

Rheumatoid arthritis

Autoimmune arthritis

Renal

Kidney graft survival

Complement-induced tubulointerstitial injury

Age-related macular degeneration

T-cell cytokine release in AMD

Nervous system

Cerebral arteriovenous malformations

Incisional pain

Nociceptive sensitization

Mitochondrial functions of PC12 cells

Complement-

Toll-like receptor cross-talk

Blood-brain barrier integrity in experimental lupus

Alzheimer's disease

Experimental autoimmune encephalomyelitis

Experimental CNS lupus

Pituitary gland function

Amyotrophic lateral sclerosis

Infection

Experimental periodontitis

Bone loss in P. gingivalis infection

Necrotizing enterocolitis

S. aureus bacteremia

Cerebral malaria

Gram-negative bacteremia and endotoxic shock

NKT and NK function in sepsis

Respiratory disease

Chronic obstructive pulmonary disease

Experimental allergic asthma

Other disease

Bullous pemphigoid

Familial Mediterranean fever

Pregnancy

Preterm delivery

Liver

Fulminant hepatic liver failure

Iyer et al., 2011

Manthey et al., 2011

Rua-Figueroa et al., 2010

Shagdarsuren et al., 2010

Kourtzelis et al., 2010

Speidl et al., 2011

Oikonomopoulou et al., 2012

Tokodai et al., 2011

Song et al., 2011

Tsuboi et al., 2011

Hueber et al., 2010

Hashimoto et al., 2010

Lewis et al., 2008; Li et al., 2010

Bao et al., 2011

Liu et al., 2011a

Haque et al., 2011

Jang et al., 2011

Jang et al., 2010

Martinus and Cook, 2011

Wang et al., 2010; Raby et al., 2011

Jacob et al., 2010c

Ager et al., 2010

Ramos et al., 2009

Jacob et al., 2010b

Francis et al., 2008

Woodruff et al., 2008

Breivik et al., 2011

Liang et al., 2011

Tayman et al., 2011

von Köckritz-Blickwede et al., 2010

Patel et al., 2008

Hollmann et al., 2008

Fusakio et al., 2011

Marc et al., 2010

Lajoie et al., 2010; Zhang et al., 2010

Heimbach et al., 2011

Erken et al., 2010

Gonzalez et al., 2011

Sun et al., 2011

Further examples of C5a involvement in disease are detailed in Monk et al. (2007). CNS, central nervous system; NK, natural killer cell; NKT, natural killer T cell.

early development (Carmona-Fontaine et al., 2011). The C3a receptor (C3a receptor, also known as C3aR; see Section IV.B) is a key mediator of insulin resistance and functions by modulating macrophage infiltration and activation in adipose tissue (Mamane et al., 2009). The homing of hemopoietic stem and progenitor cells to bone marrow also depends on the C3a-C3a receptor axis (Reca et al., 2003).

2. Adaptive Immunity. In addition to well-known roles in innate immunity, the complement peptides also act to modulate adaptive immunity (Chenoweth et al., 1982; Ottonello et al., 1999). The presence of complement peptide receptors on certain subsets of B and $\mathrm{T}$ cells has been reported (Martin et al., 1997;
Werfel et al., 2000). Expression levels are much higher on antigen-presenting cells (Sacks, 2010). C3a and C5a produced by dendritic cells (DC) are required for optimal CD4 T-cell help for CD8 T cells in murine allograft rejection (Vieyra et al., 2011). Similarly, locally produced C5a and C3a provide costimulatory and survival signals for naive $\mathrm{CD} 4^{+} \mathrm{T}$ cells (Strainic et al., 2008), and $\gamma \delta$ T-cell function in sepsis can be modulated by C5a (Han et al., 2011) due to increased production of IL-17 after blockade of DC C5a receptor (C5a $\mathrm{a}_{1}$ receptor, also known as C5R1, CD88; Section IV. C) (Xu et al., 2010a). Conversely, preventing C5a stimulation of DC by ablation of the $\mathrm{C}^{2} \mathrm{a}_{1}$ receptor or with a receptor antagonist induces Treg and $\mathrm{T}_{\mathrm{H}} 17$ cells 
by increasing the production of transforming growth factor- $\beta$ (TGF- $\beta$ ) (Weaver et al., 2010). In experimental autoimmune encephalomyelitis, a model of multiple sclerosis, interferon- $\gamma$ (IFN- $\gamma$ ) and IL-17 production in autoreactive $\mathrm{T}$ cells depends on local production of $\mathrm{C} 3 \mathrm{a}$ and C5a (Liu et al., 2008). C5a-mediated $\mathrm{T}_{\mathrm{H}} 17$ differentiation has been proposed to underlie some autoimmune and inflammatory disorders such as autoimmune arthritis (Hashimoto et al., 2010), and blockade of this pathway may be beneficial for the control of these diseases. However, C5a can negatively regulate $\mathrm{T}_{\mathrm{H}} 17$ cell differentiation in asthma (Lajoie et al., 2010), so this therapeutic strategy may be of limited use. In contrast to the many reports of $\mathrm{DC}$ activation by complement peptides, T-cell-expressed $\mathrm{C}^{2} \mathrm{a}_{1}$ receptor is required for enhanced T-cell expansion, as a result of inhibition of apoptosis (Lalli et al., 2008).

3. Hemopoiesis. In contrast to the effects of C3a on stem-cell homing to bone marrow as mentioned previously, C5a and C5a des-Arg disrupt the CXCL12 $(\mathrm{SDF}-1 \alpha) / \mathrm{CXCR} 4$ axis and increase the mobilization of hemopoietic stem and progenitor cells (Jalili et al., 2010). Mobilization of these cells is also impaired in C5-deficient mice (Lee et al., 2009). The roles of complement peptides in stem-cell mobilization have been reviewed elsewhere (Ratajczak et al., 2012).

4. Regeneration and Other Functions. Human mesenchymal stem cells (MSC), which are involved in the repair of various tissues, express complement peptide receptors and are chemoattracted to $\mathrm{C} 3 \mathrm{a}$ and $\mathrm{C} 5 \mathrm{a}$ (Schraufstatter et al., 2009). Interestingly, MSC have been found to modulate innate immunity by activating the complement cascade (Moll et al., 2011). Complement C3a and C5a can modulate bone biology in inflammation (Ignatius et al., 2011b). C5a $\mathrm{a}_{1}$ receptor has been shown to control osteoblast migration during fracture healing (Ignatius et al., 2011a), and efficient osteoclast differentiation requires local complement activation (Ignatius et al., 2011b). Normal heart function appears to depend on the $\mathrm{C} 5 \mathrm{a} / \mathrm{C} \mathrm{a}_{1}$ receptor axis, with C5 deficiency and receptor knockout or blockade causing a "state of distress" (Mullick et al., 2011). C3a also has positive effects on food intake regulation, with the administration of $\mathrm{C} 3 \mathrm{a}$ to the central nervous system leading to suppression of appetite (Ohinata et al., 2002, 2007, 2009; Ohinata and Yoshikawa, 2008).

\section{Structure of Complement Peptides}

Complement components C3, C4, and C5 are thought to have arisen by gene duplication events predating the emergence of cartilaginous fish (Terado et al., 2003). It is therefore not surprising that the complement peptides derived from these proteins all have similar primary structures, with 74 to 79 amino acids (Fig. 2, A-C) and largely conserved Cys residues that suggest similar patterns of disulfide bridges in the tertiary structures. Nuclear magnetic resonance (NMR) and $\mathrm{X}$-ray crystallographic studies have confirmed that the three-dimensional structures of C3a (Nettesheim et al., 1988) and C5a (Zuiderweg et al., 1988) are very similar overall.

\section{A. $C 3 a$}

1. Sequence. All C3a sequences found to date have six Cys residues (numbered 23, 24, 37, 50, 57, and 58 in guinea pig C3a) (Gerard et al., 1988), apart from the deuterostome, $C$. intestinalis, where the outermost pair of Cys residues are missing, implying that it has only two disulfide bridges (Fig. 2A). It is noteworthy that the disulfide bridges in human $\mathrm{C} 3 \mathrm{a}$ appear to be unusually labile (Chang et al., 2008), a phenomenon that may provide additional regulation of the activity of C3a in vivo. Guinea pig C3a has 70\% identity with rat (Jacobs et al., 1978), human, porcine (Corbin and Hugli, 1976), and mouse (Hugli et al., 1975b), and C3a from these species have identical activity in smooth muscle contraction, histamine release, and vascular permeability assays. Among all $\mathrm{C} 3 \mathrm{a}$ sequences, the overall arrangement of basic residues is also highly conserved, with a ubiquitous C-terminal Arg. There is an almost invariant C-terminal Leu-Gly-Leu-Ala-Arg sequence across species, again not wholly conserved in C. intestinalis. Despite these differences, Ciona C3a does bind to a specific receptor, which has significant homology to the mammalian C3a receptor (Melillo et al., 2006). The Ciona C3a-C3a receptor axis is responsible for the chemotaxis of hemocytes, suggesting a role for C3a in inflammation in this organism.

Interestingly, the des-Arg form of Ciona C3a also stimulates chemotaxis of hemocytes (Pinto et al., 2003) whereas C3a des-Arg is inactive in the majority of assays across other species. However, C3a and C3a des-Arg are equipotent in the killing of Gram-positive (e.g., Enterococcus faecalis) and Gram-negative (e.g., Pseudomonas aeruginosa) organisms and are actually more potent than the classic antimicrobial peptide LL37 (Nordahl et al., 2004). It has been suggested that C3a (and C4a) evolved initially as antimicrobial peptides (Pasupuleti et al., 2007), with chemoattractant activity emerging later. Antifungal activity of C3a and C3a des-Arg has also been demonstrated for Candida albicans (Sonesson et al., 2007). The mechanism appears to be the disruption of the plasma membrane and is dependent on Arg residues although the $\mathrm{C}$-terminal Arg is dispensable, demonstrating that the chemotactic and antimicrobial activities of C3a are separate. Heparin can also bind to the same regions of C3a (Andersson et al., 2004) and inhibits antimicrobial activity (Nordahl et al., 2004). Structure-activity studies show that the formation of an amphipathic helix with a high net positive charge is critical for antimicrobial activity (Pasupuleti et al., 2008). 


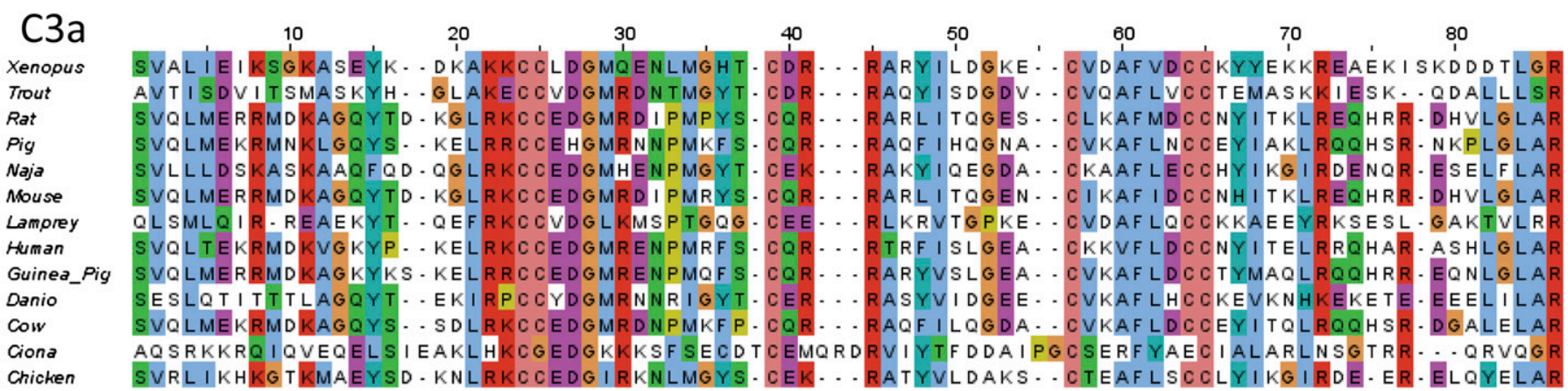

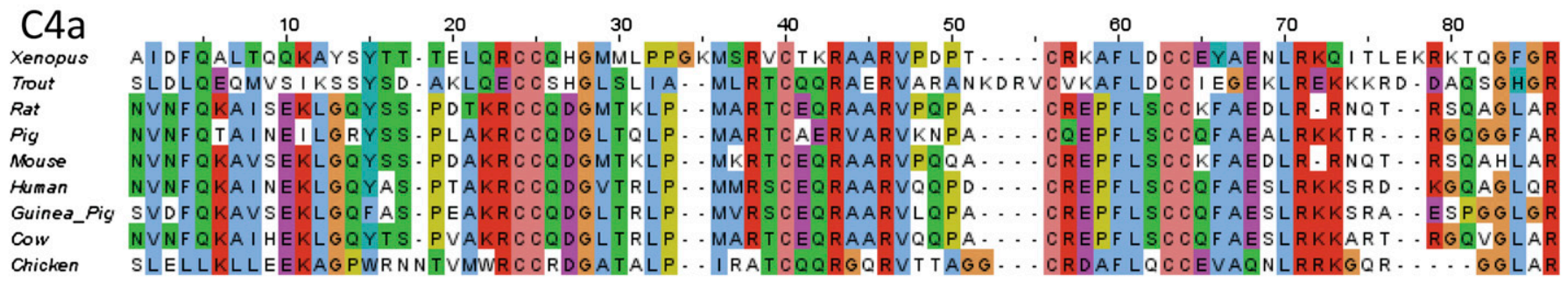

C5a

\section{Xenopus}

Trout

Rat

$$
\text { Pig }
$$

Newt

Mouse

Human

Guinea_Pig

Danio

Cow

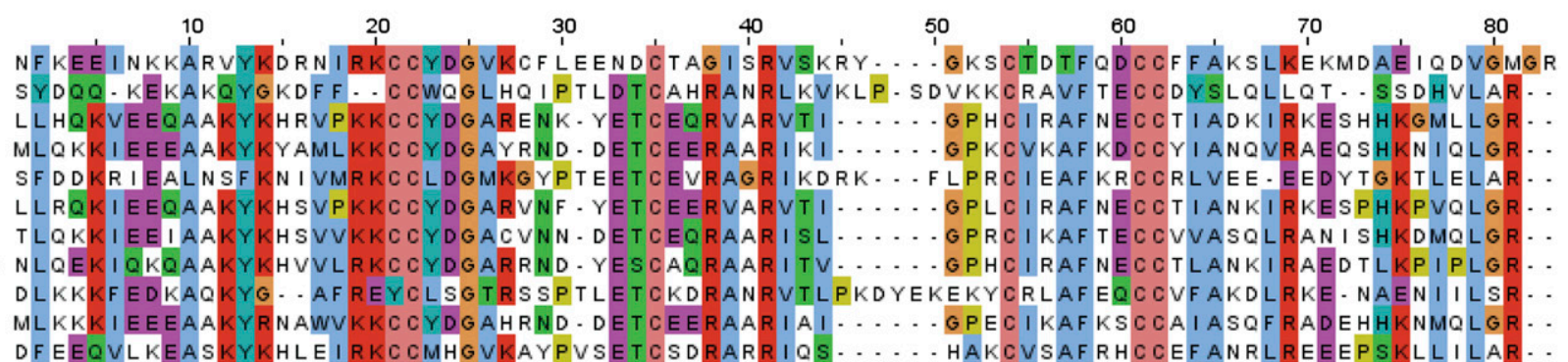

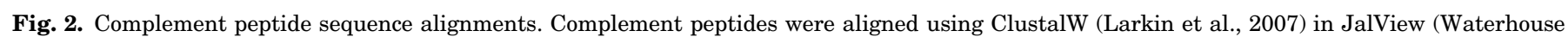
et al., 2009). Conserved residues are colored according to physicochemical properties (http://www.ebi.ac.uk/Tools/msa/clustalw2/help/faq.html\#24).

2. Structure. A crystal structure was obtained for human C3a before one was available for the other complement peptides (Huber et al., 1980; Paques et al., 1980), and it has also been investigated by NMR (Nettesheim et al., 1988). The $\mathrm{N}$ terminus of C3a is not well ordered, and the first 12 residues are not visible in the crystal structure although the NMR data also indicate some order at the C3a N terminus (Nettesheim et al., 1988), suggesting that the overall structure of C3a may be very similar to that of C5a (Fig. 3). In contrast, the $\mathrm{C}$ terminus of C3a appears to be well ordered in the crystal structure and forms a loop that turns toward the fourth helix. It has been proposed that the $\mathrm{N}$-terminal portion (residues 1-21) and the disulfide-linked core region (residues 22-57) in intact C3a serve primarily to stabilize ordered conformation in the C-terminal region (residues 58-77) $(\mathrm{Lu}$ et al., 1984). The des-argination of C3a prevents interaction with C3a receptor but does not apparently alter the structure (Hugli et al., 1975a). As shown for $\mathrm{C} 5 \mathrm{a}$, the $\mathrm{C}$ terminus of $\mathrm{C} 3 \mathrm{a}$ is involved in receptor activation although the more complete effects of desargination on C3a suggest that it is also critical for receptor binding.
3. Peptide Analogs of C3a. The pentapeptide LeuGly-Leu-Ala-Arg is the minimal sequence required for receptor activation, albeit with only $0.2 \%$ molar activity of intact C3a (Caporale et al., 1980), whereas the 13-mer sequence $\mathrm{C} 3 \mathrm{a}$ 65-77 has 6\% and the 21-mer C3a 57-77 100\% activity (Huey et al., 1984). Modifications at the $\mathrm{N}$ termini of these peptides with hydrophobic moieties such as 9-fluorenylmethyloxycarbonyl or acryloyl-amino hexanoyl improve agonist potency (Gerardy-Schahn et al., 1988; Kohl et al., 1990), and a superagonist (Trp-Trp-Gly-Lys-Lys-Tyr-Arg-Ala-SerLys-Leu-Gly-Leu-Ala-Arg) with $200 \%-1500 \%$ of the potency of $\mathrm{C} 3 \mathrm{a}$ has been reported (Ember et al., 1991), but it may not be selective for the human C3a receptor (Scully et al., 2010).

A series of hexapeptides has selective agonist and antagonist activity for the C3a receptor (Scully et al., 2010). One of these peptides, Phe-Leu-Thr-Leu-AlaArg (Fig. 4A), was shown by NMR to have a $\beta$-turn motif in dimethylsulfoxide (DMSO), which could be an important structural determinant of receptor activation. Several peptides originally developed as $\mathrm{C}^{2} \mathrm{a}_{1}$ receptor agonists (e.g., Tyr-Ser-Phe-Lys-Pro-Met-ProLeu-DAla-Arg) are also potent agonists at the C3a 


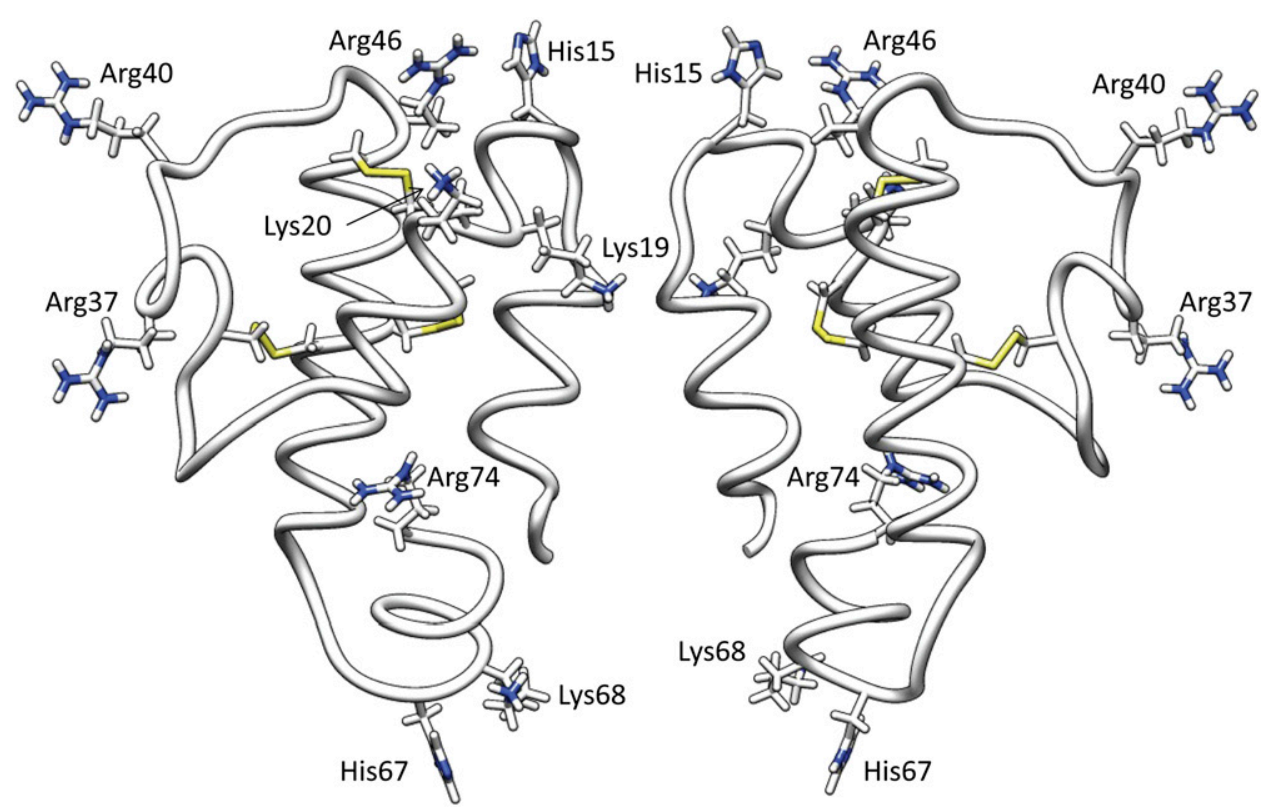

Fig. 3. C5a structure. The structure of human C5a shows the major receptor interacting residues, based on 1KJS (Zhang et al., 1997b). Structures were visualized using the UCSF Chimera package, developed by the Resource for Biocomputing, Visualization, and Informatics at the University of California-San Francisco, funded the National Institutes of Health National Center for Research Resources and the National Institute of General Medical Sciences (Pettersen et al., 2004).

receptor (Scully et al., 2010), suggesting that the same turn motifs may be required for the activation of both types of receptor.

Gly-Tyr-Pro-Met-Tyr-Pro-Leu-Pro-Arg (oryzatensin) has antianalgesic and antiamnesic properties (Jinsmaa et al., 2000; Jinsmaa et al., 2001). An analog, [Trp5]oryzatensin (Trp-Pro-Leu-Pro-Arg), is an orally available appetite suppressant (Ohinata et al., 2002, 2007) although both of these peptides have only low affinities for human C3a receptor (Scully et al., 2010). Bovine $\kappa$-casein peptide, casoxin C (Tyr-Ile-Pro-Ile-Gln-TyrVal-Leu-Ser-Arg), is also reported to have agonist properties at the C3a receptor (Takahashi et al., 1997).

4. Peptidomimetic Analogs of C3a. High-throughput screening and optimization resulted in the identification of $N(2)$-[(2,2-diphenylethoxy)acetyl]-L-arginine<smiles>CC(C)C[C@H](NC(=O)CNC(=O)[C@H](N)Cc1ccccc1)C(=O)N[C@@H](CC(C)C)C(=O)N[C@@H](C)C(=O)N[C@@H](CCCNC(=N)N)C(=O)O</smiles><smiles>N=C(N)NCCCC(NC(=O)COCC(c1ccccc1)c1ccccc1)C(=O)O</smiles>

B<smiles>Cc1ccc(C(c2ccccc2)c2ccc(C(=O)N[C@@H](CCCNC(=N)N)C(=O)O)o2)cc1</smiles><smiles>O=C(NC1CCN(C(=O)CCc2cccnc2)CC1)C1c2cc(Cl)ccc2Oc2ccc(Cl)cc21</smiles>

Fig. 4. C3a receptor antagonists. (A) C3a hexapeptide (His-Leu-Gly-Leu-Ala-Arg). (B) SB290157. (C) Arg-substituted derivative of SB290157. (D) Aminopiperidine derivative of SB290157. 
(SB290157) (Fig. 4B), a competitive antagonist for the C3a receptor (Ames et al., 2001) with a $\mathrm{pIC}_{50}$ of 6.7 at RBL-2H3 cells transfected with human C3a receptor. This compound is selective for the C3a receptor and has no activity at the $\mathrm{C}^{2} \mathrm{a}_{1}$ receptor or a number of other chemotactic G protein-coupled receptors (GPCR). SB290157 blocks $\mathrm{Ca}^{2+}$ mobilization in human neutrophils with pIC $_{50}$ of 7.6 and is also active at the guinea pig and mouse C3a receptor (Ames et al., 2001), making it potentially very useful in animal models of disease, including arthritis, allergic asthma, and ischemia-reperfusion injury ( $\mathrm{Qu}$ et al., 2009). However, this antagonist has partial agonist properties in some systems (Mathieu et al., 2005), possibly dependent on the receptor expression levels.

An Arg-containing derivative of SB290157 has also been reported (Denonne et al., 2007a) that has a higher affinity for the C3a receptor (Fig. 4C). Like SB290157, this compound has a short half-life because of the lability of the Arg moiety, so it has had very limited use in animal models (Denonne et al., 2007a). An aminopiperidine antagonist developed by the same group (Fig. 4D), which lacks the Arg but has poorer antagonist activity $\left(\mathrm{pIC}_{50}=5.8\right)$ and derivatization, has so far resulted only in higher affinity compounds with agonist activity (Denonne et al., 2007b).

\section{B. $C 4 a$}

1. Sequence. Unlike C3a and C5a, C4a appears to have little, if any, activity in humans although C4a has been reported to be a major mediator in inner ear damage (Harada et al., 1992). The amino acid sequences of $\mathrm{C} 4 \mathrm{a}$ obtained to date-such as rat (Cui et al., 1988), human (Moon et al., 1981), and bovine (Smith et al., 1982)—show conservation of the 6 Cys residues likely to form the disulfide knot and the basic residues that are present in $\mathrm{C} 3 \mathrm{a}$ and $\mathrm{C} 5 \mathrm{a}$ (Fig. 2B). Rodent but not human or bovine $\mathrm{C} 4 \mathrm{a}$ is glycosylated (Cui et al., 1988). From this sequence similarity, the three-dimensional structure of $\mathrm{C} 4 \mathrm{a}$ is inferred to be very similar to that of C3a and C5a (Fig. 3). Structurefunction studies are lacking for C4a.

$\mathrm{C} 4 \mathrm{a}$ is a potent agonist of guinea pig but not human C3a receptor (Ames et al., 1997; Lienenklaus et al., 1998). Guinea pig macrophages undergo a $\mathrm{Ca}^{2+}$ response to $\mathrm{C} 4 \mathrm{a}$ and are desensitized to subsequent stimulation by C3a (Murakami et al., 1993) although the purity of serum-derived $\mathrm{C} 4 \mathrm{a}$ may be an issue because human $\mathrm{C} 4 \mathrm{a}$ is 100 - to 1000 -fold less active as a spasmogen than human $\mathrm{C} 3 \mathrm{a}$ in guinea pig ileum (Hugli, 1981). For these activities, the C-terminal Arg residue has been shown to be critical (Gorski et al., 1979), and, as for C3a, the agonist activity of C4a is located in the C-terminal pentapeptide (Hugli et al., 1983). C4a also appears to share a similar range of antimicrobial activities with C3a (Pasupuleti et al., 2007).

\section{C. $C 5 a$}

1. Sequence. C5a, the most intensively studied of the fragments, is a 74-79 amino acid polypeptide (Fig. 2C), although the classic anaphylatoxin is actually the desarginated form, C5a des-Arg (Gerard and Hugli, 1981). Human C5a has an N-linked glycosylation site (Fernandez and Hugli, 1978) that is not found in C5a from other species. This glycosylation may be inhibitory for C5a des-Arg, as porcine C5a has no glycosylation sites (Fig. 2C) and porcine C5a des-Arg is more active than the human form. In addition, the enzymatic de-glycosylation of human C5a des-Arg increases its activity (Gerard et al., 1981). More recently, discrepancies have been observed between the activities of recombinant (aglycosylated) and purified (glycosylated) C5a des-Arg, suggesting that control of the activity of the des-Arg form is complex (Reis et al., 2012).

2. Structure. The NMR structure of human and porcine C5a has revealed a four-helix core (Zuiderweg et al., 1989; Williamson and Madison, 1990; Zhang et al., 1997a,b), stabilized by three disulfide bridges (Cys21-Cys47, Cys22-Cys54, Cys34-Cys55) (Fig. 3). The structure of bovine C5a, determined by NMR, is similar to human and porcine (Zarbock et al., 1988). The disruption of these disulfide bridges by reduction or mutation causes a loss of function (Mollison et al., 1989). The crystal structure of C5 reveals a similar structure for the C5a-moiety of the uncleaved molecule (Fredslund et al., 2008). The sequence of human C3a is $35 \%$ identical to human C5a and has disulfide linkages in comparable locations, so C5a modeled on the C3a crystal structure appears to be nearly identical (Greer, 1985).

In contrast with these studies, a recently published crystal structure of C5a des-Arg has a three-helix core with the $\mathrm{N}$-terminal domain able to adopt different conformations (Cook et al., 2010). C5a des-Arg also appeared to form dimers in these crystals, with the interaction interface potentially blocking some of the proposed ligand interacting residues we will discuss later. However, there is no empirical evidence to support dimer formation.

The $\mathrm{C}$ terminus of C5a/C5a des-Arg (residues 64-73/ 74) appears to be a disordered structure and is not observed in the crystallographic study or most NMR studies, perhaps due to a pH-dependent lability in this region (Zhang et al., 1997b). In the one study where C-terminal structure was observed, a short helix (residues 69-74) connected by a loop to the fourth helix of the core of C5a was present (Zhang et al., 1997b).

3. Receptor Interacting Residues of C5a. Unlike C3a, extensive mutagenesis studies on the entire C5a molecule have been performed that highlight basic residues, concentrated in the loops that connect the helices, and these are important in forming the interaction sites with $\mathrm{C} \mathrm{a}_{1}$ receptor (Fig. 3). These 
can be divided into three separate clusters (Mollison et al., 1989; Huber-Lang et al., 2003). Site 1 is formed by residues 12-20, including His15, Lys19 and 20, and Arg46. Site 2 includes Asp24, Arg37, Arg40, and possibly Lys49. Site 3 comprises residues $67-74$, including His67, Lys68, Arg69, and the C-terminal Arg74 (Mollison et al., 1989; Bubeck et al., 1994; Toth et al., 1994; Vlattas et al., 1994). Other important residues are hydrophobic: Val18, Leu43, Met70, and Leu72; the latter residue when mutated to either Lys or Asp causes big loss in binding affinity (Mollison et al., 1989).

The unpaired Cys27 is unique to human C5, and mutation to Arg has been found to be necessary to display C5a on phage (Cain et al., 2003; Heller et al., 1999), presumably by preventing aberrant crosslinking. However, this residue has been exploited to help map the ligand-binding site on the $\mathrm{C}^{2} \mathrm{a}_{1}$ receptor (Section IV.C.4), and the data suggest that this part of C5a lies close to the receptor $\mathrm{N}$ terminus.

Human C5a (1-69), lacking the C-terminal loop-helix structure, can still bind to cell-surface receptors, albeit with considerably lower affinity than intact C5a, but cannot activate the receptor (Chenoweth et al., 1982). The substitution of the C-terminal pentapeptide sequence of human C3a (Leu-Gly-Leu-Ala-Arg) to C5a (1-69) (Bautsch et al., 1992) gives a ligand that binds to both the $\mathrm{C}^{2} \mathrm{a}_{1}$ receptor and $\mathrm{C} 3 \mathrm{a}$ receptor, whereas adding a modified C5a C-terminal sequence through a new disulfide linkage makes a $\mathrm{C}^{2} \mathrm{a}_{1}$ receptor antagonist (Zhang et al., 1997a). These observations suggest that C5a (1-69) provides a recognition site for the receptor whereas the $\mathrm{C}$ terminus provides the activation signal.

\section{Peptide Analogs of C5a}

a. Agonists. Although the pentapeptide Met-GlnLeu-Gly-Arg that is analogous to the $\mathrm{C}$ terminus of C5a is inactive at the $\mathrm{C}_{5} \mathrm{a}_{1}$ receptor (Chenoweth and Hugli, 1980), the discovery that the C-terminal octapeptide of human C5a, His-Lys-Asp-Met-Gln-Leu-Gly-Arg, has weak agonist activity (Kawai et al., 1991, 1992) has provoked intense research into the mechanism of receptor activation and the development of antagonists.

A series of decapeptide analogs first reported by Ember et al. (1992), substituting Phe for His67, had increased potency over the native sequence. These were later developed into a large series of constrained peptides. In some of these, the insertion of Pro into the sequence has resulted in greater agonist activity (Sanderson et al., 1994) but also in a loss of selectivity (Scully et al., 2010). EP-54 (Tyr-Ser-Phe-Lys-Pro-MetPro-Leu-DAla-Arg) is an agonist at both the C5a receptor and $\mathrm{C} 3 \mathrm{a}$ receptor but has little or no activity at the second C5a receptor $\mathrm{C}_{5} \mathrm{a}_{2}$ receptor (also known as C5R2, C5L2, GPR77) (Scola et al., 2007). In contrast, EP-67 (Tyr-Ser-Phe-Lys-Asp-Met-Pro-(Me)Leu-DAlaArg) is a weak agonist at both the $\mathrm{C}^{2} \mathrm{a}_{1}$ receptor and the $\mathrm{C} 3 \mathrm{a}$ receptor but may have greater activity at the
${\mathrm{C} 5 \mathrm{a}_{2}}_{2}$ receptor (Kawatsu et al., 1996; Short et al., 1999; Taylor et al., 2001; Vogen et al., 1999a, 1999b).

Peptides such as EP-54 and EP-67 have been described as "response selective," producing different responses at the $C 5 \mathrm{a}_{1}$ receptor depending on the cell type under study (reviewed in Taylor et al., 2001). However, a more likely explanation is the nonselectivity of these peptides, with varying affinities for two or more of the known complement peptide receptors. Peptide ligands have been found to have conserved turn structures (Tyndall et al., 2005), and C5a and its analogs have a $\beta / \gamma$ turn motif that has also been observed in bradykinin, enkephalin, and vasopressin. The conservation of the turn structure may be linked to the mechanism of receptor activation because a twostep binding mechanism is a common feature of secretin family GPCR (Tyndall et al., 2005).

b. Antagonists. Further development of C-terminal peptides resulted in a family of hexapeptide analogs of the form $N(\mathrm{Me})-$ Phe-Lys-Pro-DCha-Xxx-DArg, which were potent agonists and antagonists depending on the nature of the fifth residue (Konteatis et al., 1994). Increasing aromaticity at this position was found to enhance antagonist activity, with Trp providing complete antagonism. From these studies, a cyclic peptide antagonist (PMX53; 3D53, (Ac)Phe-[Orn-Pro-DChaTrp-Arg]) has been developed that shows improved affinity (Wong et al., 1999) (Fig. 5A) and has a $\beta$-turn structure similar to the C5a C terminus, as determined by NMR (Zhang et al., 2008).

PMX53 $\left(\mathrm{pIC}_{50}=7.05\right.$ in human neutrophil membranes) is an insurmountable antagonist for C5a receptor (Strachan et al., 2000, 2001) with no discernible activity at the $\mathrm{C}^{2} \mathrm{a}_{2}$ receptor (Scola et al., 2007). Like many peptides, PMX53 has low oral bioavailability, but its long-lasting effect means that even once-daily oral dosing is sufficient to maintain circulating levels in the rat (Morgan et al., 2008). The development of PMX53 has been discontinued (http://www.evaluatepharma. com/Universal/View.aspx?type=Story\&id=178099), although PMX205, a more stable derivative (Delisle Milton et al., 2011) with a hydrocinnamic acid moiety at the $\mathrm{N}$ terminus (Fig. 5B), is now being used in animal models of disease, including rat and mouse models of neurologic diseases such as Huntington's disease, Alzheimer's disease, and amyotrophic lateral sclerosis (ALS) (Fonseca et al., 2009; Woodruff et al., 2006, 2008). However, PMX205 has been reported as unlikely to be of benefit in ALS patients (ALS-TDI http://www.als.net/ ALS-Research/PMX205/ALS-Topics/).

PMX53 also has limited selectivity, in common with the related compound JPE-1375 (Hoo-Phe-Orn-Pro-(dHLeu)-Phe4F-Phe) (Fig. 5C), and it also binds to other receptors such as NK2 and Mas-related gene 2 receptor (Schnatbaum et al., 2006; Subramanian et al., 2011). Despite this, PMX53 (and, to a lesser extent, JPE1375) has been of immense value in defining the role of 

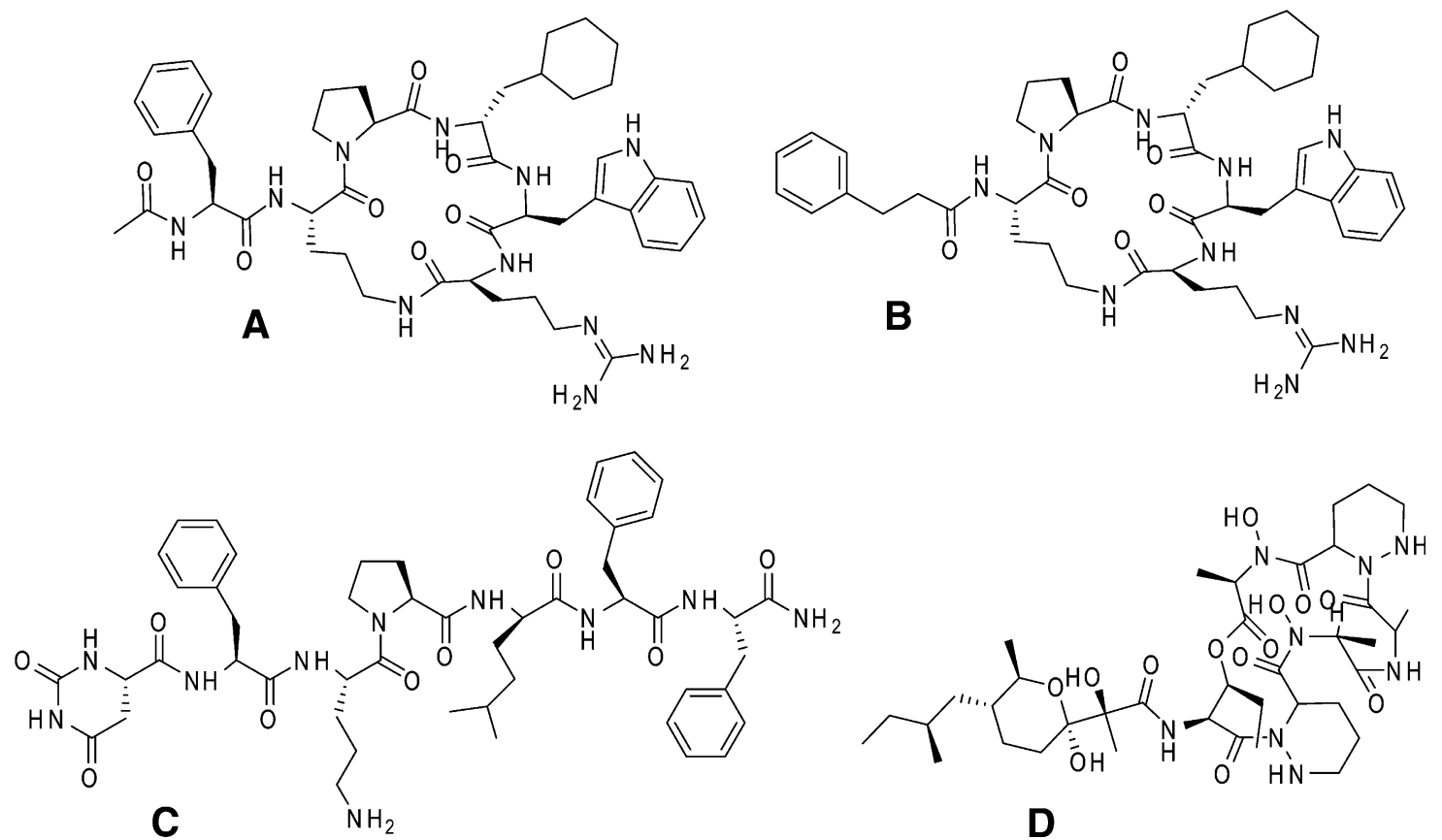

Fig. 5. C5a1 receptor peptide antagonists. (A) PMX53 (AcPhe-[Orn-Pro-DCha-Trp-Arg]). (B) PMX205 hydrocinnamic acid substituted derivative of PMX53. (C) JPE-1375. (D) L156,602.

C5a in a wide range of animal models of disease. Described in more detail in reviews (Monk et al., 2007; Klos et al., 2009; Qu et al., 2009; Woodruff et al., 2011), these include inflammatory bowel disease, ischemiareperfusion injuries, sepsis, and arthritis. Unfortunately, PMX53 and JPE-1375 have limited activity at the rodent $\mathrm{C}^{2} \mathrm{a}_{1}$ receptor in transfected cell lines, particularly when used with recombinant rodent C5a (Waters et al., 2005; P. N. Monk, unpublished observations), making the reported in vivo activities more difficult to analyze.

JPE-1375 was developed as a linear analog of PMX53 by replacing the Arg with Phe and adding hydroorotic acid (Hoo) in place of the N-acetyl group (Proctor et al., 2006; Woodruff et al., 2006). The potency of JPE-1375 is comparable with PMX53, but the former has increased stability in liver microsome preparations. JPE-1375 has been discontinued $(\mathrm{Qu}$ et al., 2009) despite showing some promise in AMD (Ricklin and Lambris, 2007), renal allograft survival (Gueler et al., 2008), experimental tubulointerstitial fibrosis (Boor et al., 2007), and atherosclerotic plaque stabilization (Shagdarsuren et al., 2010). The hexadepsipeptide L156,602 (Fig. 5D) is a nonselective antibiotic

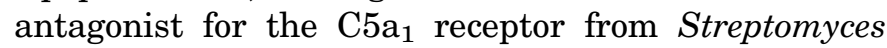
with a $\mathrm{pIC}_{50}=5.7$ at the $\mathrm{C}_{5} \mathrm{a}_{1}$ receptor, although extensive modification failed to improve selectivity (Hensens et al., 1991; Tsuji et al., 1992a,b, 1995). The C terminus of C5a has also been exploited by the use of phage display to allow selection of libraries of C5a mutants to produce a potent antagonist, $A 8^{\Delta 71-73}$ (Heller et al., 1999). This polypeptide binds both the $\mathrm{C} \mathrm{a}_{1}$ receptor and the $\mathrm{C} \mathrm{a}_{2}$ receptor (Otto et al., 2004) and has some activity in vivo (e.g., Zhang et al., 2009), although its size and protein derivation make it unsuitable for drug development.

5. Naturally Occurring Non-Complement-Derived Analogs of C5a. There are three naturally occurring ligands for $\mathrm{C}_{5} \mathrm{a}_{1}$ receptor that do not derive from C5. Skp, also known as $\mathrm{OmpH}$ (outer membrane protein $\mathrm{H}$ ), is a major structural porin of enteric bacteria such as Escherichia, Klebsiella, Salmonella, and Yersinia (Koski et al., 1989). Skp acts as a cavity chaperone to prevent aggregation (Walton et al., 2009) after forming trimers (Walton and Sousa, 2004) and is also a chemoattractant for both monocytes and polymorphonuclear neutrophils (PMN) (Shrestha et al., 2004). However Skp is not a secretagogue for these cells, unlike C5a, suggesting that it is only a partial agonist. The region of Skp proposed to interact with $\mathrm{C}^{2} \mathrm{a}_{1}$ receptor is structurally unrelated to C5a (Fig. 6A). Mutagenesis experiments have identified residues required for $\mathrm{C}^{2} \mathrm{a}_{1}$ receptor interaction, namely, Gln103-Arg105 (Jia et al., 2010). Gln103 of Skp may be equivalent in function to Leu72, a critical residue in C5a. Skp has been proposed for a novel method of vaccination against pathogenic bacteria, targeting $\mathrm{C} \mathrm{a}_{1}$ receptor on intestinal $\mathrm{M}$ cells (Luo et al., 1999).

A considerable body of work, mainly from the Yamamoto laboratory, has demonstrated the complex activity of S19 at C5 $\mathrm{a}_{1}$ receptor. S19 is a 145-aminoacid component of the ribosome, released by apoptotic cells in the form of homodimers, cross-linked by plasma transglutaminase (Semba et al., 2010). Overall, it has only $4 \%$ sequence identity with C5a (Yamamoto, 2000) and is structurally unrelated (Fig. 6B). In the 


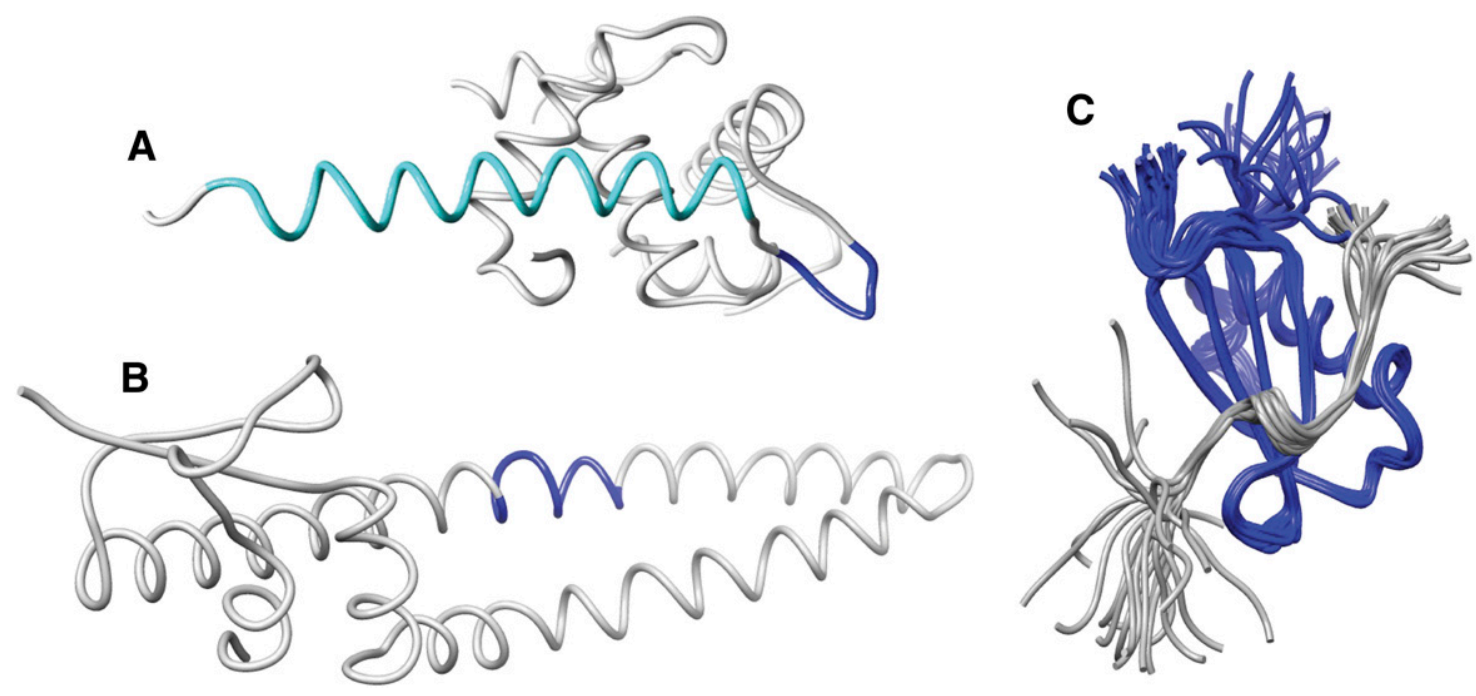

Fig. 6. Noncomplement derived C5a1 receptor ligands. (A) Skp (OmpH). (B) RP-S19. (C) CHIPS in complex with a peptide mimic of the N terminus of the $\mathrm{C}_{5} \mathrm{a}_{1}$ receptor (Ippel et al., 2009). Dark blue sections on $A$ and $B$ represent the sequences analogous to the $\mathrm{C}$ terminus of C5a. The pale blue section of $A$ represents the sequence thought to antagonist activity on neutrophils. In $C$, CHIPS is shown in dark blue, with the N-terminal peptide of C5a ${ }_{1}$ receptor in gray. Structures were visualized using the UCSF Chimera package.

extracellular milieu, it can act as an agonist at monocytes, promoting chemotaxis, and as an antagonist for neutrophils. This activity can be blocked by antibodies against the $\mathrm{C}^{2} \mathrm{a}_{1}$ receptor (Nishiura et al., 1996, 1998). The monocytic infiltrate acts to phagocytose apoptotic cells (Horino et al., 1998; Nishimura et al., 2001) although S19 itself can also promote apoptosis in fibroblasts (Nishiura et al., 2005). Crosslinked $\mathrm{S} 19$ is proposed to activate $\mathrm{C}^{2} \mathrm{a}_{1}$ receptor in the same way as C5a, through a two-step mechanism (Shibuya et al., 2001).

The first binding site is a cluster of basic residues (Lys41-His42-Lys43), and the second, which directly causes receptor activation, is Leu131-Asp132-Arg133, 12 residues from the $\mathrm{C}$ terminus of $\mathrm{S} 19$. These binding sites are divided between the two components of the homodimer (Nishiura et al., 2010a). The dual agonist/ antagonist activity of S19 is located in a "switch" region located between Leu134 and Lys144, at the C terminus beyond the second activation site (Revollo et al., 2005; Shrestha et al., 2003). Recombinant C5a (or peptide analogs) bearing the C-terminal protein of S19 also assume this dual activity (Jia et al., 2010; Oda et al., 2008). S19 appears to bind to the second C5a receptor, the $\mathrm{C} \mathrm{a}_{2}$ receptor, but this does not explain the dual activity (Nishiura et al., 2010b), proposed to be due to a diminution of $\mathrm{G} \alpha_{\mathrm{i}}$ coupling to the $\mathrm{C} \mathrm{a}_{1}$ receptor in neutrophils by an as yet unidentified cofactor (Nishiura et al., 2011).

The third noncomplement molecule that binds C5 $\mathrm{a}_{1}$ receptor is the chemotaxis inhibitory protein of Staphylococcus aureus (CHIPS) (de Haas et al., 2004). CHIPS (Fig. 6C) has been intensively studied and has been found to bind only to $\mathrm{C}^{2} \mathrm{a}_{1}$ receptor and the formyl peptide receptor FPR1. The $\mathrm{C}^{5} \mathrm{a}_{1}$ receptor is bound by
CHIPS at the $\mathrm{N}$ terminus, at a site that overlaps with the C5a binding, meaning that CHIPS is a potent antagonist for the $C 5 \mathrm{a}_{1}$ receptor $\left(K_{\mathrm{d}}=1.1 \mathrm{nM}\right)$ (de Haas et al., 2004; Haas et al., 2004; Postma et al., 2004, 2005; Ippel et al., 2009). CHIPS is too immunogenic for therapeutic use (Wright et al., 2007), but ADC-1004, a derivative of CHIPS produced by directed evolution, has minimal immunogenicity and may have therapeutic potential (Gustafsson et al., 2009a,b, 2010; van der Pals et al., 2010). More recently, a smaller peptide derivative of CHIPS has been reported (Bunschoten et al., 2011). A cofactor of C5a activity, vitamin Dbinding protein, is apparently required for maximal chemotactic activity but does not interact with either C5a or the $\mathrm{C}^{2} \mathrm{a}_{1}$ receptor (DiMartino et al., 2001).

6. Nonpeptidic Analogs of C5a. Substituted 4,6diaminoquinolines (structure not shown) were selected from a screen of positively charged compounds as analogs of the core regions of C5a but were found to be weak antagonists $\left(\mathrm{pIC}_{50}=5.5\right)$ and were not amenable to modification (Lanza et al., 1992). Most of the other analogs listed are mimics of the $\mathrm{C}$ terminus of C5a. W54011 [ $N$-[(4-dimethylaminophenyl)methyl]- $N$-(4isopropylphenyl)-7-methoxy-1,2,3,4-tetrahydronaphthalen1-carboxamide hydrochloride] (Fig. 7A) is an orally active and potent $\mathrm{C}_{5} \mathrm{a}_{1}$ receptor antagonist $\left(\mathrm{pIC}_{50}=8.7\right)$ developed by the Mitsubishi Pharmaceuticals Company by library screening and optimization. W54011 inhibits human neutrophil chemotaxis and superoxide production with low nanomolar activity (Sumichika et al., 2002) but has no detectable activity at the $\mathrm{C}^{2} \mathrm{a}_{2}$ receptor (Scola et al., 2007). Although originally described as inactive in the mouse and rat, it has been shown to have some effect on mouse $\mathrm{C}^{2} \mathrm{a}_{1}$ receptor expressed on DC in vitro (Peng et al., 2009a). 

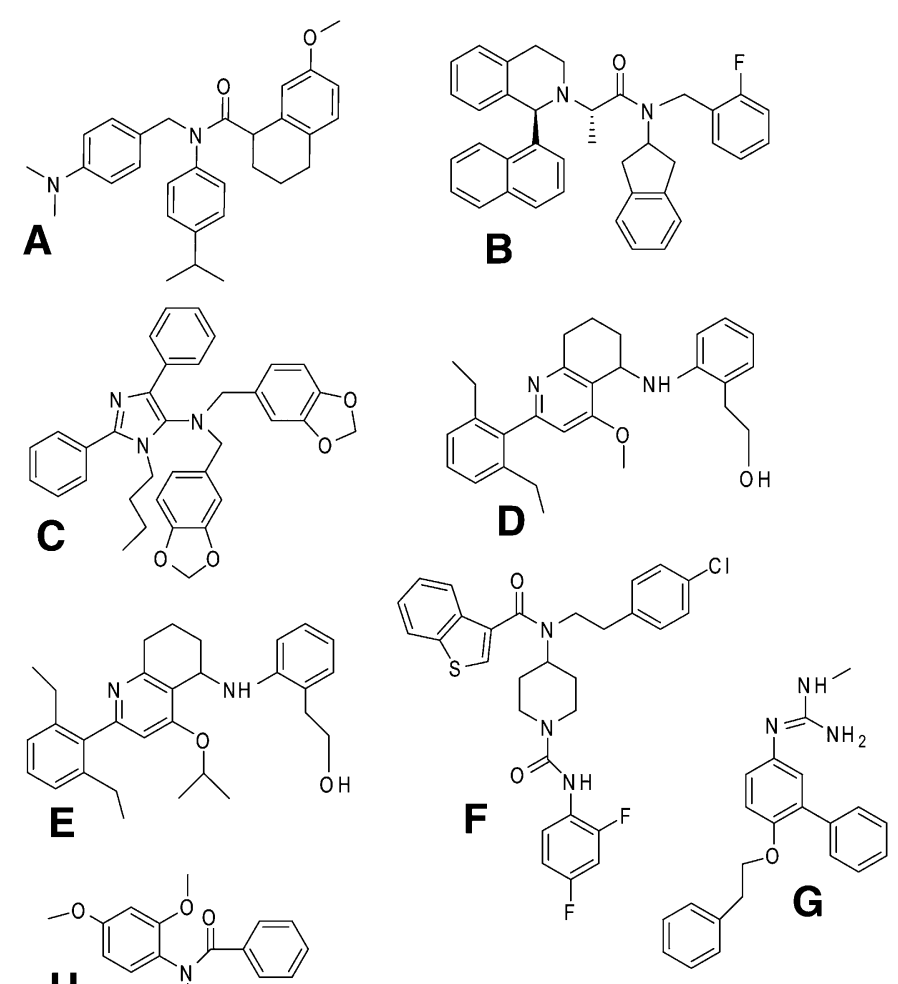

H
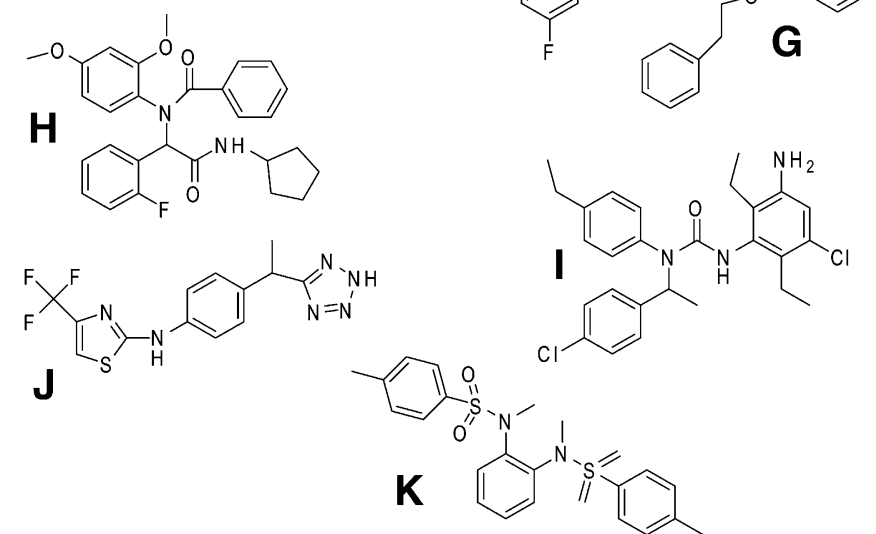

Fig. 7. C5a1 receptor nonpeptide antagonists. (A) W54011. (B) NDT 9520492. (C) NTD 9513727. (D and E) Aniline-substituted tetrahydroquinolines. (F) CPP 447,697. (G) RPR 121154. (H) Example of bis-amide series. (I) JSM 7717. (J) Example of (R) arylalkylamino series. (K) Example of bis-sulfonamide series.

NDT 9520492 (Fig. 7B) is a substituted tetrahydroisoquinoline with a $\mathrm{pIC}_{50}$ of 7.5 at the human $\mathrm{C}^{2} \mathrm{a}_{1}$ receptor that also inhibits gerbil and primate $\mathrm{C} 5 \mathrm{a}$ receptors but not rat or mouse. This pattern is also seen with W54011 and PMX53, suggesting that they bind to a similar site on the $\mathrm{C}^{2} \mathrm{a}_{1}$ receptor (Waters et al., 2005) (Section IV.C.4). NGD 2000-1 (structure unknown) is a derivative of NDT 9520492 which has been tested in phase II trials on asthma and RA. For the primary end points-forced expiratory volume in 1 second (FEV1) and C-reactive protein (CRP) levels, respectively-the drug did not show any benefits although there were some positive effects on the Subject Global Assessment of the disease in RA (Powers et al., 2011). Because of inhibition of cytochrome P450 3A4, no further development of this drug occurred (Lee et al., 2008).
NDT $9513727[N, N$-bis(1,3-benzodioxol-5-ylmethyl)1-butyl-2,4-diphenyl-1 $H$-imidazole-5-methanamine] (Fig. 7C) is an inverse agonist at the human, primate, and gerbil $\mathrm{C}^{2} \mathrm{a}_{1}$ receptor with little activity at the

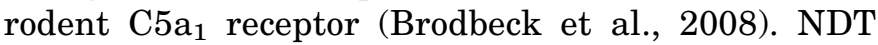
9513727 has a $\mathrm{pIC}_{50}=6.9$ at that $\mathrm{C}^{2} \mathrm{a}_{1}$ receptor but is not active at the $C 5 \mathrm{a}_{2}$ receptor and is also orally bioavailable. 5,6,7,8-tetrahydroquinoline (Barbay et al., 2008) and aniline-substituted tetrahydroquinolines (Gong et al., 2008) have been reported as C5 $\mathrm{a}_{1}$ receptor antagonists (Fig. $7, \mathrm{D}$ and $\mathrm{E}$ ), with one compound having a $\mathrm{pIC}_{50}=7.7$ and an $\mathrm{IC}_{50}=20 \mathrm{nM}$ for C5a-stimulated $\mathrm{Ca}^{2+}$ flux in human neutrophils. Closely related compounds were shown to be orally bioavailable with reasonable pharmacokinetics in the rat.

CP-447,697 (Fig. 7F) was isolated by library screening and optimization and has a $\mathrm{pIC}_{50}=7.5$ (Blagg et al., 2008b). Attempts to reduce toxicity and improve availability by increasing polarity resulted in compounds with reduced binding affinity, suggesting that the binding site on the $\mathrm{C}_{5} \mathrm{a}_{1}$ receptor did not tolerate polar or basic groups (Blagg et al., 2008a). A modified phenylguanidine, RPR121154 (Fig. 7G), was reported to have a $\mathrm{pIC}_{50}=6.1$ and could inhibit the respiratory burst in C5a-stimulated human neutrophils (Astles et al., 1997). A bis-amide compound (Fig. 7H), isolated by high-throughput screening for inhibition of C5a binding (Sanganee et al., 2009), has a $\mathrm{pIC}_{50}=7.6$ but has no activity at the rodent or dog $\mathrm{C}_{5} \mathrm{a}_{1}$ receptor or the human $\mathrm{C} \mathrm{a}_{2}$ receptor. An inability to improve stability and availability without loss of potency has led to the discontinuation of this compound.

CCX168 (Xiao et al., 2010) (undisclosed structure) is reported to antagonize the human (but not mouse) C5a $a_{1}$ receptor, $\mathrm{pIC}_{50}=9.2$, and to inhibit $\mathrm{Ca}^{2+}$ mobilization in monocytes at subnanomolar concentrations (Powers et al., 2011). JSM-7717, with a structure similar to that shown in (Fig. 7I), was developed by Jerini $\mathrm{AG}$ as a small-molecule $\mathrm{C}^{5} \mathrm{a}_{1}$ receptor antagonist, with a $\mathrm{pIC}_{50}=8.5$ and activity in vivo in a gerbil model of neutropenia (Powers et al., 2011).

A series of $(R)$-arylalkylamino compounds (e.g., Fig. $7 \mathrm{~J})$ has been produced by Dompe SpA, derived from a dual C5a and IL-8 antagonist, which were found to be selective for the $\mathrm{C} \mathrm{a}_{1}$ receptor, $\mathrm{pIC}_{60}=8$ (Allegretti et al., 2008; Powers et al., 2011). Bis-sulfonamides, exemplified by Fig. 7K, identified by screening and optimization, have also been reported as effective $\mathrm{C} \mathrm{a}_{1}$ receptor antagonists $\left(\mathrm{pIC}_{50}=7.2\right.$ in human neutrophils) (Chen et al., 2010).

\section{Receptors}

\section{A. Introduction}

The three known complement peptide receptors (http://www.iuphar-db.org/DATABASE/ 
FamilyMenuForward?familyId=5) are all members of the GPCR superfamily, in family A, subgroup A8, with the formyl peptide receptor family (Joost and Methner, 2002). They have the classic GPCR structure, comprising an extracellular $\mathrm{N}$ terminus, seven helical transmembrane domains connected by intracellular and extracellular loops, and an intracellular $\mathrm{C}$ terminus (Findlay and Pappin, 1986) (Fig. 8). Ligand binding and signaling by two of the receptors, the $\mathrm{C} \mathrm{a}_{1}$ receptor and the C3a receptor, are well characterized, but the third receptor, the $\mathrm{C}^{2} \mathrm{a}_{2}$ receptor, remains enigmatic.

\section{B. C3a Receptor}

1. Sequence and Genetics. In contrast to the other receptors, the C3a receptor (Ames et al., 1996; Crass et al., 1996) has a much smaller N-terminal domain and a greatly enlarged second extracellular domain (Fig. 8) that is conserved across all species so far sequenced (Melillo et al., 2006). In humans, C3AR is present in a single copy located on chromosome 12p13.2-3, with the entire coding sequence present in a single exon (Paral et al., 1998). Transcriptional control of C3ar expression in murine myeloid cells is mediated by activator protein 1 (AP-1), nuclear factor kappa B (NF- $\kappa$ B), Ets, and GATA (Martin and Martin, 2005); in murine glial cells, transcription is controlled by AP-1 but not Ets binding (Martin et al., 2007b). Human $C 3 A R$ does not have a functional NF- $\kappa \mathrm{B}$ site, but AP-1 and Ets control $C 3 A R$ expression in monocytic cells (Schaefer et al., 2005). A 1526G/A singlenucleotide polymorphism (SNP) in human C3AR is associated with severity of childhood bronchial asthma and $1595 \mathrm{~A} / \mathrm{G}$ with atopic dermatitis (Hasegawa et al., 2004). Other polymorphisms (http://www.ncbi.nlm.nih.
gov/SNP/snp_ref.cgi?locusId=719) (Sherry et al., 2001) have not so far been associated with disease.

\section{Post-translational Modifications}

a. Glycosylation. The human $\mathrm{C} 3 \mathrm{a}$ receptor is reported to be highly glycosylated (Mizuno et al., 2007) and has two N-linked glycosylation sites (Asn9, Asn194), in the $\mathrm{N}$ terminus and second extracellular domain, respectively. In contrast, the mouse C3a receptor has four potential sites in this domain (Tornetta et al., 1997), but it is not clear what functional role this glycosylation plays.

b. Tyrosine Sulfation. Five or six tyrosine residues in the 172-amino-acid second extracellular loop (174, $184,188,317 / 318$ ) of the human C3a receptor are sulfated in vivo (Gao et al., 2003). Tyr174 sulfation is critical for high-affinity binding of C3a but not for receptor activation by $\mathrm{C}$-terminal peptide analogs of C3a, suggesting that Tyr174 directly interacts with the core of C3a.

c. Phosphorylation. The C3a receptor is known to undergo serine/threonine phosphorylation after ligand binding, mediated by $\mathrm{G}$ protein-coupled receptor kinases (Langkabel et al., 1999), probably GRK2 and GRK3. The $\mathrm{C}$ terminus of the C3a receptor contains 10 serine/threonine residues that may undergo phosphorylation. Mutation of these to alanine indicates that disruption of phosphorylation of Ser465/470 and Thr463/466 inhibits ligand-induced internalization. Ser449 is not involved in internalization but is involved in signal transduction (Settmacher et al., 2003).

d. S-acylation. A potential S-palmitoylation site is present at the intracellular C terminus (Cys468) of the human $\mathrm{C} 3 \mathrm{a}$ receptor and also in the rat and mouse but not guinea pig C3a receptor. It is not known if this Cys

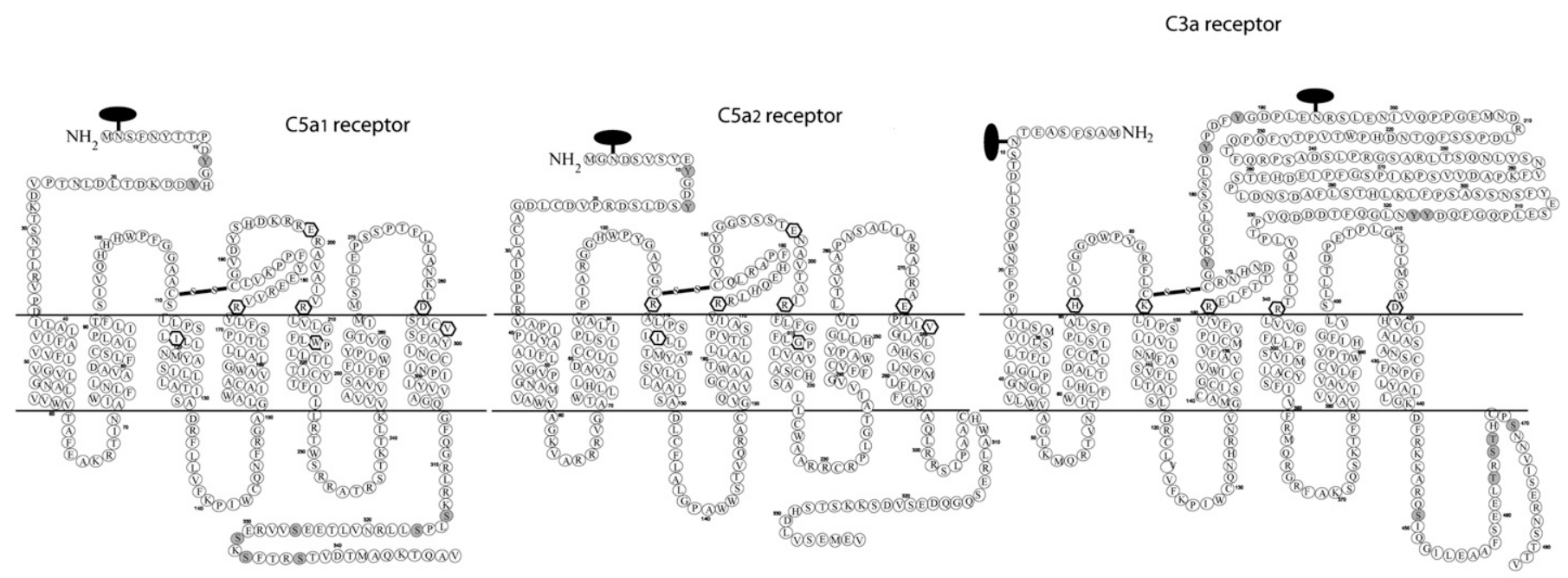

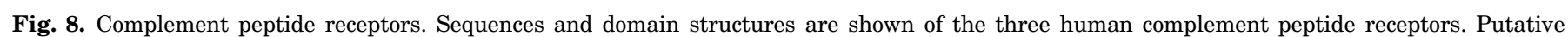

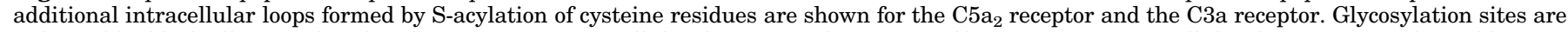

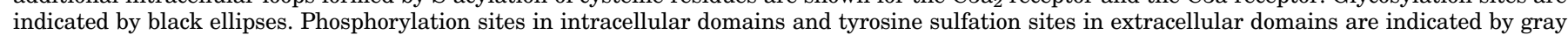

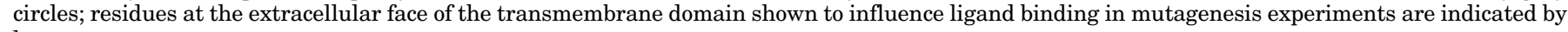
hexagons. 
is actually modified in vivo. A potential eighth helix at the $\mathrm{C}$ terminus (Asn431-Gln451) is suggested by sequence similarities to bradykinin $\mathrm{R} 2$ and other receptors (Feierler et al., 2011). Interestingly, the C5 $\mathrm{a}_{1}$ and $\mathrm{C} \mathrm{a}_{2}$ receptors do not have this basic sequence and also contain proline, a potential helix blocker.

3. Expression. The human and mouse C3a receptor appears to be broadly expressed, with mRNA detected in most tissues, albeit at widely varying levels (Ames et al., 1996; Tornetta et al., 1997), with high levels of expression in the lung, spleen, ovary, placenta, small intestine, spinal cord, and brain. In contrast to the $\mathrm{C} \mathrm{a}_{1}$ receptor, expression in leukocytes is relatively low (Ames et al., 1996), and no C3a receptor is detectable on naive $\mathrm{B}$ and $\mathrm{T}$ lymphocytes (Martin et al., 1997; Zwirner et al., 1999; Werfel et al., 2000;). However, treatment of human T cells with IFN- $\gamma$ upregulates $\mathrm{C} 3 \mathrm{a}$ receptor expression in vitro, and this receptor can be detected on $\mathrm{T}$ cells from patients with atopic dermatitis (Werfel et al., 2000).

Myeloid cells that express the $\mathrm{C} 3 \mathrm{a}$ receptor are eosinophils, DC, monocytes/macrophages, microglia, and mast cells. Nonmyeloid cells that express the C3a receptor are activated astrocytes, endothelial cells, and epithelial and smooth muscle cells from asthma patients (reviewed in Klos et al., 2009). The C3a receptor has also been detected on neurons (Davoust et al., 1999), and the neuronal C3a receptor may have a role in central nervous system inflammation (reviewed in Yanamadala and Friedlander, 2010) and during development (Benard et al., 2004, 2008).

4. Ligand Binding by C3a Receptor. Relative to the $\mathrm{C} \mathrm{a}_{1}$ receptor, little is known about the mechanism of ligand binding and receptor activation for the C3a receptor. The agonist activity of $\mathrm{C}$-terminal peptide analogs of $\mathrm{C} 3 \mathrm{a}$ suggest that, as for the $\mathrm{C}^{2} \mathrm{a}_{1}$ receptor, multiple sites are involved. Most of the data concerning the location of these sites come from an investigation using a series of chimeras between the $\mathrm{C}^{2} \mathrm{a}_{1}$ receptor and the C3a receptor (Crass et al., 1999a). The substitution of the $\mathrm{C} 3 \mathrm{a}$ receptor $\mathrm{N}$ terminus by that of the $\mathrm{C}^{2} \mathrm{a}_{1}$ receptor has little effect on the binding of $\mathrm{C} 3 \mathrm{a}$ but produces a receptor that both binds and is activated by C5a, suggesting that the primary binding site for C3a lies outside of the $\mathrm{N}$-terminal domain and confirming that this site on the $\mathrm{C}^{2} \mathrm{a}_{1}$ receptor is indeed at the $\mathrm{N}$ terminus. When the second extracellular loop of the C3a receptor was substituted by the much smaller $\mathrm{C}^{2} \mathrm{a}_{1}$ receptor loop, this chimera could not bind or be activated by $\mathrm{C} 3 \mathrm{a}$, indicating that this domain rather than the $\mathrm{N}$ terminus forms the primary binding site (Chao et al., 1999). The loss of up to $65 \%$ of this loop, however, failed to inhibit C3a binding, with the significant residues being 162-183 and 309-322, at the $\mathrm{N}$ and $\mathrm{C}$ termini of this loop, respectively.
The mutation of a series of aspartate residues in this region to lysine effectively inhibited C3a binding, suggesting that these acidic residues make up a binding site for the basic core of C3a (Chao et al., 1999). The sulfated tyrosine residue (Tyr174) also appears to form part of this binding site (Gao et al., 2003). Several charged residues at the tops of TM2, TM3, TM4, TM5, and TM7 have been mutated and found to affect C3a binding and receptor activation by both C3a and peptide analogs of the C3a C terminus (Sun et al., 1999). These data suggest that these residues form part of a binding pocket at the extracellular face of the transmembrane helical cluster of C3a receptor, similar to that predicted for the $\mathrm{C}^{2} \mathrm{a}_{1}$ receptor (Section IV.C.5).

\section{C3a Receptor Signaling}

a. $G$ protein mediated. By comparison with C5a, C3a is generally a much weaker chemotactic stimulus in leukocytes (Fernandez et al., 1978), despite sharing many of the same signaling mechanisms. Following the binding of $\mathrm{C} 3 \mathrm{a}$ to $\mathrm{C} 3 \mathrm{a}$ receptor, the primary signaling mechanism activated is through the pertussis toxin (PT)-sensitive G protein $\mathrm{G} \alpha_{\mathrm{i}}$ in human and mouse immune cells such as neutrophils (Norgauer et al., 1993), eosinophils (Elsner et al., 1994), and microglia (Moller et al., 1997). C3a has also been reported to decrease intracellular cAMP levels in murine dendritic cells ( $\mathrm{Li}$ et al., 2008), which might be dependent on $\mathrm{G} \alpha \alpha_{\mathrm{i}}$. C5a has been shown to have this effect as well in cell lines (Vanek et al., 1994) and in DC (Peng et al., 2009b). However, in endothelial cells, C3a signaling caused a PT-insensitive cytoskeletal response and ERK1/2 activation, attributed to activation of $\mathrm{G} \alpha 12$ and/or $\mathrm{G} \alpha 13$ despite the availability of $\mathrm{G} \alpha_{\mathrm{i}}$ for coupling

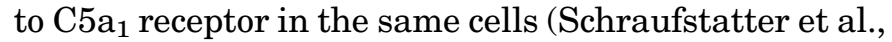
2002). The promiscuous PT-insensitive G protein $\mathrm{G} \alpha 16$ can also couple to C3a receptor in cotransfected cell lines (Crass et al., 1996). Differences have also been observed in the subsequent changes in intracellular free $\mathrm{Ca}^{2+}\left(\mathrm{Ca}^{2+}{ }_{\mathrm{i}}\right)$, with $\mathrm{C} 3 \mathrm{a}$ typically stimulating a smaller and transient increase in intracellular $\mathrm{Ca}^{2}$ ${ }^{+}{ }_{i}$ in neutrophils solely due to the influx of extracellular $\mathrm{Ca}^{2+}$ whereas $\mathrm{C5a}$ also causes the release of $\mathrm{Ca}^{2+}$ from intracellular stores and a more prolonged elevation due to the activation of phospholipase C (PLC) (Norgauer et al., 1993). However, in microglia, the $\mathrm{Ca}^{2+}{ }_{i}$ responses are equal (Moller et al., 1997), and in human MSC both C3a and C5a cause a prolonged activation of protein phosphorylation (Schraufstatter et al., 2009). Similarly, in a human astrocytic cell line, both C3a and C5a stimulated the release of $\mathrm{Ca}^{2+}$ from intracellular stores, although the response to C3a was smaller (Sayah et al., 2003).

b. Arrestin mediated. In mast cells, although C3a provokes only a transient increase in $\mathrm{Ca}^{2+}{ }_{i}$, the activation of ERK1/2 and Akt phosphorylation is sustained (Venkatesha et al., 2005). This disparity in the temporal aspects of C3a signaling in mast cells has 
been explored in great detail, and it is known that degranulation is uncoupled from other responses, such as de novo production of the chemokine CCL2 (Ahamed et al., 2001). Here, the use of a C3a receptor mutant, truncated at the $\mathrm{C}$ terminus to remove potential serine/ threonine phosphorylation sites, has shown that production is absolutely dependent on receptor phosphorylation whereas degranulation was not affected. The mutant receptor failed to bind $\beta$-arrestin 2 , suggesting that arrestins can act as mediators of additional signaling mechanisms for the C3a receptor. However, both degranulation and the production of CCL2 were equally sensitive to PT, suggesting that $\mathrm{G} \alpha_{\mathrm{i}}$ activation is still critical, most likely through ERK1/2 activation. Arrestins were originally described as adaptors that link ligand-activated GPCR to the cellular internalization machinery (Wilden et al., 1986; Lohse et al., 1990), an important part of the complex desensitization process (Jalink and Moolenaar, 2010). The $\mathrm{G}_{\mathrm{q}}$-coupled protease-activated receptor PAR2 couples to ERK1/2 through two pathways, one $\mathrm{G}$ protein dependent and one dependent on $\beta$-arrestin/Src kinase that results in ERK1/2 activation by endocytosed receptors in a particular subcellular location (DeFea et al., 2000). However, the early phase of ERK1/2 activation by C3a receptor is not dependent on Src (Ahamed et al., 2001 ), so the mechanism by which $\beta$-arrestin mediates C3a receptor signaling is still unclear. For the C3a receptor, at least, different arrestins appear to play different roles. The silencing of $\beta$-arrestin 2 in human mast cells prevents the desensitization and internalization of C3a receptor, leading to a prolonged increase in $\mathrm{Ca}^{2+}{ }_{\mathrm{i}}$ (Vibhuti et al., 2011) but has no effect on degranulation whereas silencing of $\beta$-arrestin 1 could actually inhibit degranulation. Interestingly, both arrestins were observed to suppress ERK1/2 activation by the C3a receptor, in contrast to results observed with other GPCR (Defea, 2008). Phosphorylation of the C3a receptor by GRK2, 3, 5, and 6 has been implicated in the control of the association with arrestins (Guo et al., 2011), with different GRK involved in different aspects of the response to C3a. Thus, signaling by C3a receptor, at least in mast cells, is complex and is critically dependent on arrestins as well as G proteins. This sensitivity to arrestins may explain why C3a receptor signaling is often more transient and weaker in nature relative to that of $\mathrm{C}_{5} \mathrm{a}_{1}$ receptor.

\section{C. $C 5 a_{1}$ Receptor}

1. Sequence and Genetics. C5AR1 was cloned in 1991 (Gerard and Gerard, 1991) and is located on chromosome 19q13.3-13.4 (mouse chr 7), adjacent to the gene for C5AR2 and close to genes for formyl peptide receptors (Gerard et al., 1993). C5AR1 is encoded in two exons, the first with the 5 '-untranslated region (UTR) and the initiating Met codon separated by $9 \mathrm{~kb}$ from the second exon that has the remainder of the coding sequence. Myeloid-cell specific promoter activity was detected just upstream of the initiating codon $(-49$ to -82$)$ and suppressing activity at -225 to -346 (Gerard et al., 1993). Distinct transcriptional control mechanisms appear to exist in murine myeloid and nonmyeloid cells (Martin et al., 2007a), although an LPS-response element, a CCAAT box/NF-Y binding site at -96 , a GATA site at -298 , and a CP2 site at -155 are active in both macrophages and endothelial cells (Hunt et al., 2005). More recently, NF- $\kappa \mathrm{B}, \mathrm{CCAAT}$, and NFAT sites have been identified in the first $200 \mathrm{bp}$ of the 5'-UTR of human C5AR1, with two adenylateuridylate-rich (AU-rich) elements in the 3'-UTR (Palmer et al., 2012). The latter have no effect on basal or stimulated expression levels. Although a number of SNP in the C5AR1 gene have been described (reviewed in Monk et al., 2007; http://www.ncbi.nlm.nih.gov/SNP/ snp_ref.cgi?locusId=728; Sherry et al., 2001), there are no associations with disease yet reported. In detailed studies, no association with C5AR1 SNP was found in AMD (Skeie et al., 2010) or bronchial asthma (Hasegawa et al., 2004) although a C5 haplotype was protective. SNP rs17611 in C5 has been associated with plasma C5a levels and is a risk factor for adverse cardiac events (Hoke et al., 2012).

\section{Post-translational Modifications}

a. Glycosylation. There is one potential site for Nlinked glycosylation on human $\mathrm{C}_{5} \mathrm{a}_{1}$ receptor, at Asn2. Removal of N-linked glycosylation by endoglycosidase $\mathrm{F}$ or by mutation of Asn2 had little effect on either affinity for the ligand or expression of the receptor at the cell surface (Pease and Barker, 1993).

b. Tyrosine sulfation. There are three tyrosine residues at the $\mathrm{N}$ terminus of $\mathrm{C} \mathrm{a}_{1}$ receptor, two of which (Tyr11, Tyr14) are proximal to Asp residues, making them potential sulfation sites (Rosenquist and Nicholas, 1993). Both Tyr11 and Tyr14 are sulfated, and this modification is essential for the binding of C5a (Farzan et al., 2001), C5a des-Arg (Scola et al., 2007), and CHIPS (Ippel et al., 2009; Liu et al., 2011c).

c. Phosphorylation. Phosphorylation of the $\mathrm{C}^{2} \mathrm{a}_{1}$ receptor after ligand binding or phorbol ester treatment has been linked to desensitization (Ali et al., 1993). The major phosphorylation sites are at the $C$ terminus (Ser314, Ser317, Ser327, Ser332, Ser334, and Ser338) (Giannini et al., 1995) although the third intracellular loop also contains a potential PK-C site (Lys239-Thr-Leu-Lys) (Bock et al., 1997). Mutation of Ser332, Ser334, and Ser338 to Ala reduces phosphorylation by $80 \%$ (Giannini et al., 1995) and also inhibits receptor internalization (Naik et al., 1997). This inhibition was thought to be due to a loss of association with molecules important for internalization such as $\beta$-arrestin, dynamin, and clathrin. Interestingly, $\beta$-arrestin 1 and 2 were still able to bind to phosphorylation-deficient $\mathrm{C}^{2} \mathrm{a}_{1}$ receptor but much more weakly than to a wild-type receptor (Braun et al., 
2003). However, internalization of the receptor, one mechanism for desensitization, was found to be dependent only on amino acids $335-350$ in a series of truncated $\mathrm{C}^{2} \mathrm{a}_{1}$ receptor mutants, beyond the majority of the phosphorylation sites (Bock et al., 1997). Similarly, another study found that although Ser334, Ser327, Ser332, and Ser338 could be phosphorylated by PK-C $\beta$, these sites were functionally redundant for internalization and desensitization and even that, at high concentrations of C5a, $\beta$-arrestin binding to the $\mathrm{C}$ terminus could actually inhibit phosphorylation (Pollok-Kopp et al., 2007). Thus, the role of phosphorylation in the control of receptor function remains unclear.

3. Expression. Although typically expressed at high levels on cells of myeloid origin, the $C 5 \mathrm{a}_{1}$ receptor is expressed at low-to-moderate levels on a wide variety of cell types (reviewed in Monk et al., 2007). Expression on lymphocytes remains controversial, with some reports showing expression on inactivated $\mathrm{B}$ and $\mathrm{T}$ cells with others failing to find this or to show expression restricted to small subsets (reviewed in Klos et al., 2009). Reports of expression in epithelial cells have been shown to be probably artifactual (Klos et al., 2009).

4. Ligand Binding by $C 5 a_{1}$ Receptor.

a. C5a $a_{1}$ receptor binds both C5a and C5a des-Arg. Determining the locations and mechanisms of interaction between $\mathrm{C}^{2} \mathrm{a}_{1}$ receptor and its ligands is vital to the production of effective therapeutics. As for most members of the GPCR family, there is no available crystal structure for the ${\mathrm{C} 5 \mathrm{a}_{1}}_{1}$ receptor, so structural knowledge of the receptor has been based on extensive ligand binding, receptor chimera, and mutagenesis studies. Molecular modeling of the receptor now plays a major role in our understanding, with a recent model of a ligand-bound $\mathrm{C}^{2} \mathrm{a}_{1}$ receptor providing novel insights into the mechanisms of ligand and receptor interaction (Nikiforovich et al., 2008). The most extensively studied interaction to date is between the receptor and the full-length natural ligand C5a. In vivo, C5a is rapidly converted into C5a des-Arg by carboxypeptidase enzymes, which remove the terminal arginine residue (Bokisch and Muller-Eberhard, 1970).

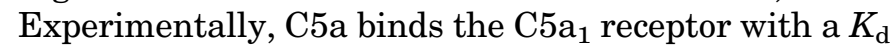
of $1 \mathrm{nM}$, whereas the truncated form has a binding affinity which is 10- to 100-fold lower than that of C5a and is a partial agonist at the $\mathrm{C} 5 \mathrm{a}_{1}$ receptor (Higginbottom et al., 2005). Interactions with this truncated form will also be considered here, where data are available.

5. Two-Site Binding Paradigm. It is now widely accepted that there are at least two sites of interaction between the $\mathrm{C} 5 \mathrm{a}$ and $\mathrm{C}^{2} \mathrm{a}_{1}$ receptors, a binding paradigm common to members of the GPCR family that bind large macromolecular ligands (Kristiansen, 2004). The first interaction is between acidic residues in the $\mathrm{N}$ terminus of the $\mathrm{C}_{5} \mathrm{a}_{1}$ receptor and basic residues in the core of $\mathrm{C} 5 \mathrm{a}$; a second binding interaction is thought to occur between the $\mathrm{C}$ terminus of $\mathrm{C} 5 \mathrm{a}$ and the transmembrane domains and charged residues at the base of the $\mathrm{C} \mathrm{a}_{1}$ receptor extracellular loops. This binding model mainly stems from mutagenesis studies, the creation of chimeric receptors, and interactions with C5a analogs. Initially, experiments showing the C-terminal octapeptide of C5a could alone bind $\mathrm{C}^{2} \mathrm{a}_{1}$ receptor led to the proposal of a binding site in the C terminus of C5a (Kawai et al., 1991) (Section III.C.4). It was also shown that C-terminal peptide analogs could act as full agonists of the $\mathrm{C} \mathrm{a}_{1}$ receptor (Ember et al., 1992), leading to the hypothesis that not only does the $\mathrm{C}$ terminus of C5a possess a receptorbinding site, but it is also critical for activation of the receptor. However, while removing the terminal pentapeptide of C5a reduced receptor activity, the binding of ligand to the receptor was unaltered, indicating the existence of a second binding site. This site was identified by the demonstration that antibodies directed against the $\mathrm{N}$-terminal domain of the $\mathrm{C}^{2} \mathrm{a}_{1}$ receptor reduced binding and activation in response to C5a (Oppermann et al., 1993). In a similar way, deletion of the first 22 residues of the receptor dramatically reduced binding of intact C5a, but the mutated receptor could still be activated by peptide analogs of the C5a C terminus, thus confirming the presence of two distinct binding sites (DeMartino et al., 1994). Critical residues and sequences within these general binding sites have been more challenging to identify, as presented here for each binding site.

a. Binding site one: $C 5 a_{1}$ receptor $N$ terminus. Yeast random saturation mutagenesis (RSM) and NMR studies on the $\mathrm{N}$ terminus of the $\mathrm{C}^{2} \mathrm{a}_{1}$ receptor have indicated the importance of the many acidic residues in C5a binding (Chen et al., 1998; Hagemann et al., 2006). In general, single/double mutations of these have had little effect on binding whereas various multiple mutations within the $\mathrm{N}$ terminus of the $\mathrm{C}^{2} \mathrm{a}_{1}$ receptor have significantly reduced the affinity of the $\mathrm{C} \mathrm{a}_{1}$ receptor for C5a. For example, the $\mathrm{C}^{2} \mathrm{a}_{1}$ receptor (D15,16,18,21N) reduced C5a affinity 40 -fold, and the C5 $\mathrm{a}_{1}$ receptor $(\mathrm{D} 10,15,16,18,21 \mathrm{~N})$ reduced affinity by 133-fold (DeMartino et al., 1994), whereas the C5a receptor $(\mathrm{D} 10 \mathrm{~N}), \mathrm{C} 5 \mathrm{a}_{1}$ receptor $(\mathrm{D} 27 \mathrm{~N})$, and $\mathrm{C} 5 \mathrm{a}_{1}$ receptor(D21,27N) had no effect on C5a binding (Mery and Boulay, 1994). The lack of importance of individual residues in forming the binding site was supported by the yeast RSM study, which concluded that no single residues were essential for ligand activation of the $\mathrm{C5}_{1}$ receptor (Hagemann et al., 2006). More recently, site-specific disulfide-trapping experiments performed in yeast have identified several potential specific points of contact between $\mathrm{C} 5 \mathrm{a}$ and the $\mathrm{N}$ terminus of

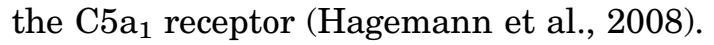


The $\mathrm{N}$ terminus of the $\mathrm{C} \mathrm{a}_{1}$ receptor is highly flexible, resulting in many possible low-energy conformations for the interaction between the C5a and ${\mathrm{C} 5 \mathrm{a}_{1}}_{1}$ receptors (Nikiforovich et al., 2008). Some interactions were consistent across many of the possible conformations and can be rationalized using available mutagenesis data, especially as these data were not used in the building of the model. The aspartate residues Asp15, Asp16, and Asp21 were predicted in most conformations to form a salt bridge with Lys17 within the $\mathrm{N}$ terminus of $\mathrm{C}^{2} \mathrm{a}_{1}$ receptor, indicating that the reductions in C5a binding affinity induced by multiple aspartate replacements likely result from changes to the overall conformation of the receptor $\mathrm{N}$ terminus. Asp27 was predicted to form a less important salt bridge than neighboring Asp28, in accordance with the lack of disruption in binding upon single mutation of this residue to asparagine (Mery and Boulay, 1994). Asp18 was predicted not to be involved in salt bridge formation within the $\mathrm{C5}_{1}$ receptor, but in a small number of conformations was predicted to interact with Lys19 or Lys20 of C5a, supported by mutagenesis data showing a reduction in binding when these lysine residues within C5a are mutated (Bubeck et al., 1994; Toth et al., 1994). Other important potential contact points include Arg46 (the side chain of which in certain conformations could interact electrostatically with Asp10 or Asp16) and Cys27, which has also been predicted to contact fragment $24-30$ of the $\mathrm{C}^{2} \mathrm{a}_{1}$ receptor by RSM (Hagemann et al., 2006) and the modeling study (Nikiforovich et al., 2008).

The importance of tyrosine sulfation in forming the ligand-binding site in other GPCRs (Hsu et al., 2005) led to the investigation of Tyr11 and Tyr14 in C5a receptor, which have been shown to be sulfated. The $\mathrm{C} \mathrm{a}_{1}$ receptor mutations $\mathrm{Y} 14 \mathrm{~F}$ and $\mathrm{Y} 11 \mathrm{~F}$ induced a $50 \%$ reduction or complete loss of binding affinity for $\mathrm{C} 5 \mathrm{a}$, respectively, indicating the importance of these sulfations in the formation of the N-terminal binding site (Farzan et al., 2001). The binding of CHIPS, which acts as an antagonist for the $\mathrm{C}^{2} \mathrm{a}_{1}$ receptor, has also been shown to be dependent on the sulfation of tyrosine residues 11 and 14 (Ippel et al., 2009; Liu et al., 2011c) (Section IV.C.2).

b. Binding site two: transmembrane/extracellular loop regions of $C 5 a_{1}$ receptor. One approach used to ascertain the general regions of $\mathrm{C}^{2} \mathrm{a}_{1}$ receptor involved in the second binding site was the construction of chimeric $\mathrm{C}^{2} \mathrm{a}_{1}$ receptor/FPR1. Replacing the first extracellular loop of the $\mathrm{C}^{2} \mathrm{a}_{1}$ receptor with the corresponding region of the FPR1 had no effect on binding affinity for C5a whereas replacement of EC2 or EC3 abolished binding (Pease et al., 1994). A lack of direct interactions between EC1 and C5a was also supported in the 2008 model (Nikiforovich et al., 2008), but the effects of several point mutations within EC1 that did alter ligand interactions indicate that this region is important for overall structural conformation (Cain et al., 2001b); the presence of the Trp-Phe-XxxGly motif in EC1, which is highly conserved among GPCR, supports this (Klco et al., 2006).

Mutagenesis studies identified Ile116, Arg175, Arg206, Glu199, Asp282, and Val286 as potential interaction sites in ligand binding (Fig. 8). A recent model of $\mathrm{C} 5 \mathrm{a}$ bound to the $\mathrm{C}_{5} \mathrm{a}_{1}$ receptor has suggested a more extensive list of potential interaction sites with residues 59-74 of C5a being predicted to interact with the side chains of Leu117, Met120, Tyr121 (TM3); Leu167, Phe172 (TM4); Leu187, Cys188, Asp191, His194 (EC2); Glu199, Arg200, Ala203, Arg206, Leu207, Leu209, Pro214 (TM5); Met265 (TM6); and Leu277, Asn279 (EC3) (Nikiforovich et al., 2008). Some of these residues had already been identified as potential ligand-binding sites in mutagenesis studies.

Analysis of mutations of residue Glu199 at the top of TM5 has produced some conflicting biologic results regarding receptor activation. An interaction between Glu199 of the C5a 1 receptor and Lys68 of C5a has been suggested in several studies and has been shown to be important for activation of the $\mathrm{C}^{2} \mathrm{a}_{1}$ receptor by $\mathrm{C} 5 \mathrm{a}$ des-Arg, but not C5a (Crass et al., 1999c; Monk et al., 1995). Specifically, an E199K mutation of the C5a receptor produced a lower binding affinity for wild-type $\mathrm{C} 5 \mathrm{a}$ and a higher binding affinity for the C5a mutant $\mathrm{K} 68 \mathrm{E}$, indicating the presence of a salt bridge between these two residues of ligand and receptor (Crass et al., 1999c). The recent model of C5a bound to the ${\mathrm{C} 5 \mathrm{a}_{1}}$ receptor does indeed predict salt bridge formation between Lys68 of C5a and the side chain of residue Glu199 of the $\mathrm{C}^{2} \mathrm{a}_{1}$ receptor, with the E199K mutation also disrupting hydrogen bonding between residues Glu199 and His194/Gln71 of the C5a $\mathrm{a}_{1}$ receptor (Nikiforovich et al., 2008). In addition to the interaction with Lys68, Glu199 has also been predicted to interact with Arg74 after a lack of response of an E199K mutant to agonists lacking a C-terminal arginine (Crass et al., 1999b; Higginbottom et al., 2005).

Another residue at the extracellular face of TM5 that has been proposed to interact with the C-terminal arginine of C5a (Arg74) is Arg206 (DeMartino et al., 1995; Gerber et al., 2001); however, subsequent studies found only a small effect on receptor activation of the R206A mutation (Cain et al., 2001a). This, along with the fact that the truncated ligand C5a des-Arg binds to the R206A mutant but does not activate it, led to the hypothesis that this mutation simply alters the global structure of the receptor (Monk et al., 2007). R206A mutants have been reported to have varying effects on C5a binding affinities from no change (DeMartino et al., 1995) to significant reductions in binding (Raffetseder et al., 1996). As stated previously, Arg206 has been predicted from modeling to interact with C5a. Within this model, the R206A mutation 
disrupts the predicted interaction between Arg206 and Arg74 of C5a but induces no major changes in residueresidue interactions and does not support experimental data indicating a complete absence of C5a binding (Nikiforovich et al., 2008).

Buried deep in TM5, Trp214 in the human C5 $\mathrm{a}_{1}$ receptor is conserved in the gerbil $\mathrm{C}^{2} \mathrm{a}_{1}$ receptor but not in rodent receptors or in human $\mathrm{C}^{5} \mathrm{a}_{2}$ and $\mathrm{C} 3 \mathrm{a}$ receptors. If substituted by its murine equivalent, Leu, the resulting $\mathrm{C}^{2} \mathrm{a}_{1}$ receptor mutant (W213L) is no longer antagonized by W54011 or NDT9520492. Con-

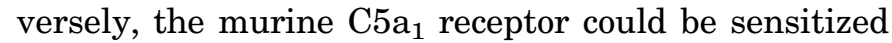
to these antagonists by the reciprocal substitution L214W (Waters et al., 2005). Interestingly, PMX53 showed no activity at either the wild-type murine receptor or the mutant $\mathrm{L} 214 \mathrm{~W}$, suggesting that this antagonist binds at a different site.

Other residues that have been predicted to interact with the $\mathrm{C}$ terminus of C5a include Arg175 and Asp282. Arg175 is located in EC2, and it too has been predicted to interact with Arg74 of C5a with R175A and $\mathrm{R} 175 \mathrm{D}$ mutations, both causing a reduction in $\mathrm{C} 5 \mathrm{a}$ binding affinities and activation of $\mathrm{C}^{2} \mathrm{a}_{1}$ receptor (Cain et al., 2003; Higginbottom et al., 2005). In the C5a bound model of $\mathrm{C}^{2} \mathrm{a}_{1}$ receptor, no major disruptions in binding were predicted with an R175D mutant, indicating no specific interaction between Arg175 and C5a (Nikiforovich et al., 2008). However, the mutagenesis data can be explained by the loss of a salt bridge between Arg175 and Glu179 in the mutant receptors, an interaction that may be crucial in stabilizing the "open" conformation of EC2. Asp282 is at the extracellular face of TM7 and is predicted to form an important interaction with Arg74 of C5a. In support of this, the D282R mutant is relatively unresponsive to C5a but sensitive to C5a des-Arg and analogs (Cain et al., 2001a, 2003). However, again minimal changes were detected in the C5a bound model of the $\mathrm{C}^{2} \mathrm{a}_{1}$ receptor for the D282R mutant. Although both Arg175 and Asp282 were not predicted to interact directly with C5a in this model, they have previously been predicted to interact with the cyclic hexapeptide antagonist PMX53, along with Glu199, Arg206, and Ile116 among others (Higginbottom et al., 2005).

Ile116 in TM3 of the C5a $\mathrm{a}_{1}$ receptor was predicted to be part of an activation switch after an I116A mutation altered the activity of the C5a peptide C-terminal analog (Phe-Lys-Pro-DCha-Trp-DArg) from antagonist to agonist (Gerber et al., 2001). Further studies mutating this residue found an increased affinity for agonists but a decreased activation of the $\mathrm{C}^{2} \mathrm{a}_{1}$ receptor, indicating that the mutation reduced the activation efficiency of the $\mathrm{C}^{2} \mathrm{a}_{1}$ receptor (Higginbottom et al., 2005). In more recent modeling studies, the side chains of C5a fragment 59-74 have been predicted to contact the nearby Leu117 residue (Nikiforovich et al., 2008) but not Ile116 itself, whereas modeling based on the binding of hexapeptide antagonist has predicted interactions with Ile116 (Gerber et al., 2001; Higginbottom et al., 2005). Val286, in TM7, has also been proposed to be involved in the activation switch mechanism, with its side chain being proposed to point toward that of Ile116, allowing the two residues to form a binding cleft for ligands. In recent models, Val286 too has been predicted to interact with peptide ligands but not intact C5a (Higginbottom et al., 2005; Nikiforovich et al., 2008).

Much of the information now available indicates that different ligands bind the $\mathrm{C}^{2} \mathrm{a}_{1}$ receptor in different ways; even just the cleaving of the terminal arginine residue in $\mathrm{C} 5 \mathrm{a}$ des-Arg changes the predicted interactions between receptor and ligand. Through modeling of the ligand-receptor interaction, two important differences in the way in which C5a des-Arg binds compared with C5a were the lack of an interaction between Arg206 and the missing Arg74 of the ligand, and the lack of an interaction between Arg200 and Asp69. In addition to these specific missing interactions, the $\mathrm{C}$ terminus of C5a des-Arg was predicted to bind in an entirely different orientation to C5a (Nikiforovich et al., 2008). Available antagonists and analogs of the native ligand are again predicted to interact with different residues of $\mathrm{C}^{2} \mathrm{a}_{1}$ receptor; identifying the mechanisms important in eliciting desired effects, such as antagonism, will be crucial in directing the future development of therapeutic agents.

In addition to identifying ligand-binding positions, many mutations in the second extracellular loop of the $\mathrm{C} \mathrm{a}_{1}$ receptor have also been found to result in constitutive receptor activity, identifying a negative regulatory role of EC2 (Klco et al., 2005). As constitutively active GPCR are thought to most likely represent the activated GPCR state, the study of such mutants could provide vital insight into the activation switch of GPCR in general. In modeling studies, the EC2 loops of constitutively active $\mathrm{C}^{2} \mathrm{a}_{1}$ receptor mutants were found to contact the EC3 loops, leading to interaction of EC2 domains with TM3 (Nikiforovich and Baranski, 2012). This in turn triggers the movement of TM7 toward TM2 and TM3 with a resultant change in hydrogen bonding between these regions known to be crucial for $\mathrm{C}^{2} \mathrm{a}_{1}$ receptor activation (Nikiforovich et al., 2011).

c. Comparison with $\mathrm{C}_{5} \mathrm{a}_{2}$ receptor. The second identified receptor for $\mathrm{C} 5 \mathrm{a}$, the $\mathrm{C} \mathrm{a}_{2}$ receptor, shares $\sim 35 \%$ identity with the $\mathrm{C} 5 \mathrm{a}_{1}$ receptor; in contrast with the $\mathrm{C} \mathrm{a}_{1}$ receptor, the $\mathrm{C} \mathrm{a}_{2}$ receptor binds C5a des-Arg and C5a with similar affinities (Scola et al., 2007), implying different binding mechanisms. Interfering with the $\mathrm{N}$ terminus of the $\mathrm{C}_{5} \mathrm{a}_{2}$ receptor using an antibody did not alter the binding of C5a to the $\mathrm{C}^{2} \mathrm{a}_{2}$ receptor, but it did significantly inhibit the binding of C5a des-Arg to the C5a $\mathrm{a}_{2}$ receptor (Scola et al., 2007). Replacing the $\mathrm{N}$ terminus of the $\mathrm{C}^{2} \mathrm{a}_{2}$ receptor with 
that of the $C 5 \mathrm{a}_{1}$ receptor did not affect the affinity for C5a des-Arg. Many of the residues at the extracellular face of the transmembrane domain of C5a $\mathrm{a}_{1}$ that have been shown to influence ligand binding are also present in the $\mathrm{C}^{2} \mathrm{a}_{2}$ receptor (Fig. 8).

\section{6. $C 5 a_{1}$ Receptor Signaling}

a. $G$ protein mediated. Often the most potent of the complement peptides, C5a has also been the most intensively studied with regard to signal transduction (reviewed in Monk et al., 2007; Klos et al., 2009). The C5 $\mathrm{a}_{1}$ receptor couples primarily to the PT-sensitive G protein $\mathrm{G} \alpha_{\mathrm{i} 2}$ (Sheth et al., 1991; Skokowa et al., 2005) in cells such as neutrophils and mast cells or, less frequently, to PT-insensitive G proteins such as $\mathrm{G} \alpha 16$ / G $\alpha 15$ (Amatruda et al., 1993; Monk and Partridge, 1993; Davignon et al., 2000) in cells of the monocytic lineage. The $\mathrm{C} \mathrm{a}_{1}$ receptor is unusual among GPCR in being precoupled to $\mathrm{G}$ proteins (Siciliano et al., 1990); mutants that are unable to precouple in this way have reduced affinity for C5a (Raffetseder et al., 1996). Precoupling is also seen in a mutant of the $\alpha_{2 \mathrm{~B}}$ adrenoreceptor, where it increases agonist potency (Ge et al., 2003); it is tempting to speculate that this may also be the case for the $\mathrm{C} \mathrm{a}_{1}$ receptor, allowing the response to C5a to predominate over responses to other chemoattractants such as C3a.

As with the C3a receptor, the downstream response to receptor ligation is cell type dependent. For example, the $\mathrm{Ca}^{2+}$ response in C5a-activated neutrophils is predominantly due to release from intracellular compartments, whereas in monocyte-like cells a much greater contribution from extracellular influx is observed (Monk and Partridge, 1993). Similarly, mast cells respond to $\mathrm{C5a}$ with a rapid and transient increase in $\mathrm{Ca}^{2+}{ }_{i}$ (Hartmann et al., 1997) whereas microglial cells respond with a more prolonged response (Moller et al., 1997). In neutrophils and macrophages, sphingosine-1-phosphate (S-1-P) production by sphingosine kinase 1 is required for the C5astimulated release of $\mathrm{Ca}^{2+}$ from intracellular stores (Ibrahim et al., 2004; Melendez and Ibrahim, 2004). S-1-P also up-regulates the expression of the $\mathrm{C}^{2} \mathrm{a}_{2}$ receptor (the second C5a receptor) in mouse neutrophils, which is thought to be a protective response against endotoxemia (Bachmaier et al., 2012).

b. Arrestin signaling. Phosphorylation of the C5 $\mathrm{a}_{1}$ receptor leads to association with arrestins and subsequent targeting to clathrin-coated pits for internalization (Braun et al., 2003). PK-C $\beta$ II and GRK2 interact with intracellular loop 3 and the C-terminal domain of the $\mathrm{C}_{5} \mathrm{a}_{1}$ receptor and may be responsible for the serine/threonine phosphorylation of the receptor (Suvorova et al., 2008). A dileucine motif in the C terminus of the C5a $\mathrm{a}_{1}$ receptor is thought to stabilize the "eighth helix" (Gln305-Arg320) proximal to the membrane (Suvorova et al., 2008). This structure, sometimes stabilized by a palmitoylated cysteine residue, often acts as a protein interaction site in GPCR (Huynh et al., 2009) and may be involved in receptor internalization (Thomas et al., 1995). Interestingly, the other receptors-the $\mathrm{C} 3 \mathrm{a}$ receptor and ${\mathrm{C} 5 \mathrm{a}_{2}}_{2}$ receptor-both have cysteine residues in the C-terminal domains whereas the $\mathrm{C}^{5} \mathrm{a}_{1}$ receptor does not (Fig. 8). In some GPCR with cysteine residues in the C-terminal domain, such as bradykinin B2, helix 8 is critical for the association with $\beta$-arrestins, so the lack of a cysteine residue in this position in the $\mathrm{C}_{5} \mathrm{a}_{1}$ receptor may be responsible for some of the differences in signaling observed for the complement peptide receptors. Unlike the C3a receptor, there is no evidence that the $\mathrm{C5}_{1}$ receptor signals through arrestins (Gripentrog and Miettinen, 2008), although an association occurs (Braun et al., 2003; Kalant et al., 2005; van Lith et al., 2009). Kinase activation by the $\mathrm{C}^{2} \mathrm{a}_{1}$ receptor is almost entirely $\mathrm{G} \alpha_{\mathrm{i}}$ dependent (Buhl et al., 1994; Gripentrog and Miettinen, 2008), with little evidence to date that arrestins are directly involved. It is also interesting that the $\mathrm{C}$ terminus of the $\mathrm{C}^{2} \mathrm{a}_{1}$ receptor can be substantially deleted (from residue 311) without a negative effect on signaling (Matsumoto et al., 2007a,b; Monk et al., 1994), although it is required for trafficking to the cell surface and for internalization (Bock et al., 1997).

The ability of the $\mathrm{C} 5 \mathrm{a}_{1}$ receptor to form homodimers and heterodimers has been demonstrated (Geva et al., 2000; Huttenrauch et al., 2005; Klco et al., 2003). In both cases, ligation of a dimerized $\mathrm{C}^{2} \mathrm{a}_{1}$ receptor can cause the phosphorylation and/or internalization of the partner receptor. The functional consequences of this ability to form oligomers are unknown but may be linked to the cross-modulation of the response to chemoattractants or the rapid down-regulation of the C5 $\mathrm{a}_{1}$ receptor in severe conditions such as sepsis.

\section{D. $\mathrm{C}_{5} \mathrm{a}_{2}$ Receptor as a C5a and C5a des-Arg Receptor}

1. Sequence and Genetics. In 2000, a seventransmembrane domain receptor sharing high sequence identity with human C5AR1 was cloned and designated human C5a receptor-like 2 (C5L2, GPR77) (Ohno et al., 2000). The $\mathrm{C}^{2} \mathrm{a}_{2}$ receptor was found to be encoded for by the human GPR77 gene, which is located within the respective gene cluster on chromosome 19q13 (Lee et al., 2001). GPR77, now to be described as C5AR2, shows the two-exon structure characteristic of chemoattractant receptor family members, with the $5^{\prime}$-UTR and initiating methionine encoded in the first exon, and the actual coding sequence and 3 '-UTR in the second (Gerard et al., 1993). Message size heterogeneity was later described for the human and mouse $\mathrm{C} \mathrm{a}_{2}$ receptors and was attributed to alternative splicing in the UTR (Okinaga et al., 2003). Two SNP possibly linked to fatty acid metabolism have been identified in the human C5AR2 gene. First, SNP 968G/T, causing an amino acid 
exchange of S323I, was found associated with inheritable combined hyperlipemia in a French Canadian family, but could not be identified in a screening that involved Han, Uygur, and Kazakh subjects with familial hyperlipemia or type 2 diabetes (Cui et al., 2009b; Marcil et al., 2006; Zheng et al., 2011a). Second, a recently discovered $698 \mathrm{C} / \mathrm{T}$ substitution, leading to a P233L amino acid exchange, appears to be a genetic marker of coronary artery disease and type 2 diabetes mellitus in the Han and Uygur populations in northwestern China (Zheng et al., 2011b, 2012). Furthermore, $C 5 a_{2} R$ displays two synonymous SNP at $614 \mathrm{G} / \mathrm{A}$ and $860 \mathrm{C} / \mathrm{T}$ without any known association with human disease (Birney et al., 2006). Other SNP have not yet been associated with disease (http:// www.ncbi.nlm.nih.gov/SNP/snp_ref.cgi?locusId=27202; Sherry et al., 2001). Due to its homology with the chemoattractant receptors $\mathrm{C}^{2} \mathrm{a}_{1}$ receptor, $\mathrm{C} 3 \mathrm{a}$ receptor, FPR, and ChemR23, the ${\mathrm{C} 5 \mathrm{a}_{2}}_{2}$ receptor was categorized into the GPCR subfamily A8 (Joost and Methner, 2002). Correspondingly, the $\mathrm{C}^{2} \mathrm{a}_{2}$ receptor was clustered with A8 subfamily members and other chemoattractant receptors such as the type- 2 angiotensin-II receptor, bradykinin receptor, and several orphan receptors in a study that compared the transmembrane domain-binding cavities of various human GPCR (Surgand et al., 2006).

\section{Post-translational Modification}

a. Glycosylation. A potential N-linked glycosylation site exists at Asp3 of the human ${\mathrm{C} 5 \mathrm{a}_{2}}_{2}$ receptor, and, although the glycosylation status of this residue has not been formally investigated, the apparent molecular weight observed by Western blot analysis suggests that the receptor is glycosylated in vivo (Okinaga et al., 2003).

b. Tyrosine sulfation. Like the $\mathrm{C}^{2} \mathrm{a}_{1}$ receptor, there are three tyrosine residues at the $\mathrm{N}$ terminus of the $\mathrm{C} \mathrm{a}_{2}$ receptor, all of which (Tyr8, Tyr10, and Tyr13) are proximal to acidic residues, making them potential sulfation sites (Rosenquist and Nicholas, 1993). Mutation of Tyr10 or Tyr13 but not Tyr8 can affect ligand binding to the $\mathrm{C}^{2} \mathrm{a}_{2}$ receptor, but only the binding of C5a des-Arg is significantly inhibited (Scola et al., 2007).

c. Phosphorylation. The $\mathrm{C}^{2} \mathrm{a}_{2}$ receptor has only seven serine/threonine residues at the $\mathrm{C}$ terminus, in comparison with the $\mathrm{C}^{2} \mathrm{a}_{1}$ receptor which has 11 . A low level of phosphorylation of the $\mathrm{C}^{2} \mathrm{a}_{2}$ receptor has been observed after C5a treatment of transfected cells (Okinaga et al., 2003), suggesting that few of these residues are phosphorylated, perhaps because of the lack of the PK-C $\beta$ II binding site found on the third intracellular loop of the C5a $\mathrm{a}_{1}$ receptor (Section IV.C.2).

d. S-acylation. Similar to the C3a receptor, the $\mathrm{C} \mathrm{a}_{2}$ receptor has a cysteine in the $\mathrm{C}$-terminal domain that is a potential S-acylation site. It is not known whether any modification of this residue occurs in vivo.
3. $C 5 a_{2}$ Receptor Expression. In most tissues, the $\mathrm{C} \mathrm{a}_{2}$ receptor is coexpressed with the $\mathrm{C} 5 \mathrm{a}_{1}$ receptor, with overall levels tending to be lower than those of the $\mathrm{C5}_{1}$ receptor (Okinaga et al., 2003; Lee et al., 2008;

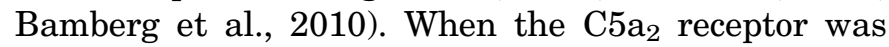
first described, its transcripts were found to be most abundant in human leukocytes and the spleen by Northern blot analysis; using polyclonal antiserum, the receptor protein could be detected on immature but not mature DC (Ohno et al., 2000). In mice, bone marrow and peripheral blood leukocytes were identified as the most abundant sources of the $\mathrm{C}^{2} \mathrm{a}_{2}$ receptor message (Okinaga et al., 2003). Subsequently, C5a $\mathrm{a}_{2}$ receptor expression on the mRNA or protein level was described for a broad range of immune and nonimmune mouse, rat, and human cells and tissues, including neutrophils, macrophages, thyroid, adipocytes, skin fibroblasts, neurons and astroglia of the CNS, spinal cord, adrenal gland, lung, heart, liver, kidney, ovary, and testis (Lee et al., 2001; Okinaga et al., 2003; Otto et al., 2004; Gao et al., 2005; Gavrilyuk et al., 2005; Kalant et al., 2005; Bamberg et al., 2010).

a. Intracellular or extracellular localization for $\mathrm{C}^{5} \mathrm{a}_{2}$ receptor. Although it is generally accepted that mouse, rat, and human PMN express the C5 $\mathrm{a}_{2}$ receptor, controversy exists about $\mathrm{C} \mathrm{a}_{2}$ receptor localization in this cell type. Some investigators did not detect significant amounts of the receptor on the cell surface (Otto et al., 2004; Bamberg et al., 2010), but others could verify surface expression in binding assays or by flow cytometry (Okinaga et al., 2003; Gao et al., 2005; Rittirsch et al., 2008). Finally, Scola et al. (2009) suggested a wide natural variation in $\mathrm{C}^{2} \mathrm{a}_{2}$ receptor surface expression between human individuals. In some cases, opposing findings were subsequently published by the same group (Okinaga et al., 2003; Bamberg et al., 2010). These discrepancies may in part be due to differential regulation of $\mathrm{C}^{2} \mathrm{a}_{2}$ receptor expression depending on the activation status of the cells. Also, not all of the polyclonal antisera or monoclonal antibodies used may have been suitable to detect the $\mathrm{C} \mathrm{a}_{2}$ receptor on primary cells. Some antibodies raised against antigenic peptides or against transfected cells fail to recognize their antigen on primary cells, despite being able to detect it on transfected cells. This should be taken into account whenever newly developed antibodies are used for detection of this receptor on primary cells (Jorg Köhl, personal communication).

b. Regulation of expression. The regulation of $\mathrm{C}^{5} \mathrm{a}_{2}$ receptor expression is influenced by proinflammatory and anti-inflammatory signals. Several cell lines have been shown to express the $\mathrm{C}^{2} \mathrm{a}_{2}$ receptor either constitutively or after induction with certain substances. On HeLa cells, the $\mathrm{C}^{2} \mathrm{a}_{2}$ receptor but not the C5a receptor is detected at low levels, and it decreases upon treatment with IFN- $\gamma$ or tumor-necrosis factor $\alpha$ 
(TNF- $\alpha$ ). Both the $\mathrm{C} 5 \mathrm{a}_{1}$ and $\mathrm{C} 5 \mathrm{a}_{2}$ receptors are absent from the surface of native HL-60 or U937 cells, but their expression can be induced with $\mathrm{Bt}_{2}$-cAMP or IFN$\gamma$, whereas TNF- $\alpha$ has no effect (Johswich et al., 2006). In rat astrocytes, $\mathrm{C} \mathrm{a}_{2}$ receptor mRNA and protein were found to be up-regulated by noradrenaline, associated with suppression of nitric oxide synthase 2 and NF- $\kappa$ B genes (Gavrilyuk et al., 2005). Huber-Lang et al. (2005) could show that prolonged exposure of rat and human PMN to C5a in vitro decreased $\mathrm{C}_{5} \mathrm{a}_{2}$ receptor expression. Likewise, $\mathrm{C} \mathrm{a}_{2}$ receptor is reduced on PMN isolated from septic patients or from rats subjected to sepsis induced by cecal ligation and puncture (CLP). TLR activation in human PBMCs was found to inhibit $\mathrm{C}^{2} \mathrm{a}_{2}$ receptor expression, thereby increasing cellular responsiveness to $\mathrm{C}^{2} \mathrm{a}_{1}$ receptor signaling. Thus, the $\mathrm{C}^{2} \mathrm{a}_{2}$ receptor appears to be differentially regulated in different cell types, and its expression level may influence cellular functions, especially in the context of inflammation.

\section{Ligand Binding by $\mathrm{C}_{5} \mathrm{a}_{2}$ Receptor}

a. C5a and C5a des-Arg. The $\mathrm{C}^{2} \mathrm{a}_{2}$ receptor was initially speculated to be the long sought-after $\mathrm{C} 4 \mathrm{a}$ receptor (Ohno et al., 2000; Lee et al., 2001), but in fact turned out to be a second human receptor for C5a, binding both C5a and C5a des-Arg with high affinity (Cain and Monk, 2002; Okinaga et al., 2003; Johswich et al., 2006). The $K_{\mathrm{d}}$ values of $\mathrm{C} \mathrm{a}_{2}$ receptor binding were in the range of $\sim 3-10 \mathrm{nM}$ for $\mathrm{C} 5 \mathrm{a}$, and $\sim 12-36$ $\mathrm{nM}$ for C5a des-Arg, respectively, with $\mathrm{C}_{5} \mathrm{a}_{2}$ receptor having 10- to 100-fold higher affinity for C5a des-Arg in comparison with the $\mathrm{C}^{2} \mathrm{a}_{1}$ receptor. Although the affinity of the human $\mathrm{C}^{2} \mathrm{a}_{2}$ receptor is about equal for $\mathrm{C} 5 \mathrm{a}$ and $\mathrm{C} 5 \mathrm{a}$ des-Arg, both mouse and rat $\mathrm{C}^{2} \mathrm{a}_{2}$ receptor homologs clearly prefer species-matched $\mathrm{C} 5 \mathrm{a}$ des-Arg over C5a, with mouse $\mathrm{C}_{5} \mathrm{a}_{2}$ receptor displaying an over 4000-fold higher affinity for C5a des-Arg than for C5a. As in humans, the rodent $\mathrm{C}^{2} \mathrm{a}_{2}$ receptor outmatches the rodent $\mathrm{C} \mathrm{a}_{1}$ receptor in its affinity for C5a des-Arg (Scola et al., 2007). Moreover, in one study, the human ${\mathrm{C} 5 \mathrm{a}_{2}}_{2}$ receptor exhibited distinctly $(\sim 100$-fold) slower on-rates and slightly ( 3 -fold $)$ slower off-rates for $\mathrm{C} 5 \mathrm{a}$ at $0^{\circ} \mathrm{C}$ and in the presence of azide (Okinaga et al., 2003).

b. Other complement peptides. Whether the $\mathrm{C}^{2} \mathrm{a}_{2}$ receptor can bind $\mathrm{C} 3 \mathrm{a} / \mathrm{C} 3 \mathrm{a}$ des-Arg or $\mathrm{C} 4 \mathrm{a} / \mathrm{C} 4 \mathrm{a}$ des-Arg is a matter of controversy. Moderate to low binding of $\mathrm{C} 3 \mathrm{a}$ and $\mathrm{C} 4 \mathrm{a}$ to a site distinct from the C5a binding site was first detected in 2002 (Cain and Monk, 2002). Shortly thereafter, Kalant et al. (2003) reported binding of the des-arginated ligands C3a des-Arg and $\mathrm{C} 4 \mathrm{a}$ des-Arg to the $\mathrm{C}_{5} \mathrm{a}_{2}$ receptor, and observed increased triglyceride synthesis in $\mathrm{C}_{5} \mathrm{a}_{2}$ receptortransfected cells after stimulation with C3a des-Arg, also referred to as acylation-stimulating protein (ASP), or with $\mathrm{C} 3 \mathrm{a}$. In contrast, others were unable to detect binding of any ligands apart from C5a and C5a des-Arg

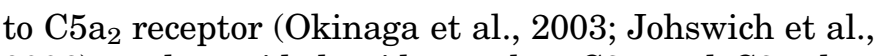
2006), and provided evidence that C3a and C3a desArg interact with plastic surfaces in a pattern highly suggestive of specific receptor-ligand binding (Johswich et al., 2006). The complex issue of $\mathrm{C}^{2} \mathrm{a}_{2}$ receptor as a functional receptor for C3a des-Arg is reviewed in more detail in Section IV.E.

c. Comparison with $C 5 a_{1}$ Receptor ligand binding. $\mathrm{C} 5 \mathrm{a}$ and $\mathrm{C} 5 \mathrm{a}$ des-Arg binding by the $\mathrm{C}^{2} \mathrm{a}_{2}$ receptor differs from that of the $\mathrm{C}_{5} \mathrm{a}_{1}$ receptor, despite the two receptors sharing patterns of tyrosine and acidic $\mathrm{N}$ terminal residues as well as charged and hydrophobic residues in the extracellular loops and transmembrane

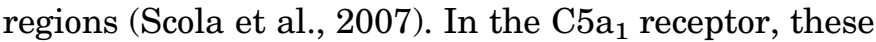
residues are known to interact with the core and $\mathrm{C}$ terminus of C5a, respectively (Oppermann et al., 1993; Pease et al., 1994). However, the well-characterized antagonist PMX53 (Wong et al., 1999; Taylor et al., 2001) and other effective peptidic and nonpeptidic ligands for the transmembrane hydrophobic pocket of the human $\mathrm{C}^{2} \mathrm{a}_{1}$ receptor are moderate-to-poor inhibitors of ligand binding to the $\mathrm{C}^{2} \mathrm{a}_{2}$ receptor, suggesting that the C5a core segment is the most relevant for C5a binding to the $\mathrm{C}^{2} \mathrm{a}_{2}$ receptor (Okinaga et al., 2003; Otto et al., 2004; Scola et al., 2007). An antibody raised against the $\mathrm{N}$ terminus of human $\mathrm{C}^{2} \mathrm{a}_{2}$ receptor inhibited the binding of C5a des-Arg to the $\mathrm{C}^{2} \mathrm{a}_{2}$ receptor but left $\mathrm{C5a}$ binding unaffected, while substituting the $\mathrm{N}$ terminus of the $\mathrm{C}^{2} \mathrm{a}_{2}$ receptor with that of the $\mathrm{C}^{2} \mathrm{a}_{1}$ receptor had little effect on the high affinity of the $\mathrm{C}_{5} \mathrm{a}_{2}$ receptor for C5a des-Arg (Scola et al., 2007). Finally, mutational analyses revealed three N-terminal residues of the $\mathrm{C}^{2} \mathrm{a}_{2}$ receptor that were essential for C5a des-Arg binding but had little involvement in C5a binding (Scola et al., 2007). Taken together, these findings indicate that the $\mathrm{N}$ terminus is an important but not the only determinant of the high affinity of the human $\mathrm{C}^{2} \mathrm{a}_{2}$ receptor for C5a des-Arg, and that, unlike the $\mathrm{C}^{2} \mathrm{a}_{1}$ receptor, critical $\mathrm{N}$-terminal residues of the $\mathrm{C}^{2} \mathrm{a}_{2}$ receptor interact with C5a des-Arg only, not with C5a.

d. Modulation of ligand binding. While a number of blocking antibodies specific for the mouse, rat, or human ${\mathrm{C} 5 \mathrm{a}_{2}}_{2}$ receptor have been developed and employed by different investigators in vitro and in vivo (Gao et al., 2005; Cui et al., 2007; Lee et al., 2008; Bamberg et al., 2010), to our knowledge the only antagonists for the human $\mathrm{C}^{2} \mathrm{a}_{2}$ receptor are the C5a mutant jun/fos-A8, and its derivative jun/fos-A $8^{\Delta 71-73}$, which inhibit ligand binding to both the $\mathrm{C}_{5} \mathrm{a}_{1}$ receptor and ${\mathrm{C} 5 \mathrm{a}_{2}}_{2}$ receptor (Heller et al., 1999; Otto et al., 2004).

\section{5. $\mathrm{C} \mathrm{a}_{2}$ Receptor Signaling}

a. $G$ protein mediated. Despite sharing the 7TM structure of typical GPCR, the $\mathrm{C}^{2} \mathrm{a}_{2}$ receptor is widely accepted to be uncoupled from G proteins (Cain and 
Monk, 2002; Kalant et al., 2003; Okinaga et al., 2003; Johswich et al., 2006; Scola et al., 2009). This is believed to be due to changes in conserved sequences shared by most functional chemoattractant or chemokine receptors, including the $\mathrm{C}^{5} \mathrm{a}_{1}$ receptor. Primarily, both mouse and human $\mathrm{C}^{2} \mathrm{a}_{2}$ receptors lack the highly conserved "DRX" motif usually found at the end of TM3 (Oliveira et al., 1994; Ballesteros et al., 1998), actually Asp-Arg-Phe in the human $\mathrm{C}^{2} \mathrm{a}_{1}$ receptor. In the $\mathrm{C}^{2} \mathrm{a}_{2}$ receptor, it reads Asp-Leu-Cys, thus lacking the arginine residue that is most important for the interaction with G proteins (Savarese and Fraser, 1992; Scheer et al., 1996; Cain and Monk, 2002; Okinaga et al., 2003). Mutating the respective arginine in FPR, CCR5, histamine $\mathrm{H}_{2}$ receptor, and other receptors greatly decreases or altogether abolishes their ability to couple to G proteins (Prossnitz et al., 1999; Alewijnse et al., 2000; Lagane et al., 2005; Rovati et al., 2007). Conversely, C5a binding to a C5a receptor in which Asp-Leu-Cys is mutated to AspArg-Cys induces a low level of intracellular $\mathrm{Ca}^{2+}$ mobilization in HEK293 cells cotransfected with $\mathrm{G} \alpha 16$, indicative of a partial gain-of-function in coupling to this rather promiscuous $\mathrm{G}$ protein subtype (Okinaga et al., 2003). However, RBL-2H3 cells transfected with the $\mathrm{C}_{5} \mathrm{a}_{2}$ receptor mutated to resemble the $\mathrm{C} \mathrm{a}_{1}$ receptor at this motif did not respond to C5a or $\mathrm{C} 5 \mathrm{a}$ des-Arg in an intracellular free $\mathrm{Ca}^{2+}$ assay (Scola et al., 2009). Given that rat basophilic leukemia (RBL) cells do not endogenously express $\mathrm{G} \alpha 16$, variations in the amount and selectivity of the two G proteins may explain these differing results.

Further residues in the mouse and human $\mathrm{C}^{2} \mathrm{a}_{2}$ receptors that differ from conserved sequences in the $\mathrm{C} \mathrm{a}_{1}$ receptor and other GPCR are in the "NPXXY" motif (Asn-Pro-Leu-Met-Phe in $\mathrm{C}^{2} \mathrm{a}_{2}$ receptor) in TM7, and deletions of serine/threonine residues and a basic region $\left({ }^{239}\right.$ Lys-Thr-Leu-Lys in $\mathrm{C}^{2} \mathrm{a}_{1}$ receptor) that truncate the third intracellular domain (Cain and Monk, 2002; Scola et al., 2009). Substitution of the analogous serine/threonine residues with alanine in the ${\mathrm{C} 5 \mathrm{a}_{1}}$ receptor does not interfere with ligand binding but abolishes downstream signaling, suggesting that this region is also involved in $G$ protein coupling (Bock et al., 1997). Different mutations of the NPXXY motif have been shown to inhibit the activation of $G_{q}$ by the cholecystokinin $B$ receptor and to disturb internalization, ligand binding, or coupling to selected downstream pathways in the case of FPR (Gales et al., 2000).

In an effort to further elucidate the regions responsible for uncoupling the $\mathrm{C} \mathrm{a}_{2}$ receptor from $\mathrm{G}$ proteins, a recent study compared the $\mathrm{C}^{2} \mathrm{a}_{1}$ receptor and the $\mathrm{C} \mathrm{a}_{2}$ receptor with four substitution mutants of the human C5 $\mathrm{a}_{2}$ receptor: DRX (Asp-Arg-Phe), NPXXY (Asn-Pro-Met-Leu-Tyr), DRX/NPXXY double mutant, a chimeric receptor carrying the third intracellular loop of $\mathrm{C} \mathrm{a}_{2}$ receptor, and a triple mutant containing all of the mentioned modifications. Unlike the ${\mathrm{C} 5 \mathrm{a}_{1}}$ receptor, none of the mutants exhibited ligand-induced internalization, $\mathrm{Ca}^{2+}$ mobilization, or translocation of endogenous $\beta$-arrestin 1 in RBL-2H3 cells, and neither did the wild-type $\mathrm{C}^{2} \mathrm{a}_{2}$ receptor (Scola et al., 2009). Taken together, multiple structural features contribute to effectively restrict $G$ proteincoupled signaling by the $\mathrm{C}^{2} \mathrm{a}_{2}$ receptor.

In accordance, several groups have consistently found that binding of $\mathrm{C} 5 \mathrm{a}, \mathrm{C} 3 \mathrm{a}, \mathrm{C} 4 \mathrm{a}$, or their desarginated derivatives to the wild-type $\mathrm{C}^{2} \mathrm{a}_{2}$ receptor in vitro does not support $G$ protein-mediated cellular responses such as $\mathrm{Ca}^{2+}$ mobilization, degranulation, chemotaxis, or activation of the mitogen-activated protein kinase (MAPK) pathway, in striking contrast to the diverse effects induced by the $\mathrm{C}^{2} \mathrm{a}_{1}$ receptor (Cain and Monk, 2002; Kalant et al., 2003; Okinaga et al., 2003; Johswich et al., 2006; Scola et al., 2009). Pretreatment of human $\mathrm{C}^{2} \mathrm{a}_{2}$ receptor-expressing RBL-2H3 cells with C5a, C5a des-Arg, C3a, or C4a could facilitate FceRI-mediated secretory responses (Cain and Monk, 2002), implying that, at the most, the $\mathrm{C} \mathrm{a}_{2}$ receptor exhibits very limited capacities for signal transduction under particular conditions.

b. Internalization of $\mathrm{C}_{5} \mathrm{a}_{2}$ receptor. The $\mathrm{C}^{2} \mathrm{a}_{2}$ receptor has been suggested to act as a decoy receptor, limiting the availability of C5a or C5a des-Arg to competing receptors, especially the $\mathrm{C} \mathrm{a}_{1}$ receptor (Okinaga et al., 2003; Scola et al., 2009). This concept was first described in 1993 for IL-1RII (Colotta et al., 1993), and has since then been extended to GPCR including D6, DARC, US28, CCX CKR (CCRL-1), CRAM-B (CCRL-2), and CXCR7 (Nibbs et al., 1997; Gosling et al., 2000; Randolph-Habecker et al., 2002; Lee et al., 2003; Burns et al., 2006; Hartmann et al., 2008; Leick et al., 2010). By sequestering ligands and targeting them for degradation, these receptors negatively regulate cellular responses to inflammatory mediators. Decoy receptors are commonly uncoupled from G proteins, most of them due to lack of the DRX motif. Unlike signaling receptors, they do not undergo ligand-induced internalization, but some of them recycle constitutively between the cell surface and intracellular compartments, thus efficiently removing ligands from the extracellular space. This may lead to a relatively high proportion of intracellular receptors, as demonstrated for D6 (Weber et al., 2004).

It has been demonstrated by the use of human PMN or transfected cell lines, including RBL-2H3, that significant amounts of $\mathrm{C}^{2} \mathrm{a}_{2}$ receptor are located intracellularly, and that human $\mathrm{C}^{2} \mathrm{a}_{2}$ receptor is neither phosphorylated nor internalized upon binding of C5a or C5a des-Arg (Cain and Monk, 2002; Okinaga et al., 2003; Scola et al., 2009; Bamberg et al., 2010). Instead, clathrin-dependent constitutive internalization occurs, resulting in net transport of ligand into the 
cell and in ligand degradation (Scola et al., 2009). This appeared to be more efficient for C5a des-Arg than for C5a, suggesting that the $\mathrm{C}^{2} \mathrm{a}_{2}$ receptor might be responsible for removing the more abundant desarginated form from the circulation (Scola et al., 2009). Interestingly, a predominantly intracellular location and constitutive internalization were recently reported for FPR3, which, despite being capable of eliciting cellular responses, does not seem to activate $\mathrm{G}$ proteins (Rabiet et al., 2011). In the respective study, the N-terminal extracellular region and TM1 were identified to contain the structural determinants of this unusual recycling behavior, which appears to be clathrin- and $\beta$-arrestin-independent. Based on these results, the investigators hypothesized that FPR3 may serve a ligand scavenging or intracellular receptor function, in analogy to what has been described for the

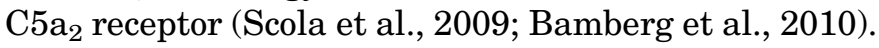
Again, contrasting data have come from studies investigating the $\mathrm{C5}_{2}$ receptor as a receptor for C3a desArg /ASP: here, ligand-induced clathrin-dependent receptor endocytosis and recycling were observed in HEK293 cells, and were impaired by an S323I mutation, indicating that this residue is vital for $\mathrm{C} 3 \mathrm{a}$ des-Arg /ASP-induced $\mathrm{C}^{2} \mathrm{a}_{2}$ receptor activation (Cui et al., 2009b).

c. Arrestin-mediated signaling. Because there is no evidence for the involvement of $G$ proteins in the observed $\mathrm{C}^{2} \mathrm{a}_{2}$ receptor-mediated effects, the idea emerged that the $\mathrm{C}_{5} \mathrm{a}_{2}$ receptor uses $\mathrm{G}$ proteinindependent signaling, such as pathways targeted by $\beta$-arrestins (reviewed in Defea, 2008). A $\beta$-arrestin 1-GFP fusion protein was translocated to the human $\mathrm{C5a}_{2}$ receptor in transfected HEK293 cells after stimulation with C5a, C5a des-Arg, C3a, or C3a desArg (Kalant et al., 2005). The presence of large amounts of exogenous protein or varying preferences of the $\mathrm{C}^{2} \mathrm{a}_{2}$ receptor for $\beta$-arrestin subtypes depending on the cell type may account for the divergence between these and other results (Scola et al., 2009). Later, two independent studies of $\mathrm{C}^{2} \mathrm{a}_{2}$ receptortransfected cells concordantly reported C5a-induced translocation of $\beta$-arrestin 2 (Cui et al., 2009b; van Lith et al., 2009). In addition, the role attributed to the $\mathrm{C}^{2} \mathrm{a}_{2}$ receptor as a functional receptor for C3a des-Arg (ASP) in lipid metabolism seems to be associated with recruitment of $\beta$-arrestin 2-GFP (Cui et al., 2009a). Furthermore, it was recently shown in the human mast cell line HMC-1 that G protein-mediated ERK1/2 activation downstream of the C3a receptor may be negatively regulated by $\beta$-arrestins (Vibhuti et al., 2011). Colocalization of $\beta$-arrestin 1 with the $\mathrm{C} 5 \mathrm{a}_{1}$ and $\mathrm{C} \mathrm{a}_{2}$ receptors occurs in endosomal vesicles of C5astimulated human PMNs and was found to be dependent on $\mathrm{C}^{2} \mathrm{a}_{1}$ receptor activation (Bamberg et al., 2010). Assuming a regulatory interplay of the $\mathrm{C}^{2} \mathrm{a}_{2}$ receptor with the $\mathrm{C} \mathrm{a}_{1}$ receptor, as they had already hypothesized earlier (Gerard et al., 2005), the investigators showed that two putative signaling events downstream of $\beta$-arrestin 1, ERK1/2 activation and chemotaxis, are enhanced after antibody blockade of the $\mathrm{C} \mathrm{a}_{2}$ receptor. However, it remains to be confirmed that $\beta$-arrestin 1 mediates $\mathrm{C} \mathrm{a}_{1}$ receptor-induced functions in human primary cells or transfected cells, as they may as well result from G protein activation (Buhl et al., 1994; Nilsson et al., 1996; Haribabu et al., 1999; Schraufstatter et al., 2009; Nishiura et al., 2010b;). In summary, there are credible indications of an active signaling function of the ${\mathrm{C} 5 \mathrm{a}_{2}}$ receptor involving $\beta$-arrestin, but further confirmation should be aimed at elucidating how this modulates the cellular response to C5a.

d. Dimerization. For the $\mathrm{C}^{2} \mathrm{a}_{1}$ receptor, homodimerization as well as heterodimerization with CCR5 have been observed, and have been shown to lead to homologous or heterologous co-internalization of phosphorylation-deficient $\mathrm{C}^{2} \mathrm{a}_{1}$ receptor or of CCR5, respectively, upon C5a binding to the wild-type $\mathrm{C}^{2} \mathrm{a}_{1}$ receptor (Huttenrauch et al., 2005; Rabiet et al., 2008). Interestingly, the chemokine receptor CXCR7, which is known to associate with $\mathrm{G} \alpha_{\mathrm{i}}$ but does not elicit any intracellular signaling (Levoye et al., 2009), has been found to heterodimerize with CXCR4. The dimers were constitutively associated with $\beta$-arrestin and concomitantly decoupled from $\mathrm{G} \alpha_{\mathrm{i}}$, resulting in potentiated CXCL12-induced signaling via MAPK pathways to promote cell migration (Decaillot et al., 2011). It is tempting to speculate that a similar interaction could take place between the $C 5 \mathrm{a}_{1}$ receptor and the $\mathrm{C}_{5} \mathrm{a}_{2}$ receptor, shifting or switching downstream signaling from $\mathrm{G}$ protein-dependent to $\beta$-arrestin-mediated events, and thus providing at least some explanation for the unresolved controversies about the functions of the $\mathrm{C} \mathrm{a}_{2}$ receptor. This possibility has been considered, but no evidence was seen in mouse cells (Chen et al., 2007), and it was not reported in human PMN, even when modulation of $\mathrm{C}^{2} \mathrm{a}_{1}$ receptor signaling was observed (Bamberg et al., 2010). The investigators considered differential regulation of downstream pathways rather than dimerization as the underlying mechanism (Chen et al., 2007; Bamberg et al., 2010). However, more recent evidence points to the formation of hetero- and homodimers by C5a1 and C5a2 (Croker et al., 2012; Poursharifi et al., 2013), although the functional significance is still unclear.

e. Cross-talk with Toll-like receptors. Apparently, nonsignaling 7TM receptors may also act as chemokine chaperones or transporters (Middleton et al., 1997; Nibbs et al., 2003), but to date, none of these functions have been attributed to the $\mathrm{C}^{2} \mathrm{a}_{2}$ receptor. Lately, a cross-talk between TLR and the $\mathrm{C}^{2} \mathrm{a}_{1}$ receptor/C5a receptor has been described, in which TLR activation reduces ${\mathrm{C} 5 \mathrm{a}_{2}}_{2}$ receptor activity, thereby releasing the $\mathrm{C} \mathrm{a}_{1}$ receptor from negative modulation and enhancing the inflammatory response to C5a (Raby et al., 2011). 
This study suggests that in the course of every inflammatory reaction, a balance between TLRinduced cellular hypersensitivity to $\mathrm{C} 5 \mathrm{a}$ and the $\mathrm{C}^{2} \mathrm{a}_{2}$ receptor counteracting this effect has to be established, and that the net outcome of the process varies considerably among individuals.

6. Pro- and Anti-inflammatory Effects of $\mathrm{C}^{2} \mathrm{a}_{2}$ Receptor. The human ${\mathrm{C} 5 \mathrm{a}_{2}}_{2}$ receptor shares many features with the well-characterized chemokine scavenging receptor D6, clearly implying they have analogous functions. The $\mathrm{C} \mathrm{a}_{2}$ receptor should thus be expected to have anti-inflammatory effects in vivo and to negatively regulate $\mathrm{C5a}_{1}$ receptor-mediated responses (Locati et al., 2005; Borroni et al., 2006). In fact, when compared with wild-type animals, mice with a targeted deletion of C5ar2 mounted an exaggerated inflammatory reaction, with a 2 - to 3 -fold increased neutrophil influx and higher levels of IL- 6 and TNF- $\alpha$ in a model induced by ovalbumin (OVA) of pulmonary immune complex injury; the chemotaxis of murine C5ar2 $2^{-1-}$ bone marrow cells was also enhanced in vitro (Gerard et al., 2005). Up-regulation of the $\mathrm{C}^{2} \mathrm{a}_{2}$ receptor in rat astrocytes is associated with suppression of proinflammatory genes (Gavrilyuk et al., 2005); upon stimulation with C5a and LPS, rat neutrophils pretreated with a ${\mathrm{C} 5 \mathrm{a}_{2}}_{2}$ receptor-blocking antibody produced higher amounts of IL-6 than untreated control cells (Gao et al., 2005). Similarly, a study of human septic patients found that low $\mathrm{C}^{2} \mathrm{a}_{2}$ receptor expression on PMN correlated with multiorgan failure and nonsurvival, and corresponding results were obtained from rats subjected to CLP-induced sepsis (Huber-Lang et al., 2005).

The decoy receptor hypothesis has been contrasted by a recent report that the $\mathrm{C}^{2} \mathrm{a}_{2}$ receptor can positively modulate $\mathrm{C}^{2} \mathrm{a}_{1}$ receptor- and $\mathrm{C} 3 \mathrm{a}$ receptor-induced inflammatory responses (Chen et al., 2007). The C5ar2 $2^{-1-}$ mouse strains on $\mathrm{C} 57 \mathrm{BL} / 6$ and BALB/c background used here were generated independently of the animals used for the aforementioned studies (Gerard et al., 2005), and several disease models were investigated. In comparison with wild-type mice, C5ar2 $2^{-1-}$ animals showed reduced macrophage infiltration in peritonitis induced by thioglycolate (TGC), and less pronounced cellular infiltration and activation after injection of C5a and TGC in a dorsal air-pouch model of inflammation (Chen et al., 2007). C5ar2 ${ }^{-1-}$ mice were also less affected by OVA-induced airway hyperresponsiveness than wild-type mice, as characterized by one lung function parameter and histologic evaluation of the inflammatory infiltrate. After in vitro stimulation with $\mathrm{C} 3 \mathrm{a}$ or C5a, up-regulation of cellsurface markers and activation of downstream MAPK pathways were diminished in neutrophils and macrophages from $C 5 a r 2^{-1-}$ animals. Then again, deletion of C5ar2 seems to render mice more susceptible to LPS-induced shock, as indicated by elevated IL-1 $\beta$ serum levels and high mortality after i.p. injection of LPS (Chen et al., 2007).

Likewise, Rittirsch et al. (2008) support a proinflammatory role for the $\mathrm{C} \mathrm{a}_{2}$ receptor: according to their observations in $\mathrm{C}_{5 \mathrm{ar} 1^{-1-}}$ and $\mathrm{C} 5 \mathrm{ar} 2^{-1-}$ mice subjected to CLP-induced sepsis, and treated or not with blocking antibodies, the synergistic action of both receptors is required for the development of full-blown sepsis. Only a combined pretreatment with both anti-C5 $\mathrm{a}_{1}$ receptor and anti-C5a $\mathrm{a}_{2}$ receptor antibodies could lower the plasma levels of proinflammatory mediators and reduce lethality, with the role of the $\mathrm{C}^{2} \mathrm{a}_{2}$ receptor being linked to the release of HMGB1 (Rittirsch et al., 2008). It may be assumed that the animals used in this study were provided by the Gerard group, although this was not explicitly specified.

Recently, a complex role for the $\mathrm{C} \mathrm{a}_{2}$ receptor has emerged in the pathogenesis of experimental allergic asthma in mice. Here, the $\mathrm{C}^{2} \mathrm{a}_{2}$ receptor acts at the $\mathrm{mDC} / \mathrm{T}$ cell interface to suppress $\mathrm{T}_{\mathrm{H}} 1$ and $\mathrm{T}_{\mathrm{H}} 17$ polarization, while concomitantly driving $\mathrm{T}_{\mathrm{H}} 2$ cytokine production in other pulmonary cells (Zhang et al., 2010).

\section{E. C5a $a_{2}$ Receptor as a Possible Receptor for C3a des- Arg /Acylation Stimulating Protein}

1. Mediators of Metabolic Activity. The adipose tissue is an active endocrine organ that secretes mediators such as adiponectin, leptin, or resistin, which are prototypical adipokines (or adipocytokines) (Kershaw and Flier, 2004). This term describes a group of factors secreted by the white adipose tissue. Adiponectin is a member of the pattern-recognition family of defense collagens, and it interacts with a number of target molecules, including surface structures of damaged endothelium and apoptotic cells. It can bind to complement factor C1q, thus activating the classic pathway of the complement system (Peake et al., 2008), and it is regulated by factor $\mathrm{H}$, a soluble complement inhibitor (Peake and Shen, 2010). Other adipokines include cytokines and chemokines such as IL-1, IL-6, IL-8, IL-18, TNF- $\alpha$, MCP-1 (CCL2), CXCL5, and proteins involved in the acute phase response such as PAI-1 (Kershaw and Flier, 2004; Ouchi et al., 2011). Adipsin, also known as factor $\mathrm{D}$ of the alternative pathway, was one of the first recognized adipokines (Cook et al., 1987; White et al., 1992). Adipokines influence energy metabolism, appetite, body weight, and insulin resistance. Most of them stimulate inflammation, but some (adiponectin and SFRP5) are anti-inflammatory. They play an important role in obesity-related metabolic dysfunction, the pathogenesis of which implies chronic low-grade inflammation (Ouchi et al., 2011), as well as in classic inflammatory diseases such as sepsis (Hillenbrand et al., 2012). Hence, there is a growing interest in adipokines in biomedical sciences. 
2. Acylation-Stimulating Protein. ASP has been proposed mainly by the Sniderman and Cianflone group as a potent mediator of triglyceride synthesis, simultaneously increasing glucose transport, and as an adipokine with both metabolic and immune functions. Purification from human serum and sequence analysis have revealed that ASP is identical to the des-arginated form of C3a: C3a des-Arg (Cianflone et al., 1987, 1989b, 2003). Functional impairment of ASP has been suggested as major cause of familial hyperapobetalipoproteinemia (Sniderman et al., 1985; Cianflone et al., 1988, 1990; Sniderman and Cianflone, 1994). Moreover, it has been claimed that the $\mathrm{C}^{2} \mathrm{a}_{2}$ receptor serves as a signaling receptor for ASP on adipocytes and other cell types (Baldo et al., 1993; Kalant et al., 2003; Kalant et al., 2005; Maslowska et al., 2005; MacLaren et al., 2008). Although dozens of elaborate studies have already been published, these issues remain highly contro versial.

3. The Challenges in Designing Studies Involving Acylation-Stimulating Protein. Due to the complexity of this topic, the involved research groups face a variety of challenges with study design and data interpretation. The following points must be considered to critically assess the respective publications and our knowledge of ASP.

a. Lack of an acylation-stimulating protein knockout model. C3a des-Arg /ASP as a cleavage product of C3 is generated in all situations where the complement cascade is activated by the main activation routes. Unfortunately, it is impossible to generate a knockout mouse with an isolated deletion of C3a des-Arg /ASP without interfering with other functions of the complement system.

b. Problems with C3 knockout animals. Although mice deficient in the precursor molecule C3 have erroneously been described as "ASP knock-out mice" or "ASP-deficient mice" (Cianflone et al., 1999), beyond lacking C3a des-Arg /ASP (Murray et al., 1999c,d, 2000; Xia et al., 2002, 2004) these animals are deficient in main complement effector functions downstream of $\mathrm{C} 3$ - that is, opsonization due to $\mathrm{C} 3 \mathrm{~b}$, inflammation and immune modulation mediated by C3a and C5a, sublytic cell activation, and cell lysis of bystander cells caused by MAC. Thus, C3 knockout mice cannot be considered an adequate model to specifically investigate the role of C3a des-Arg (ASP).

c. Receptor for acylation-stimulating protein. As described previously, the $\mathrm{C}^{2} \mathrm{a}_{2}$ receptor is widely accepted as a receptor for C5a and C5a des-Arg. Its role as a signaling receptor for C3a des-Arg /ASP, however, is controversial (Kalant et al., 2005; Johswich et al., 2006; Johswich and Klos, 2007; Klos et al., 2009). Thus, mice with a C5ar2 gene knockout might be more appropriate for the analysis of ASP-related issues than C3 knockout mice, the caveat being that it remains to be proven that the $\mathrm{C}^{2} \mathrm{a}_{2}$ receptor is indeed a functional receptor for ASP.

d. C3a des-Arg regarded as inert. Traditionally, a large number of researchers working in the complement field consider C3a des-Arg as a relatively stable metabolite without any biologic potential, making it a useful marker for complement activation (Burger et al., 1988; Klos et al., 1988; Hartmann et al., 1993; Stove et al., 1995). Although C5a des-Arg retains some affinity for its receptors, most complement researchers assume that C3a des-Arg does not interact with the C3a receptor (Klos et al., 1992; Ames et al., 1996; Crass et al., 1996; Johswich et al., 2006). It is thus neither internalized nor degraded, remaining detectable in the bloodstream. In line with this point of view, correlations of an increase in C3a des-Arg /ASP in body fluids of humans or animals with a certain genotype or a disease suggest a role of complement activation and inflammation in general, and not necessarily a role of this particular complement cleavage product and its assumed function. This is further stressed by the fact that unbalanced obesity and insulin resistance are thought to be linked to chronic inflammation in adipose tissue (Ouchi et al., 2011), and that complement activation is a typical early component of an inflammatory response (Manabe, 2011).

e. Difficulties working with C3a/C3a des-Arg. Partially due to their charge, C3a and C3a des-Arg are difficult to handle, more difficult than C5a and C5a des-Arg (Hugli, 1975). C3a and C3a des-Arg /ASP show a significantly higher nonspecific binding to cells and surfaces (Burg et al., 1996). For this reason, plastic materials have to be coated with silicone, albumin, or other inert proteins when handling C3a or C3a des-Arg /ASP. Synthetic C-terminal peptides of C3a with high purity and more favorable physiochemical properties have been used to study binding and activation of C3a receptor by C3a (Ames et al., 1996; Ember et al., 1991; Hugli and Erickson, 1977; Kretzschmar et al., 1992). However, such peptides have rarely been used to study the interaction between the $\mathrm{C}_{5} \mathrm{a}_{2}$ receptor and C3a desArg, and they mimic the effects of ASP only partially (Murray et al., 1999a).

f. Simulation of specific binding. In addition, an easily misleading, rare phenomenon can simulate specific binding in the absence of any cellular receptor. This occurs when binding studies with adherent cells are performed in cell culture dishes or 96-well plates, or when membranes instead of a sucrose gradient are used to separate free from cell-bound labeled ligands. This binding of ${ }^{125} \mathrm{I}-\mathrm{C} 3 \mathrm{a}$ or ${ }^{125} \mathrm{I}-\mathrm{C} 3 \mathrm{a}$ des-Arg (ASP) to the surface of materials occurs despite the presence of albumin or dry milk powder (but because of albumin: Cui et al., 2009a), and can be effectively and dosedependently competed with nonlabeled C3a or C3a des-Arg, thereby imitating specific binding with a $K_{\mathrm{d}}$ of the "plastic $\mathrm{C} 3 \mathrm{a} / \mathrm{C} 3 \mathrm{a}$ des-Arg receptor" in the 
nanomolar range $\left(\mathrm{EC}_{50}\right.$ of $\left.\sim 20 \mathrm{nM}\right)$. This phenomenon is not observed using ${ }^{125} \mathrm{I}-\mathrm{C} 5 \mathrm{a}$ or C5a des-Arg. To prevent this pseudo-specific nonreceptor binding of ${ }^{125} \mathrm{I}-\mathrm{C} 3 \mathrm{a}$ and ${ }^{125} \mathrm{I}-\mathrm{C} 3 \mathrm{a}$ des-Arg /ASP, all plates and materials have to be preincubated with protamine sulfate (or histones) in addition to albumin (Johswich et al., 2006). To address this easily misleading feature of C3a or C3a des-Arg /ASP in binding studies, the use of control cells that do not express the ASP receptor in question are essential. Likewise, when investigating primary cells, the experiment must also be performed in the absence of any cells.

g. Purification of acylation-stimulating protein. The purity of plasma-derived C3a des-Arg (pASP) is another critical issue to be considered, especially in the context of the high concentrations used to show ASPmediated functions. Human C5a and C5a des-Arg bind to and activate the $\mathrm{C} \mathrm{a}_{1}$ receptor with an $\mathrm{EC}_{50}$ of $\sim 1$ $\mathrm{nM}$ (Burg et al., 1995); the $\mathrm{EC}_{50}$ of C3a needed for C3a receptor activation is only slightly higher (Klos et al., 1992; Settmacher et al., 2003). The first biologic effects of these fragments can even be observed at $\sim 0.1 \mathrm{nM}$. Of note, in experiments on metabolic responses, pASP has been used at concentrations ranging from $30 \mathrm{nM}$ to $10 \mu \mathrm{M}$, with an $\mathrm{EC}_{50}$ of one to several hundred nanomolars. As C3a/C3a des-Arg and C5a/C5a desArg are related cationic peptides sharing common features like molecular weight, isoelectric point, or acid stability (Hugli et al., 1975b, 1981a; Paques et al., 1980; Daumy et al., 1988), it is rather difficult to obtain highly pure preparations of C3a des-Arg from plasma without low contaminations of other fragments still being present. Thus, one must exclude even minor contaminations of $\mathrm{C} 5 \mathrm{a} / \mathrm{C} 5 \mathrm{a}$ des-Arg or $\mathrm{C} 3 \mathrm{a}$ to rule out the possibility of a (still intriguing) effect of these polypeptides on lipid and glucose metabolism. Additionally, when observed more than 20 years ago, mast-cell activation by $\mathrm{C} 3 \mathrm{a}$ and $\mathrm{C} 3 \mathrm{a}$ des-Arg at concentrations exceeding $10 \mu \mathrm{M}$ was proposed to be based on "a nonspecific mechanism similar to that of other polybasic compounds" (Fukuoka and Hugli, 1990).

h. Recombinant acylation-stimulating protein. The use of recombinant C3a des-Arg (rASP) could solve this problem. However, recombinant purified protein has been consequently applied only in some experiments of more recent publications (Cui et al., 2009b; Paglialunga et al., 2010). Formerly, it seemed to have been difficult to produce in large amounts (K. Cianflone, personal communication) and was therefore reserved for a few key experiments that revealed rASP-induced effects in the micromolar range (Murray et al., 1997). In any case, adequate controls are needed to exclude contaminations such as LPS, which might interfere with biologic responses in cell culture or in animal models, when rASP is prepared from Escherichia coli (Roy et al., 2011).
4. Review of Evidence for $\mathrm{C5a}_{2}$ Receptor as the Receptor for Acylation-Stimulating Protein

a. Introduction. Based on these considerations, and to identify the studies providing the best evidence for the proposed role of C3a des-Arg /ASP and the $\mathrm{C}^{2} \mathrm{a}_{2}$ receptor, this review will address the following questions:

a. How credible is the evidence that ASP is identical with C3a des-Arg, and that it influences energy metabolism?

b. How indisputably has it been demonstrated that the $\mathrm{C}^{2} \mathrm{a}_{2}$ receptor plays a role in energy metabolism?

c. How convincing is the evidence that C3a des-Arg /ASP binds to and signals via the $\mathrm{C} \mathrm{a}_{2}$ receptor?

d. Can the $\mathrm{C} 3 \mathrm{a} / \mathrm{C} 3 \mathrm{a}$ receptor or the $\mathrm{C} 5 \mathrm{a} / \mathrm{C} 5 \mathrm{a}$ des-Arg $/ \mathrm{C} 5 \mathrm{a}_{1}$ receptor be ruled out as confounding mediators and signaling components?

e. Do the effects observed and the concentrations of ASP used in cell culture represent a physiologic situation in vivo?

f. Is the effect on lipid metabolism a main physiologic function of the complement system and ASP? Or should it be considered as one component of "inflammatory" diseases including obesity?

b. Changes after application of an oral fat load in diets. Using a competitive enzyme-linked immunosorbent assay (ELISA), it was shown in 1989 that the serum levels of $\mathrm{C} 3 \mathrm{a} / \mathrm{C} 3 \mathrm{a}$ des-Arg increased significantly within hours after an oral fat load, but not after challenge with glucose (Cianflone et al., 1989a, 1992). However, this was not affirmed by others (Charlesworth et al., 1998; van Oostrom et al., 2004). In moderately hypercholesterolemic women, ASP levels were altered after hydrogenated fat consumption (Matthan et al., 2001). Plasma ASP concentration and adipose tissue C3 mRNA expression were higher in obese than in lean men, and fasting plasma ASP concentration and C3 mRNA expression negatively correlated with insulin sensitivity (Koistinen et al., 2001). Moderate weight loss of obese women or a prolonged fast led to decreased ASP plasma levels (Sniderman et al., 1991; Cianflone et al., 1995). After gastric bypass surgery in morbidly obese subjects, body weight, ASP, and leptin decreased and adiponectin increased, while plasma lipids and insulin resistance improved (Faraj et al., 2003). Thus, diet and obesity can influence ASP concentrations in plasma.

c. Modified acylation-stimulating protein levels in various diseases and during a modified hormonal status. Plasma ASP was significantly higher in patients with coronary artery disease, and there was an association with plasma triglyceride, very lowdensity lipoprotein (VLDL) cholesterol, VLDL, 
apolipoprotein B (apoB), and certain apolipoprotein $\mathrm{E}$ (apoE) phenotypes (Cianflone et al., 1997). Children with Prader-Willi syndrome frequently suffer from high ASP levels and dyslipidemia (de Lind van Wijngaarden et al., 2010). Increased levels of plasma ASP, CRP, insulin, cholesterol, and nonesterified fatty acids are present in women with polycystic ovary syndrome compared with controls (Wu et al., 2009). In pregnant women, ASP levels were markedly elevated. They correlated with elevated levels of triglycerides, apoB, low-density lipoprotein cholesterol, and body mass index (BMI) (Saleh et al., 2007). In neonates, cord blood ASP showed a positive correlation with fetal birth weight above average, and with maternal plasma TG (Saleh et al., 2008).

For a complementologist, an increase of C3a des-Arg /ASP in body fluids indicates that an activation of the complement system has taken place. One can assume that besides this (surrogate) marker, all effector molecules that are released during activation of the complement cascade, such as C3a, C5a, C5a des-Arg, $\mathrm{C} 3 \mathrm{~b}$, or the MAC, were at least transiently present as well. A direct conclusion regarding a biologic function of C3a des-Arg should thus not be drawn. In any case, it is remarkable that a correlation of complement activation and lipid metabolism has been observed in various settings. This supports the concept that unbalanced obesity is linked to chronic low-grade inflammation, and suggests that drastic fat uptake can rapidly trigger a low inflammatory response.

d. Animal models, complement factor C3, acylationstimulating protein, and energy metabolism. Serum from obese rats was found to contain almost twice as much $\mathrm{C} 3$ as serum from lean rats (Boggs et al., 1998). In $C 3^{-1-}$ mice, which lack significant parts of the complement system, including ASP, a marked delay in postprandial TG clearance, reduced body fat, and lower leptin levels were observed in comparison with wild-type animals. Also, postprandial nonesterified fatty acids were increased in serum/plasma independently of low or high fat diets, and modest changes in insulin/glucose metabolism implied increased insulin sensitivity (Murray et al., 1999d). In contrast and of note, the Wetsel group found no significant differences in the plasma TG, cholesterol, or free fatty acid concentrations of fasted $C 3^{-1-}$ mice compared with their wild-type litter mates. Plasma lipoprotein analyses indicated no significant differences in various lipoproteins and triglycerol in the absence of ASP. The $C 3^{-1-}$ animals were not impaired in their ability to clear TG and free fatty acids from their circulation after an oral fat load (Wetsel et al., 1999). These contradicting results might be caused by differences in the $C 3^{-1-}$ and wild-type mouse strains bred and used by the two research groups in different facilities. It suggests that the genetic background of these animals should be checked thoroughly (e.g., by
SNP analysis) to prove sufficient and effective backcrossing.

A third research group cross-bred $C 3^{-1-}$ mice to mice deficient in both apoE and the low-density lipoprotein receptor (Apoe ${ }^{-1-} L d l r^{-1-}$ mice). Compared with controls, mice additionally lacking C3 had higher serum TG levels and a more proatherogenic lipoprotein profile, and lower body weight and fat content. In contrast, there were no differences between factor Bdeficient mice, being additionally analyzed where complement activation of the alternative pathway is hampered, and wild-type animals. Moreover, the size of lesions in the aorta was significantly higher in $C 3^{-1-}$ mice than in controls. The investigators concluded that complement activation by the classic or lectin pathway exerts atheroprotective effects, possibly through the regulation of lipid metabolism (Persson et al., 2004).

e. C5ar2 $2^{-1-}$ mice and blockade of $\mathrm{C}^{-1} \mathrm{a}_{2}$ receptor by antibodies. In studies conducted by or in cooperation with the Cianflone group, C5ar2 $2^{-/-}$mice also showed changes in their metabolism as compared with wildtype controls: these mice are hyperphagic on a low-fat diet. Nevertheless, their body weight and adipose tissue mass did not differ from that of wild-type litter mates. On a high-fat diet, average adipocyte size and adipose tissue triglyceride/DNA content were significantly reduced. Postprandial clearance of TG was delayed in $C 5 \mathrm{ar}^{-1-}$ animals, and the synthesis of adipose tissue triglycerides, lipolysis, and fatty acid re-esterification were significantly reduced. Indirect calorimetry measurements suggested preferential fatty acid utilization over carbohydrate (Paglialunga et al., 2007).

In vivo, application of anti-ASP and anti-C5a $\mathrm{a}_{2}$ receptor antibodies did not alter body weight, adipose tissue mass, food intake, or levels of insulin, leptin, or adiponectin. However, the blockade particularly of the anti-C5 $\mathrm{a}_{2}$ receptor induced a significant delay in TG and nonesterified fatty acids clearance and decreased perirenal, hepatic, and muscle TG mass. Adenosine monophosphate-activated protein kinase (AMPK) and lipoprotein lipase (LPL) activity were increased by this treatment. Thus, the ASP/C5a 2 receptor neutralizing antibodies that effectively block the ASP-C5a $\mathrm{a}_{2}$ receptor interaction altered lipid distribution and energy utilization. Moreover, continuous administration of antiASP antibodies as compared with an IgG negative control had effects on energy expenditure and glucose storage, increasing in vivo whole-body energy utilization (Cui et al., 2007; Paglialunga et al., 2010).

f. Systemic application of purified acylation-stimulating protein or recombinant acylation-stimulating protein. Injection of $500 \mu \mathrm{g}$ i.p. of ASP accelerated TG clearance after a fat load in vivo in C57BL/6 mice, and reduced plasma glucose within a few hours (Murray et al., 1999b). Untreated male and female $C 3^{-1-}$ mice had elevated oxygen consumption, 
increased fatty acid oxidation in liver and muscle, and increased inguinal fat and muscle mRNA expression. Fatty acid incorporation into lipids was decreased but could be normalized by administration of ASP together with oral fat intake (Xia et al., 2004). However, assuming complete resorption of $500 \mu \mathrm{g}$ of ASP from the peritoneum, its redistribution into an estimated 2 $\mathrm{ml}$ of total blood volume should lead to $\sim 25 \mu \mathrm{M}$ ASP in the circulation. For pASP, a purity of 99\% was ascertained by mass spectrophotometry, potentially permitting up to $250 \mathrm{nM}$ of contaminating proteins with a molecular weight similar to ASP in the bloodstream. Of note, this impedes interpretation of data from the corresponding experiments because $\sim 10-50 \mathrm{nM}$ C3a, C5a, or C5a des-Arg would already result in maximal cellular responses mediated by the C3a receptor or $\mathrm{C}^{2} \mathrm{a}_{1}$ receptor. Thus, when applying $500 \mu \mathrm{g}$ of pASP, it cannot be excluded that contaminating factors could be responsible for the observed effects.

Yet there are more convincing studies with a continuous administration of recombinant instead of purified ASP over up to 4 weeks that clearly demonstrate decreased fasting levels of nonesterified fatty acids and decreased energy expenditure in $C 3^{-1-}$ mice, but only small (if any) changes in body weight or food uptake (Paglialunga et al., 2010). As a negative control, saline is applied instead of an inert recombinant protein purified from $E$. coli in parallel with the rASP. In differentiated adipocytes, $100 \mathrm{nM}$ rASP resulted in a drastic increase in fatty acid uptake in vitro. This was blocked in vitro by incubation with an anti-ASP antibody, excluding the possibility that contaminations, such as LPS, are responsible for the observed effect on adipocytes. The interpretation of the data obtained in the mouse is more difficult due to the absence of a similar specificity control (i.e., inhibition by antibody directed against ASP) and also due to the fact that, surprisingly, the achieved and effective serum steady-state levels of rASP delivered by an osmotic pump were very small (i.e., only in the range of $0.25 \mathrm{nM})$. This large difference in concentrations needed between the in vitro assay to see cellular responses and the in vivo experiment makes it more difficult to draw conclusions about a common underlying mechanism.

On the other hand, continuous application of antibodies against endogenous ASP with corresponding IgG controls in the animal model resulted in clear effects on the lipid and glucose metabolism (Paglialunga et al., 2010). Moreover, injection of rASP into the third ventricle of the brain inhibits food intake and locomotor activity in rats (Roy et al., 2011). Again, data interpretation is limited by the absence of a negative control which could exclude that impurities in the rASP might account for effects in this system. Further, it is difficult to judge what concentrations of rASP are reached in the cerebrospinal fluid, and whether they are in the physiologic range or rather correspond to a situation of severe neurologic disease such as meningitis. Nevertheless, these are interesting data as they indicate additional functions for the complement system and its cleavage products.

\section{g. In vitro data using purified acylation-stimulating} protein, synthetic C3a-related peptides, or recombinant acylation-stimulating protein. There are a variety of older publications using human pASP. They have been presented and reviewed in detail elsewhere (Johswich and Klos, 2007; Klos et al., 2009). Therefore, this review focuses on a selection of key data from more recent publications, preferentially based on the use of recombinant ASP or synthetic peptides. For in vitro studies on human skin fibroblasts (HSF) and murine 3T3 cells, ASP was chemically and enzymatically modified; additionally, synthetic C3a-analogous Cterminal peptides, known ligands of the human C3a receptor, were analyzed (Murray et al., 1999a). The results show that the N-terminal region of ASP plays a minor role in receptor binding (determined by inhibition of ${ }^{125}$ I-ASP binding) and triacylglycerol synthesis. An intact disulfide-linked core region is essential for lipid synthesis but not for receptor interaction. The C3a-analogous C-terminal peptide P117 (containing a C-terminal Arg) can inhibit ASP binding and can partially activate lipid synthesis, suggesting "that this region participates but is not sufficient for complete receptor binding" (Murray et al., 1999a), whereas smaller C-terminal peptides were ineffective.

On the human $\mathrm{C} 3$ a receptor, $\mathrm{P} 117$ has an $\mathrm{EC}_{50}$ in the range of $50 \mathrm{nM}$ (while ASP is completely ineffective) (Martin et al., 1997; Johswich and Klos, 2007; Klos et al., 2009). Triacylglycerol synthesis was stimulated by $\mathrm{P} 117$ at 1000 -fold higher concentrations of $4-40 \mu \mathrm{M}$, similar to the molar concentrations of ASP needed. Surprisingly, in competition studies using $1 \mathrm{nM}$ ${ }^{125}$ I-ASP as a tracer on HSF, unlabeled P117 and ASP were equally potent, with an $\mathrm{IC}_{50}$ in the range of only $100 \mathrm{nM}\left(\mathrm{pIC}_{50}=7\right)$. This behavior is rather surprising as the ligand concentrations needed for binding and dose-response curves are usually quite similar.

As mentioned previously, C3a and C3a des-Arg show high nonspecific binding as well as "pseudo-specific nonreceptor binding" to various surfaces in the absence of any cell, with a $K_{\mathrm{d}}$ close to that observed in binding studies (Johswich et al., 2006). This suggests that the binding of ${ }^{125} \mathrm{I}-\mathrm{ASP}$ and the surprisingly low $K_{\mathrm{d}}$ observed in the Cianflone group, at least in earlier studies on adipocytes of fibroblasts, are best explained by this effect. Of note, in experiments of the Klos group, neither $100 \mathrm{nM}$ fluorescence-labeled (FL) pC3a nor the des-arginated peptide (FL-ASP) bound to $\mathrm{C}^{2} \mathrm{a}_{2}$ receptor expressed on human embryonic kidney (HEK) cells as compared with HEK control cells, whereas 
FL-C3a was still able to bind to the C3a receptor (Johswich et al., 2006). In contrast, when similar studies were performed by the Cianflone group, using FL-rASP, HEK cells stably expressing $\mathrm{C}^{2} \mathrm{a}_{2}$ receptor bound and internalized this ligand more strongly than nontransfected HEK control cells (Cui et al., 2009a). Both studies using FL-ligands seem to be thoroughly performed, so there is presently no explanation for the differing results.

With an $\mathrm{EC}_{50}$ of $\sim 1.5 \mu \mathrm{M}$, the rASP used here was much more active in stimulating lipid synthesis and fatty acid uptake than the ASP purified from blood and former preparations. In the same study, $\mathrm{C}^{2} \mathrm{a}_{2}$ receptorexpressing HEK cells bound $1 \mathrm{nM}$ of ${ }^{125} \mathrm{I}$-ASP much better than nontransfected cells or the no-cell control with a $K_{\mathrm{d}}$ of $34 \mathrm{nM}$. HEK and Chinese hamster ovary (CHO) cells expressing $\mathrm{C}^{2} \mathrm{a}_{2}$ receptor bound FL-rASP in a dose-dependent manner at similar concentrations (Cui et al., 2009a).

h. Summary and assessment of the role of C3a desArg/ASP and C5a $a_{2}$ receptor. The pathogenesis of obesity-related metabolic dysfunction is considered to include chronic low-grade inflammation (Ouchi et al., 2011). Various cytokines and chemokines act as adipokines, simultaneously influencing inflammation and metabolism (Kershaw and Flier, 2004). The complement system appears to be linked with adipokine signaling in multiple ways: cells in the adipose tissue can produce various complement factors (Choy et al., 1992; White et al., 1992), and adiponectin itself can trigger the classic pathway of complement activation (Peake et al., 2008). Moreover, complement factor $D$ has been identified as an adipokine. Considering this connection between obesity and inflammation, it does not seem unlikely that other components of the activated complement system might play a similar dual role as proinflammatory mediators and metabolic modulators. In accordance, activation of the complement cascade as evidenced by the increase of the "activation marker" C3a des-Arg /ASP is associated with changes in lipid and glucose metabolism. In this context the publications of the Cianflone group are very informative.

The majority of investigations using ASP purified from blood (or synthetic C3a-related peptides) and most data from animal models are in accordance with a potential role of ASP in metabolism, but they do not provide final proof that C3a des-Arg is indeed the responsible and active mediator. In particular, they do not exclude that contaminations with $\mathrm{C} 3 \mathrm{a}$ or C5a desArg, and their interactions with the $\mathrm{C} 3 \mathrm{a}$ receptor or $\mathrm{C}^{5} \mathrm{a}_{1}$ receptor, respectively, might be causing some of the observed effects of pASP. A few recent key publications using recombinant $\mathrm{C} 3 \mathrm{a}$ des-Arg (ASP) provide much stronger evidence for an active role of ASP and for the $\mathrm{C} \mathrm{a}_{2}$ receptor as its receptor. However, there are some contradictory results from both animal studies (Wetsel et al., 1999) and in vitro experiments (Johswich et al.,
2006) that should be borne in mind when assessing the role of C3a des-Arg as a metabolic regulator.

\section{Complement Peptide Functions Not Mediated by the Three Known Receptors}

\section{A. $C 4 a$}

Although C4a has receptor-mediated effects in the guinea pig (see Section III.B.1), its effects on human cells have not been shown to be receptor mediated, and serum-derived C4a may be contaminated with C3a. Studies showing that $\mathrm{C} 4 \mathrm{a}$ can enhance vascular permeability in human skin (Gorski et al., 1979), desensitize smooth muscle contraction by C3a (Hugli et al., 1981b), and stimulate mast cells to secrete (Hugli and Muller-Eberhard, 1978; Moon et al., 1981) should be repeated with recombinant $\mathrm{C} 4 \mathrm{a}$. However, recombinant $\mathrm{C} 4 \mathrm{a}$ has been demonstrated to inhibit C3a- and C5a-stimulated degranulation of human mast cells by increasing cAMP levels through an unidentified receptor (Xie et al., 2012). A derivative of C4 in synovial fluid has been shown to indirectly inhibit the chemotaxis of human monocytes but not neutrophils (Matsubara et al., 1991). This was later shown to be $\mathrm{C} 4 \mathrm{a}$, which worked at concentrations as low as $10^{-16} \mathrm{M}$, but this could be inactivated by conversion to C4a des-Arg (Tsuruta et al., 1993). An anti-inflammatory role for $\mathrm{C} 4 \mathrm{a}$ in glomerulonephritis has also been proposed (Welch et al., 2001). C3a and C4a can both form complexes with IgG (Nezlin and Freywald, 1992), one molecule for each $\mathrm{H}$ and $\mathrm{L}$ chain. One gram of IgG can bind up to $0.3 \mathrm{mg}$ C3a (1:200 molar ratio). The function of this is unknown but has been proposed to eliminate complement peptides from the circulation.

\section{B. $C 3 a$}

In many instances, a biologic activity is shared by both C3a and its metabolite C3a des-Arg. It is clear that C3a des-Arg does not interact with the C3a receptor (Wilken et al., 1999; Johswich et al., 2006), so these activities are presumed to be not receptor mediated. The homing of bone-marrow hemopoietic cells in response to CXCL12 is enhanced by both C3a and C3a des-Arg (Honczarenko et al., 2005b) in mice that are $\mathrm{C} 3 \mathrm{a}$ receptor or $\mathrm{C}^{2} \mathrm{a}_{2}$ receptor deficient (Honczarenko et al., 2005a). The LPS-mediated production of proinflammatory cytokines by PBMC mediated by LPS is also enhanced by both C3a and C3a des-Arg (Takabayashi et al., 1996) whereas B-cell cytokine production is diminished (Fischer and Hugli, 1997). Both polypeptides have been shown to stimulate pituitary cell cultures to secrete a variety of hormones (Francis et al., 2003), with the C3a des-Arg response being insensitive to pertussis intoxication.

Another shared activity is the inhibition of bacterial and fungal growth. These antimicrobial properties are 
conserved from invertebrates to humans (Pasupuleti et al., 2007), and C3a and C4a (but not C5a) have been suggested to have evolved primarily as antibacterial agents (Malmsten and Schmidtchen, 2007).

C3a-derived peptides have also been shown to bind to the high affinity IgE receptor, FceRI, and can inhibit signaling and cytokine secretion by mast cells (Peterfy et al., 2008). C3a and C3a des-Arg can also enhance CXCL12-mediated platelet production (Wysoczynski et al., 2007). The receptor for advanced glycation end products (RAGE) can bind $\mathrm{C} 3 \mathrm{a}, \mathrm{CpG}$ oligos, and DNA/ C3a complexes, resulting in the stimulation of IFN- $\gamma$ production in human PBMC (Ruan et al., 2010).

Oxidized LDL and C3a colocalize in atherosclerotic plaques as a result of C3a binding to modified lysine side chains. C3a also recognizes oxidized lipids on apoptotic cells in a similar way (Veneskoski et al., 2011), possibly aiding the removal of C3a from the circulation. As a cationic amphiphile, C3a can also activate $G$ proteins independent of the receptor by cross-linking sialic acid residues displayed on a variety of membrane proteins (Emadi-Khiav et al., 1995). Finally, C3a has been shown to bind to GPCR Masrelated genes MrgX1 and MrgX2 (Kashem et al., 2011) on human mast cells, allowing $\mathrm{C} 3 \mathrm{a}$ to stimulate degranulation in a non-C3a receptor-dependent manner (Kashem et al., 2011; Subramanian et al., 2011).

\section{C. $C 5 a$}

C5a has also been shown to be bound by immunoglobulins (Basta et al., 2003), and $\mathrm{F}(\mathrm{ab})^{\prime}{ }_{2}$ fragments of irrelevant specificity can neutralize the ability of both $\mathrm{C} 3 \mathrm{a}$ and C5a to activate the human mast cell line HMC-1. To our knowledge, no other nonreceptormediated functions of C5a or C5a des-Arg have been reported.

\section{Conclusions, Future Directions}

1. Nomenclature. Although originally termed anaphylatoxins, the $\mathrm{C} 5 \mathrm{a}, \mathrm{C} 4 \mathrm{a}$, and $\mathrm{C} 3 \mathrm{a}$ act only indirectly to mediate an anaphylactic response (Taylor et al., 1994), and it is now clear that they have many more functions inside and outside of the immune system. For this reason, we would suggest the use of the term "complement peptides" rather than anaphylatoxins. The second C5a receptor, sometimes described as a binding protein (Okinaga et al., 2003) or as a "receptor-like" protein (Kalant et al., 2003), has clearly been shown to transduce signals, particularly in mouse cells, so we propose that the symbol $\mathrm{C}^{2} \mathrm{a}_{2}$ receptor is ascribed to this receptor (human gene name C5AR2).

2. Drugs That Act at Complement Peptide Receptors. Despite many years of intensive investigation, there are still no useful drugs that act directly at the complement peptide receptors. It is not clear as to whether this is due to peculiar molecular mechanisms associated with receptor binding and activation or to the complex biology of the receptors. The former is becoming increasingly well understood as satisfying models, at least for $\mathrm{C} 5 \mathrm{a}$ and the $\mathrm{C}_{5} \mathrm{a}_{1}$ receptor, are being produced. However, the relatively low affinities of many of the antagonists for rodent fragment receptors has troubled the development of many drug leads and may have provided some misleading information about the roles of the complement peptides in disease. It is possible that inhibition of complement peptide formation by agents that act on the complement cascade may prove to be the most effective drugs. Here, however, the extrinsic pathways of fragment generation may confound this expectation, so further work on the consequences of these pathways is required.

3. Signaling by Complement Peptide Receptors. The events that occur after receptor binding are also proving difficult to untangle. Although signaling through $G$ proteins is well understood, the role of arrestins in signal transduction remains obscure. Work on the C3a receptor suggests that these proteins have complex roles in the modulation of signaling, but for the $\mathrm{C5}_{1}$ and $\mathrm{C5} \mathrm{a}_{2}$ receptors little is yet known. Signaling by the $\mathrm{C}^{2} \mathrm{a}_{2}$ receptor is still controversial, and the question of ligand selectivity has not been finally settled. Even if limited to just C5a and C5a desArg, the $\mathrm{C}^{2} \mathrm{a}_{2}$ receptor may be a signaling receptor equivalent to the $\mathrm{C} \mathrm{a}_{1}$ receptor; it may provide "negative" signals, through arrestins, to counteract the $\mathrm{C} \mathrm{a}_{1}$ receptor; or it may cause ligand sequestration and degradation. The role of homo- and heterodimerization of C5a1 and C5a2 in the control of signaling also awaits elucidation. Interestingly, although the $\mathrm{C}_{5} \mathrm{a}_{2}$ receptor binds C5a des-Arg with the same affinity as $\mathrm{C} 5 \mathrm{a}$, the des-arginated form is rarely used in experiments with this receptor, resulting in the potential loss of important information. Further, the reported activity of the ${\mathrm{C} 5 \mathrm{a}_{2}}$ receptor may depend on the species under investigation, or perhaps it is the expressing cell type (or cellular activation status) that determines the role of this receptor. Selective agonists and antagonists are urgently required for the $\mathrm{C}^{2} \mathrm{a}_{2}$ receptor, and it is to be hoped that such compounds, once identified, can be used to solve the enigma that this receptor represents.

\section{Authorship Contributions}

Wrote or contributed to the writing of the manuscript: Klos, Wende, Wareham, Monk.

\section{References}

Abdul-Salam VB, Paul GA, Ali JO, Gibbs SR, Rahman D, Taylor GW, Wilkins MR and Edwards RJ (2006) Identification of plasma protein biomarkers associated with idiopathic pulmonary arterial hypertension. Proteomics 6:2286-2294.

Abou-Ragheb HH, Williams AJ, Brown CB, and Milford-Ward A (1991) Plasma levels and mode of excretion of the anaphylatoxins $\mathrm{C} 3 \mathrm{a}$ and $\mathrm{C} 4 \mathrm{a}$ in renal disease. $J$ Clin Lab Immunol 35:113-119.

Abou-Ragheb HH, Williams AJ, Brown CB, and Milford-Ward A (1992) Plasma levels of the anaphylatoxins C3a and C4a in patients with IgA nephropathy/HenochSchönlein nephritis. Nephron 62:22-26.

Ager RR, Fonseca MI, Chu SH, Sanderson SD, Taylor SM, Woodruff TM, and Tenner AJ (2010) Microglial C5aR (CD88) expression correlates with amyloid-beta deposition in murine models of Alzheimer's disease. J Neurochem 113:389-401. 
Ahamed J, Haribabu B, and Ali H (2001) Cutting edge: differential regulation of chemoattractant receptor-induced degranulation and chemokine production by receptor phosphorylation. J Immunol 167:3559-3563.

Alewijnse AE, Timmerman H, Jacobs EH, Smit MJ, Roovers E, Cotecchia S, and Leurs $\mathrm{R}$ (2000) The effect of mutations in the DRY motif on the constitutive activity and structural instability of the histamine $\mathrm{H}(2)$ receptor. Mol Pharmacol 57:890-898.

Ali H, Richardson RM, Tomhave ED, Didsbury JR, and Snyderman R (1993) Differences in phosphorylation of formylpeptide and C5a chemoattractant receptors correlate with differences in desensitization. J Biol Chem 268:24247-24254.

Allegretti M, Moriconi A, Aramini A, Candida CM, Beccari AR, and Bertini R (2008) inventors; Dompe Pharma SPA, assignee. $(R)$-Arylalkylamino derivatives and pharmaceutical compositions containing them. E.P.O. patent no. EP1951663A2. 1995 Aug 6.

Amara U, Flierl MA, Rittirsch D, Klos A, Chen H, Acker B, Brückner UB, Nilsson B Gebhard F, Lambris JD, and Huber-Lang M (2010) Molecular intercommunication between the complement and coagulation systems. $J$ Immunol 185:5628-5636.

Amara U, Rittirsch D, Flierl M, Bruckner U, Klos A, Gebhard F, Lambris JD, and Huber-Lang M (2008) Interaction between the coagulation and complement system. Adv Exp Med Biol 632:71-79.

Amatruda TT 3rd, Gerard NP, Gerard C, and Simon MI (1993) Specific interactions of chemoattractant factor receptors with G-proteins. J Biol Chem 268:10139-10144.

Ames RS, Lee D, Foley JJ, Jurewicz AJ, Tornetta MA, Bautsch W, Settmacher B, Klos A, Erhard KF, and Cousins RD, et al. (2001) Identification of a selective nonpeptide antagonist of the anaphylatoxin C3a receptor that demonstrates antiinflammatory activity in animal models. J Immunol 166:6341-6348.

Ames RS, Li Y, Sarau HM, Foley JJ, Ellis C, Zeng Z, Su K, Jurewicz AJ, Hertzberg RP, Bergsma DJ, and Kumar C, et al. (1996) Molecular cloning and characterization of the human anaphylatoxin C3a receptor. J Biol Chem 271:20231-20234.

Ames RS, Tornetta MA, Foley JJ, Hugli TE, and Sarau HM (1997) Evidence that the receptor for $\mathrm{C} 4 \mathrm{a}$ is distinct from the $\mathrm{C} 3 \mathrm{a}$ receptor. Immunopharmacology 38:87-92.

Andersson E, Rydengård V, Sonesson A, Mörgelin M, Björck L, and Schmidtchen A (2004) Antimicrobial activities of heparin-binding peptides. Eur J Biochem 271 $1219-1226$

Astles PC, Brown TJ, Cox PJ, Halley F, Lockey PM, McCarthy C, McLay IM, Majid $\mathrm{TN}$, Morley $\mathrm{AD}$, and Porter $\mathrm{B}$, et al. (1997) New non peptidic C5a receptor antagonists. Bioorg Med Chem Lett 7:907-912.

Bachmaier K, Guzman E, Kawamura T, Gao X, and Malik AB (2012) Sphingosine kinase 1 mediation of expression of the anaphylatoxin receptor C5L2 dampens the inflammatory response to endotoxin. PLoS ONE 7:e30742.

Bajzar L, Manuel R, and Nesheim ME (1995) Purification and characterization of TAFI, a thrombin-activable fibrinolysis inhibitor. J Biol Chem 270:14477-14484.

Baldo A, Sniderman AD, St-Luce S, Avramoglu RK, Maslowska M, Hoang B, Monge JC, Bell A, Mulay S, and Cianflone K (1993) The adipsin-acylation stimulating protein system and regulation of intracellular triglyceride synthesis. J Clin Invest 92:1543-1547.

Ballesteros J, Kitanovic S, Guarnieri F, Davies P, Fromme BJ, Konvicka K, Chi L, Millar RP, Davidson JS, Weinstein $H$, and Sealfon SC (1998) Functional microdomains in G-protein-coupled receptors. The conserved arginine-cage motif in the gonadotropin-releasing hormone receptor. J Biol Chem 273:10445-10453.

Bamberg CE, Mackay CR, Lee H, Zahra D, Jackson J, Lim YS, Whitfeld PL, Craig S Corsini E, and Lu B, et al. (2010) The C5a receptor (C5aR) C5L2 is a modulator of C5aR-mediated signal transduction. $J$ Biol Chem 285:7633-7644.

Banda NK, Hyatt S, Antonioli AH, White JT, Glogowska M, Takahashi K, Merkel TJ, Stahl GL, Mueller-Ortiz S, and Wetsel R, et al. (2012) Role of C3a receptors, C5a receptors, and complement protein $\mathrm{C} 6$ deficiency in collagen antibody-induced arthritis in mice. J Immunol 188:1469-1478.

Banda NK, Levitt B, Wood AK, Takahashi K, Stahl GL, Holers VM, and Arend WP (2010) Complement activation pathways in murine immune complex-induced arthritis and in C3a and C5a generation in vitro. Clin Exp Immunol 159:100-108.

Bao L, Wang Y, Haas M, and Quigg RJ (2011) Distinct roles for C3a and C5a in complement-induced tubulointerstitial injury. Kidney Int 80:524-534.

Barbay JK, Gong Y, Buntinx M, Li J, Claes C, Hornby PJ, Van Lommen G, Van Wauwe J, and He W (2008) Synthesis and characterization of 5,6,7,8-tetrahydroquinoline C5a receptor antagonists. Bioorg Med Chem Lett 18:2544-2548.

Basta M, Van Goor F, Luccioloi S, Billings EM, Vortmeyer AO, Baranyi L, Szebeni J, Alving CR, Carroll MC, Berkower I, et al. (2003) F(ab)'2-mediated neutralization of C3a and C5a anaphylatoxins: a novel effector function of immunoglobulins. Nat Med 9:431-438.

Bautsch W, Kretzschmar T, Stühmer T, Kola A, Emde M, Köhl J, Klos A, and BitterSuermann D (1992) A recombinant hybrid anaphylatoxin with dual C3a/C5a activity. Biochem J 288:261-266.

Bénard M, Gonzalez BJ, Schouft MT, Falluel-Morel A, Vaudry D, Chan P, Vaudry H, and Fontaine $\mathrm{M}$ (2004) Characterization of C3a and C5a receptors in rat cerebellar granule neurons during maturation. Neuroprotective effect of C5a against apoptotic cell death. J Biol Chem 279:43487-43496.

Bénard M, Raoult E, Vaudry D, Leprince J, Falluel-Morel A, Gonzalez BJ, Galas L, Vaudry H, and Fontaine M, et al. (2008) Role of complement anaphylatoxin receptors (C3aR, C5aR) in the development of the rat cerebellum. Mol Immunol 45:3767-3774.

Bengtson A, Lannsjö W, and Heideman M (1987) Complement and anaphylatoxin responses to cross-clamping of the aorta. Studies during general anaesthesia with or without extradural blockade. Br J Anaesth 59:1093-1097.

Birney E, Andrews D, Caccamo M, Chen Y, Clarke L, Coates G, Cox T, Cunningham F, Curwen V, and Cutts T, et al. (2006) Ensembl 2006. Nucleic Acids Res 34 (Database issue):D556-D561.

Blagg J, Mowbray C, Pryde DC, Salmon G, Fairman D, Schmid E, and Beaumont K (2008a) Small, non-peptide C5a receptor antagonists: part 2. Bioorg Med Chem Lett 18:5605-5608

Blagg J, Mowbray C, Pryde DC, Salmon G, Schmid E, Fairman D, and Beaumont K (2008b) Small, non-peptide C5a receptor antagonists: part 1. Bioorg Med Chem Lett 18:5601-5604.
Bock D, Martin U, Gärtner S, Rheinheimer C, Raffetseder U, Arseniev L, Barker MD, Monk PN, Bautsch W, Köhl J, and Klos A (1997) The C terminus of the human C5a receptor (CD88) is required for normal ligand-dependent receptor internalization. Eur J Immunol 27:1522-1529.

Boggs RD, McCumbee WD, Cobbs SL, Todd DG, Kahle EB, Stewart NL, Bailey M, and Reichenbecher VE (1998) Increased expression of complement component C3 in the plasma of obese Zucker fa and $\mathrm{LA} / \mathrm{N}$ fa(f) rats compared with their lean counterparts. Obes Res 6:361-367.

Bokisch VA and Müller-Eberhard HJ (1970) Anaphylatoxin inactivator of human plasma: its isolation and characterization as a carboxypeptidase. J Clin Invest $\mathbf{4 9}$ 2427-2436.

Bokisch VA, Müller-Eberhard HJ, and Cochrane CG (1969) Isolation of a fragment (C3a) of the third component of human complement containing anaphylatoxin and chemotactic activity and description of an anaphylatoxin inactivator of human serum. J Exp Med 129:1109-1130.

Boor P, Konieczny A, Villa L, Schult AL, Bücher E, Rong S, Kunter U, van Roeyen CR, Polakowski T, and Hawlisch H, et al. (2007) Complement C5 mediates experimental tubulointerstitial fibrosis. J Am Soc Nephrol 18:1508-1515.

Borroni EM, Buracchi C, de la Torre YM, Galliera E, Vecchi A, Bonecchi R, Mantovani A, and Locati M (2006) The chemoattractant decoy receptor D6 as a negative regulator of inflammatory responses. Biochem Soc Trans 34:1014-1017.

Braun L, Christophe T, and Boulay F (2003) Phosphorylation of key serine residues is required for internalization of the complement $5 \mathrm{a}$ (C5a) anaphylatoxin receptor via a beta-arrestin, dynamin, and clathrin-dependent pathway. $J$ Biol Chem 278 : $4277-4285$

Breivik T, Gundersen Y, Gjermo P, Taylor SM, Woodruff TM, and Opstad PK (2011) Oral treatment with complement factor C5a receptor (CD88) antagonists inhibits experimental periodontitis in rats. J Periodontal Res 46:643-647.

Brodbeck RM, Cortright DN, Kieltyka AP, Yu J, Baltazar CO, Buck ME, Meade R, Maynard GD, Thurkauf A, Chien DS, Hutchison AJ, and Krause JE (2008) Identification and characterization of NDT 9513727 [N,N-bis(1,3-benzodioxol-5 ylmethyl)-1-butyl-2,4-diphenyl-1H-imidazole-5-methanamine], a novel, orally bioavailable C5a receptor inverse agonist. J Pharmacol Exp Ther 327:898-909.

Bubeck P, Grötzinger J, Winkler M, Köhl J, Wollmer A, Klos A, and Bautsch W (1994) Site-specific mutagenesis of residues in the human C5a anaphylatoxin which are involved in possible interaction with the C5a receptor. Eur J Biochem 219 897-904.

Buhl AM, Avdi N, Worthen GS, and Johnson GL (1994) Mapping of the C5a receptor signal transduction network in human neutrophils. Proc Natl Acad Sci USA 91: 9190-9194

Bunschoten A, Ippel JH, Kruijtzer JA, Feitsma L, de Haas CJ, Liskamp RM, and Kemmink J (2011) A peptide mimic of the chemotaxis inhibitory protein of Staphylococcus aureus: towards the development of novel anti-inflammatory compounds. Amino Acids 40:731-740.

Burg M, Martin U, Bock D, Rheinheimer C, Köhl J, Bautsch W, and Klos A (1996 Differential regulation of the C3a and C5a receptors (CD88) by IFN-gamma and PMA in U937 cells and related myeloblastic cell lines. J Immunol 157:5574-5581.

Burg M, Martin U, Rheinheimer C, Köhl J, Bautsch W, Böttger EC, and Klos A (1995) IFN-gamma up-regulates the human C5a receptor (CD88) in myeloblastic U937 cells and related cell lines. J Immunol 155:4419-4426.

Burger F and Zilow EP (1993) Complement-derived anaphylatoxins in natural immunity, in The Natural Immune System: Humoral Factors (Sim E, ed) pp 209-232, Oxford University Press, Oxford.

Burger R, Zilow G, Bader A, Friedlein A, and Naser W (1988) The C terminus of the anaphylatoxin $\mathrm{C} 3 \mathrm{a}$ generated upon complement activation represents a neoantigenic determinant with diagnostic potential. J Immunol 141:553-558.

Burns JM, Summers BC, Wang Y, Melikian A, Berahovich R, Miao Z, Penfold ME, Sunshine MJ, Littman DR, and Kuo CJ, et al. (2006) A novel chemokine receptor for SDF-1 and I-TAC involved in cell survival, cell adhesion, and tumor development. J Exp Med 203:2201-2213.

Busche MN and Stahl GL (2010) Role of the complement components C5 and C3a in a mouse model of myocardial ischemia and reperfusion injury. Ger Med Sci 8:8, Doc20.

Cain SA, Coughlan T, and Monk PN (2001a) Mapping the ligand-binding site on the C5a receptor: arginine74 of C5a contacts aspartate282 of the C5a receptor. Biochemistry 40:14047-14052.

Cain SA, Higginbottom A, and Monk PN (2003) Characterisation of C5a receptor agonists from phage display libraries. Biochem Pharmacol 66:1833-1840.

Cain SA and Monk PN (2002) The orphan receptor C5L2 has high affinity binding sites for complement fragments C5a and C5a des-Arg(74). J Biol Chem 277: $7165-7169$.

Cain SA, Woodruff TM, Taylor SM, Fairlie DP, Sanderson SD, and Monk PN (2001b) Modulation of ligand selectivity by mutation of the first extracellular loop of the human C5a receptor. Biochem Pharmacol 61:1571-1579.

Campbell W, Okada N, and Okada H (2001) Carboxypeptidase R is an inactivator of complement-derived inflammatory peptides and an inhibitor of fibrinolysis. Immunol Rev 180:162-167.

Campbell WD, Lazoura E, Okada N, and Okada H (2002) Inactivation of C3a and C5a octapeptides by carboxypeptidase R and carboxypeptidase N. Microbiol Immunol 46:131-134.

Campo A, Hausmann G, Martí RM, Estrach T, Grau JM, Porcel JM, and Herrero C (2007) Complement activation products (C3a and C5b-9) as markers of activity of dermatomyositis. Comparison with usual biochemical parameters [article in Spanish]. Actas Dermosifiliogr 98:403-414.

Caporale LH, Tippett PS, Erickson BW, and Hugli TE (1980) The active site of C3a anaphylatoxin. J Biol Chem 255:10758-10763.

Carmona-Fontaine C, Theveneau E, Tzekou A, Tada M, Woods M, Page KM, Parsons M, Lambris JD, and Mayor R (2011) Complement fragment C3a controls mutua cell attraction during collective cell migration. Dev Cell 21:1026-1037.

Carroll MV and Sim RB (2011) Complement in health and disease. Adv Drug Deliv Rev 63:965-975. 
Chang JY, Lin CC, Salamanca S, Pangburn MK, and Wetsel RA (2008) Denaturation and unfolding of human anaphylatoxin C3a: an unusually low covalent stability of its native disulfide bonds. Arch Biochem Biophys 480:104-110.

Chao TH, Ember JA, Wang M, Bayon Y, Hugli TE, and Ye RD (1999) Role of the second extracellular loop of human $\mathrm{C} 3 \mathrm{a}$ receptor in agonist binding and receptor function. $J$ Biol Chem 274:9721-9728.

Charlesworth JA, Peake PW, Campbell LV, Pussell BA, O'Grady S, and Tzilopoulos T (1998) The influence of oral lipid loads on acylation stimulating protein (ASP) in healthy volunteers. Int J Obes Relat Metab Disord 22:1096-1102.

Chen JJ, Cole DC, Ciszewski G, Crouse K, Ellingboe JW, Nowak P, Tawa GJ, Berstein G, and Li W (2010) Identification of a new class of small molecule C5a receptor antagonists. Bioorg Med Chem Lett 20:662-664.

Chen NJ, Mirtsos C, Suh D, Lu YC, Lin WJ, McKerlie C, Lee T, Baribault H, Tian H, and Yeh WC (2007) C5L2 is critical for the biological activities of the anaphylatoxins C5a and C3a. Nature 446:203-207.

Chen Z, Zhang X, Gonnella NC, Pellas TC, Boyar WC, and Ni F (1998) Residues 21-30 within the extracellular $\mathrm{N}$-terminal region of the $\mathrm{C} 5 \mathrm{a}$ receptor represent a binding domain for the C5a anaphylatoxin. J Biol Chem 273:10411-10419.

Chenoweth DE, Goodman MG, and Weigle WO (1982) Demonstration of a specific receptor for human C5a anaphylatoxin on murine macrophages. J Exp Med 156:68-78.

Chenoweth DE and Hugli TE (1980) Human C5a and C5a analogs as probes of the neutrophil C5a receptor. Mol Immunol 17:151-161.

Choy LN, Rosen BS, and Spiegelman BM (1992) Adipsin and an endogenous pathway of complement from adipose cells. J Biol Chem 267:12736-12741.

Cianflone K, Kalant D, Marliss EB, Gougeon R, and Sniderman AD (1995) Response of plasma ASP to a prolonged fast. Int J Obes Relat Metab Disord 19:604-609.

Cianflone K, Kwiterovich PO, Walsh M, Forse A, Rodriguez MA, and Sniderman AD (1987) Stimulation of fatty acid uptake and triglyceride synthesis in human cultured skin fibroblasts and adipocytes by a serum protein. Biochem Biophys Res Commun 144:94-100.

Cianflone K, Maslowska M, and Sniderman AD (1999) Acylation stimulating protein (ASP), an adipocyte autocrine: new directions. Semin Cell Dev Biol 10:31-41.

Cianflone K, Rodriguez MA, Walsh M, Vu H, and Sniderman AD (1988) The effect of a plasma protein fraction on lipid synthesis in cultured skin fibroblasts from normals and patients with hyperapobetalipoproteinemia. Clin Invest Med 11:99-107.

Cianflone K, Vu H, Walsh M, Baldo A, and Sniderman A (1989a) Metabolic response of acylation stimulating protein to an oral fat load. J Lipid Res 30:1727-1733.

Cianflone K, Xia Z, and Chen LY (2003) Critical review of acylation-stimulating protein physiology in humans and rodents. Biochim Biophys Acta 1609:127-143.

Cianflone K, Zhang XJ, Genest J Jr, and Sniderman A (1997) Plasma acylationstimulating protein in coronary artery disease. Arterioscler Thromb Vasc Biol 17 1239-1244

Cianflone KM, Maslowska MH, and Sniderman AD (1990) Impaired response of fibroblasts from patients with hyperapobetalipoproteinemia to acylationstimulating protein. J Clin Invest 85:722-730.

Cianflone KM, Sniderman AD, Dallongeville J, Bertrand M, Raffaï E, and Davignon J (1992) The relation between triglyceride synthesis in peripheral tissues and postprandial plasma triglyceride levels: preliminary evidence of a role for acylation stimulating protein. Clin Invest Med 15:132-140.

Cianflone KM, Sniderman AD, Walsh MJ, Vu HT, Gagnon J, and Rodriguez MA (1989b) Purification and characterization of acylation stimulating protein. $J$ Biol Chem 264:426-430.

Cleary PP, Prahbu U, Dale JB, Wexler DE, and Handley J (1992) Streptococcal C5a peptidase is a highly specific endopeptidase. Infect Immun 60:5219-5223.

Cochrane CG and Müller-Eberhard HJ (1968) The derivation of two distinct anaphylatoxin activities from the third and fifth components of human complement. $J$ Exp Med 127:371-386.

Colotta F, Re F, Muzio M, Bertini R, Polentarutti N, Sironi M, Giri JG, Dower SK, Sims JE, and Mantovani A (1993) Interleukin-1 type II receptor: a decoy target for IL-1 that is regulated by IL-4. Science 261:472-475.

Cook KS, Min HY, Johnson D, Chaplinsky RJ, Flier JS, Hunt CR, and Spiegelman BM (1987) Adipsin: a circulating serine protease homolog secreted by adipose tissue and sciatic nerve. Science 237:402-405

Cook WJ, Galakatos N, Boyar WC, Walter RL, and Ealick SE (2010) Structure of human desArg-C5a. Acta Crystallogr D Biol Crystallogr 66:190-197.

Corbin NC and Hugli TE (1976) The primary structure of porcine C3a anaphylatoxin. $J$ Immunol 117:990-995.

Crass T, Ames RS, Sarau HM, Tornetta MA, Foley JJ, Köhl J, Klos A, and Bautsch W (1999a) Chimeric receptors of the human C3a receptor and C5a receptor (CD88). $J$ Biol Chem 274:8367-8370.

Crass T, Bautsch W, Cain SA, Pease JE, and Monk PN (1999b) Receptor activation by human C5a des Arg74 but not intact C5a is dependent on an interaction between Glu199 of the receptor and Lys68 of the ligand. Biochemistry 38:9712-9717.

Crass T, Bautsch W, Cain SA, Pease JE, and Monk PN (1999c) Receptor activation by human C5a des Arg74 but not intact C5a is dependent on an interaction between Glu199 of the receptor and Lys68 of the ligand. Biochemistry 38:9712-9717.

Crass T, Raffetseder U, Martin U, Grove M, Klos A, Köhl J, and Bautsch W (1996) Expression cloning of the human $\mathrm{C} 3 \mathrm{a}$ anaphylatoxin receptor $(\mathrm{C} 3 \mathrm{aR})$ from differentiated U-937 cells. Eur J Immunol 26:1944-1950.

Croker DE, Halai R, Fairlie DP, and Cooper MA (2012) Ligand-induced dimerisation of the complement C5aR and C5L2 receptors by C5a but not C5a des-Arg. Immunobiology 217:1181-1182.

Cui L, Ferreri K, and Hugli TE (1988) Structural characterization of the C4a anaphylatoxin from rat. Mol Immunol 25:663-671.

Cui W, Lapointe M, Gauvreau D, Kalant D, and Cianflone K (2009a) Recombinant C3adesArg/acylation stimulating protein (ASP) is highly bioactive: a critical evaluation of C5L2 binding and 3T3-L1 adipocyte activation. Mol Immunol 46 $3207-3217$.

Cui W, Paglialunga S, Kalant D, Lu H, Roy C, Laplante M, Deshaies Y, and Cianflone $\mathrm{K}$ (2007) Acylation-stimulating protein/C5L2-neutralizing antibodies alter triglyceride metabolism in vitro and in vivo. Am J Physiol Endocrinol Metab 293 . E1482-E1491.

Cui W, Simaan M, Laporte S, Lodge R, and Cianflone K (2009b) C5a- and ASPmediated C5L2 activation, endocytosis and recycling are lost in S323I-C5L2 mutation. Mol Immunol 46:3086-3098.

Daumy GO, Delgarno D, McColl AS, Merenda JM, and Schulte GR (1988) The use of high field NMR to determine homogeneity in a preparation of human C5a produced by Escherichia coli. Biochim Biophys Acta 967:326-330.

Davignon I, Catalina MD, Smith D, Montgomery J, Swantek J, Croy J, Siegelman M, and Wilkie TM (2000) Normal hematopoiesis and inflammatory responses despite discrete signaling defects in G $\alpha 15$ knockout mice. Mol Cell Biol 20:797-804.

Davoust N, Jones J, Stahel PF, Ames RS, and Barnum SR (1999) Receptor for the C3a anaphylatoxin is expressed by neurons and glial cells. Glia 26:201-211.

de Haas CJ, Veldkamp KE, Peschel A, Weerkamp F, Van Wamel WJ, Heezius EC, Poppelier MJ, Van Kessel KP, and van Strijp JA (2004) Chemotaxis inhibitory protein of Staphylococcus aureus, a bacterial antiinflammatory agent. $J$ Exp Med 199:687-695.

de Lind van Wijngaarden RF, Cianflone K, Gao Y, Leunissen RW, and HokkenKoelega AC (2010) Cardiovascular and metabolic risk profile and acylationstimulating protein levels in children with Prader-Willi syndrome and effects of growth hormone treatment. J Clin Endocrinol Metab 95:1758-1766.

Décaillot FM, Kazmi MA, Lin Y, Ray-Saha S, Sakmar TP, and Sachdev P (2011) CXCR7/CXCR4 heterodimer constitutively recruits beta-arrestin to enhance cell migration. J Biol Chem 286:32188-32197.

Defea K (2008) Beta-arrestins and heterotrimeric G-proteins: collaborators and competitors in signal transduction. Br J Pharmacol 153 (Suppl 1):S298-S309.

DeFea KA, Zalevsky J, Thoma MS, Déry O, Mullins RD, and Bunnett NW (2000) Beta-arrestin-dependent endocytosis of proteinase-activated receptor 2 is required for intracellular targeting of activated ERK1/2. J Cell Biol 148:1267-1281.

DeMartino JA, Konteatis ZD, Siciliano SJ, Van Riper G, Underwood DJ, Fischer PA and Springer MS (1995) Arginine 206 of the C5a receptor is critical for ligand recognition and receptor activation by C-terminal hexapeptide analogs. J Biol Chem 270:15966-15969.

DeMartino JA, Van Riper G, Siciliano SJ, Molineaux CJ, Konteatis ZD, Rosen H, and Springer MS (1994) The amino terminus of the human C5a receptor is required for high affinity C5a binding and for receptor activation by C5a but not C5a analogs. J Biol Chem 269:14446-14450.

Denonne F, Binet S, Burton M, Collart P, Defays S, Dipesa A, Eckert M, Giannaras A, Kumar S, Levine B, Nicolas JM, Pasau P, and Pégurier C, et al. (2007a) Discovery of new C3aR ligands. Part 2: amino-piperidine derivatives. Bioorg Med Chem Lett 17:3262-3265.

Denonne F, Binet S, Burton M, Collart P, Dipesa A, Ganguly T, Giannaras A, Kumar $\mathrm{S}$, Lewis T, and Maounis F, et al. (2007b) Discovery of new C3aR ligands. Part 1: arginine derivatives. Bioorg Med Chem Lett 17:3258-3261.

Dillard P, Wetsel RA, and Drouin SM (2007) Complement C3a regulates Muc5ac expression by airway Clara cells independently of Th2 responses. Am J Respir Crit Care Med 175:1250-1258.

DiMartino SJ, Shah AB, Trujillo G, and Kew RR (2001) Elastase controls the binding of the vitamin D-binding protein (Gc-globulin) to neutrophils: a potential role in the regulation of C5a co-chemotactic activity. J Immunol 166:2688-2694.

Dobrina A, Pausa M, Fischetti F, Bulla R, Vecile E, Ferrero E, Mantovani A and Tedesco F (2002) Cytolytically inactive terminal complement complex causes transendothelial migration of polymorphonuclear leukocytes in vitro and in vivo. Blood 99:185-192.

Ducruet AF, Hassid BG, Mack WJ, Sosunov SA, Otten ML, Fusco DJ, Hickman ZL, Kim GH, Komotar RJ, Mocco J, and Connolly ES (2008) C3a receptor modulation of granulocyte infiltration after murine focal cerebral ischemia is reperfusion dependent. J Cereb Blood Flow Metab 28:1048-1058.

Elsner J, Oppermann M, Czech W, Dobos G, Schöpf E, Norgauer J, and Kapp A (1994) C3a activates reactive oxygen radical species production and intracellular calcium transients in human eosinophils. Eur J Immunol 24:518-522.

Emadi-Khiav B, Mousli M, Bronner C, and Landry Y (1995) Human and rat cutaneous mast cells: involvement of a $\mathrm{G}$ protein in the response to peptidergic stimuli. Eur J Pharmacol 272:97-102.

Ember JA, Johansen NL, and Hugli TE (1991) Designing synthetic superagonists of C3a anaphylatoxin. Biochemistry 30:3603-3612.

Ember JA, Sanderson SD, Taylor SM, Kawahara M, and Hugli TE (1992) Biologic activity of synthetic analogues of C5a anaphylatoxin. J Immunol 148:3165-3173.

Erken E, Gunesacar R, and Ozer HT (2010) Investigation of C5a receptor gene $450 \mathrm{C} /$ $\mathrm{T}$ polymorphism in Turkish patients with familial Mediterranean fever. $\mathrm{Mol} \mathrm{Biol}$ Rep 37:273-276.

Faraj M, Havel PJ, Phélis S, Blank D, Sniderman AD, and Cianflone K (2003) Plasma acylation-stimulating protein, adiponectin, leptin, and ghrelin before and after weight loss induced by gastric bypass surgery in morbidly obese subjects. $J$ Clin Endocrinol Metab 88:1594-1602.

Farzan M, Schnitzler CE, Vasilieva N, Leung D, Kuhn J, Gerard C, Gerard NP, and Choe H (2001) Sulfated tyrosines contribute to the formation of the C5a docking site of the human C5a anaphylatoxin receptor. J Exp Med 193:1059-1066.

Fassbender A, D'Hooghe T, Mihalyi A, Kyama C, Simsa P, and Lessey BA (2009) Plasma C3a-des-Arg levels in women with and without endometriosis. Am $J$ Reprod Immunol 62:187-195.

Feierler J, Wirth M, Welte B, Schüssler S, Jochum M, and Faussner A (2011) Helix 8 plays a crucial role in bradykinin $\mathrm{B}(2)$ receptor trafficking and signaling. $J$ Biol Chem 286:43282-43293.

Fernandez HN, Henson PM, Otani A, and Hugli TE (1978) Chemotactic response to human C3a and C5a anaphylatoxins. I. Evaluation of C3a and C5a leukotaxis in vitro and under stimulated in vivo conditions. J Immunol 120:109-115.

Fernandez HN and Hugli TE (1978) Primary structural analysis of the polypeptide portion of human $\mathrm{C} 5 \mathrm{a}$ anaphylatoxin. Polypeptide sequence determination and assignment of the oligosaccharide attachment site in C5a. J Biol Chem 253: $6955-6964$ 
Findlay JB and Pappin DJ (1986) The opsin family of proteins. Biochem $J \mathbf{2 3 8}$ : 625-642.

Fischer WH and Hugli TE (1997) Regulation of B cell functions by C3a and C3a (desArg): suppression of TNF-alpha, IL-6, and the polyclonal immune response. $J$ Immunol 159:4279-4286.

Fonseca MI, Ager RR, Chu SH, Yazan O, Sanderson SD, LaFerla FM, Taylor SM, Woodruff TM, and Tenner AJ (2009) Treatment with a C5aR antagonist decreases pathology and enhances behavioral performance in murine models of Alzheimer's disease. J Immunol 183:1375-1383.

Francis K, Lewis BM, Akatsu H, Monk PN, Cain SA, Scanlon MF, Morgan BP, Ham J, and Gasque P (2003) Complement C3a receptors in the pituitary gland: a novel pathway by which an innate immune molecule releases hormones involved in the control of inflammation. FASEB J 17:2266-2268.

Francis K, Lewis BM, Monk PN, and Ham J (2008) Complement C5a receptors in the pituitary gland: expression and function. $J$ Endocrinol 199:417-424

Fredslund F, Laursen NS, Roversi P, Jenner L, Oliveira CL, Pedersen JS, Nunn MA Lea SM, Discipio R, Sottrup-Jensen L, and Andersen GR (2008) Structure of and influence of a tick complement inhibitor on human complement component 5 . Nat Immunol 9:753-760.

Fujiwara A, Taguchi O, Takagi T, D’Alessandro-Gabazza CN, Boveda-Ruiz D, Toda M, Yasukawa A, Matsushima Y, Miyake Y, Kobayashi H, and Kobayashi T, et al. (2012) Role of thrombin-activatable fibrinolysis inhibitor in allergic bronchial asthma. Lung 190:189-198.

Fukuoka Y and Hugli TE (1990) Anaphylatoxin binding and degradation by rat peritoneal mast cells. Mechanisms of degranulation and control. J Immunol 145 $1851-1858$.

Fukuoka Y, Xia HZ, Sanchez-Muñoz LB, Dellinger AL, Escribano L, and Schwartz LB (2008) Generation of anaphylatoxins by human beta-tryptase from C3, C4, and C5. J Immunol 180:6307-6316.

Fusakio ME, Mohammed JP, Laumonnier Y, Hoebe K, Kohl J, and Mattner J (2011) C5a regulates NKT and NK cell functions in sepsis. J Immunol 187:5805-5812

Galés C, Kowalski-Chauvel A, Dufour MN, Seva C, Moroder L, Pradayrol L, Vaysse N, Fourmy D, and Silvente-Poirot S (2000) Mutation of Asn-391 within the conserved NPXXY motif of the cholecystokinin B receptor abolishes Gq protein activation without affecting its association with the receptor. J Biol Chem 275 : 17321-17327.

Gao H, Neff TA, Guo RF, Speyer CL, Sarma JV, Tomlins S, Man Y, Riedemann NC, Hoesel LM, and Younkin E, et al. (2005) Evidence for a functional role of the second C5a receptor C5L2. FASEB J 19:1003-1005.

Gao J, Choe H, Bota D, Wright PL, Gerard C, and Gerard NP (2003) Sulfation of tyrosine 174 in the human C3a receptor is essential for binding of C3a anaphylatoxin. J Biol Chem 278:37902-37908.

Garrett MC, Otten ML, Starke RM, Komotar RJ, Magotti P, Lambris JD, Rynkowski MA, and Connolly ES (2009) Synergistic neuroprotective effects of C3a and C5a receptor blockade following intracerebral hemorrhage. Brain Res 1298:171-177.

Gavrilyuk V, Kalinin S, Hilbush BS, Middlecamp A, McGuire S, Pelligrino D, Weinberg G, and Feinstein DL (2005) Identification of complement 5a-like receptor (C5L2) from astrocytes: characterization of anti-inflammatory properties. $J \mathrm{Neu}$ rochem 92:1140-1149.

Ge H, Scheinin M, and Kallio J (2003) Constitutive precoupling to G(i) and increased agonist potency in the alpha(2B)-adrenoceptor. Biochem Biophys Res Commun 306:959-965.

Gerard C, Chenoweth DE, and Hugli TE (1981) Response of human neutrophils to C5a: a role for the oligosaccharide moiety of human C5ades Arg-74 but not of C5a in biologic activity. J Immunol 127:1978-1982.

Gerard C and Hugli TE (1981) Identification of classical anaphylatoxin as the desArg form of the C5a molecule: evidence of a modulator role for the oligosaccharide unit in human des-Arg74-C5a. Proc Natl Acad Sci USA 78:1833-1837.

Gerard NP, Bao L, Xiao-Ping H, Eddy RL Jr, Shows TB, and Gerard C (1993) Human chemotaxis receptor genes cluster at 19q13.3-13.4. Characterization of the human C5a receptor gene. Biochemistry 32:1243-1250.

Gerard NP and Gerard C (1991) The chemotactic receptor for human C5a anaphylatoxin. Nature 349:614-617.

Gerard NP, Lively MO, and Gerard C (1988) Amino acid sequence of guinea pig C3a anaphylatoxin. Protein Seq Data Anal 1:473-478.

Gerard NP, Lu B, Liu P, Craig S, Fujiwara Y, Okinaga S, and Gerard C (2005) An anti-inflammatory function for the complement anaphylatoxin C5a-binding protein, C5L2. J Biol Chem 280:39677-39680.

Gerardy-Schahn R, Ambrosius D, Casaretto M, Grötzinger J, Saunders D, Wollmer A, Brandenburg D, and Bitter-Suermann D (1988) Design and biological activity of a new generation of synthetic C3a analogues by combination of peptidic and nonpeptidic elements. Biochem $J$ 255:209-216.

Gerber BO, Meng EC, Dotsch V, Baranski TJ, and Bourne HR (2001) An activation switch in the ligand binding pocket of the C5a receptor. $J$ Biol Chem 276: 3394-3400.

Geva A, Lassere TB, Lichtarge O, Pollitt SK, and Baranski TJ (2000) Genetic mapping of the human C5a receptor. Identification of transmembrane amino acids critical for receptor function. J Biol Chem 275:35393-35401.

Giannini E, Brouchon L, and Boulay F (1995) Identification of the major phosphorylation sites in human C5a anaphylatoxin receptor in vivo. J Biol Chem 270 19166-19172.

Gombos T, Förhécz Z, Pozsonyi Z, Széplaki G, Kunde J, Füst G, Jánoskuti L, Karádi I, and Prohászka Z (2012) Complement anaphylatoxin C3a as a novel independent prognostic marker in heart failure. Clin Res Cardiol 101:607-615.

Gong Y, Barbay JK, Buntinx M, Li J, Wauwe JV, Claes C, Lommen GV, Hornby PJ, and $\mathrm{He} \mathrm{W}(2008)$ Design and optimization of aniline-substituted tetrahydroquinoline C5a receptor antagonists. Bioorg Med Chem Lett 18:3852-3855.

Gonzalez JM, Dong Z, Romero R, and Girardi G (2011) Cervical remodeling/ripening at term and preterm delivery: the same mechanism initiated by different mediators and different effector cells. PLOS ONE 6:e26877.
Gorski JP, Hugli TE, and Müller-Eberhard HJ (1979) C4a: the third anaphylatoxin of the human complement system. Proc Natl Acad Sci USA 76:5299-5302.

Gosling J, Dairaghi DJ, Wang Y, Hanley M, Talbot D, Miao Z, and Schall TJ (2000) Cutting edge: identification of a novel chemokine receptor that binds dendritic celland $\mathrm{T}$ cell-active chemokines including ELC, SLC, and TECK. J Immunol 164: $2851-2856$

Governa M, Amati M, Fenoglio I, Valentino M, Coloccini S, Bolognini L, Carlo Botta G, Emanuelli M, Pierella F, and Volpe AR, et al. (2005) Variability of biological effects of silicas: different degrees of activation of the fifth component of complement by amorphous silicas. Toxicol Appl Pharmacol 208:68-77.

Governa M, Amati M, Valentino M, Visonà I, Fubini B, Botta GC, Volpe AR and Carmignani M (2000) In vitro cleavage by asbestos fibers of the fifth component of human complement through free-radical generation and kallikrein activation. J Toxicol Environ Health A 59:539-552.

Governa M, Fenoglio I, Amati M, Valentino M, Bolognini L, Coloccini S, Volpe AR, Carmignani M, and Fubini B (2002) Cleavage of the fifth component of human complement and release of a split product with C5a-like activity by crystalline silica through free radical generation and kallikrein activation. Toxicol Appl Pharmacol 179:129-136.

Greer J (1985) Model structure for the inflammatory protein C5a. Science 228: $1055-1060$

Gripentrog JM and Miettinen HM (2008) Formyl peptide receptor-mediated ERK1/2 activation occurs through G(i) and is not dependent on beta-arrestin1/2. Cell Signal 20:424-431.

Gueler F, Rong S, Gwinner W, Mengel M, Bröcker V, Schön S, Greten TF, Hawlisch $\mathrm{H}$, Polakowski T, and Schnatbaum K, et al. (2008) Complement 5a receptor inhibition improves renal allograft survival. J Am Soc Nephrol 19:2302-2312.

Guo Q, Subramanian H, Gupta K, and Ali H (2011) Regulation of C3a receptor signaling in human mast cells by $\mathrm{G}$ protein coupled receptor kinases. PLoS ONE 6: e22559.

Gustafsson E, Forsberg C, Haraldsson K, Lindman S, Ljung L, and Furebring C (2009a) Purification of truncated and mutated chemotaxis inhibitory protein of Staphylococcus aureus an anti-inflammatory protein. Protein Expr Purif 63:95-101.

Gustafsson E, Haas PJ, Walse B, Hijnen M, Furebring C, Ohlin M, van Strijp JA and van Kessel KP (2009b) Identification of conformational epitopes for human IgG on chemotaxis inhibitory protein of Staphylococcus aureus. BMC Immunol 10:13.

Gustafsson E, Rosén A, Barchan K, van Kessel KP, Haraldsson K, Lindman S, Forsberg C, Ljung L, Bryder K, and Walse B, et al. (2010) Directed evolution of chemotaxis inhibitory protein of Staphylococcus aureus generates biologically functional variants with reduced interaction with human antibodies. Protein Eng Des Sel 23:91-101.

Haas PJ, de Haas CJ, Kleibeuker W, Poppelier MJ, van Kessel KP, Kruijtzer JA Liskamp RM, and van Strijp JA (2004) N-terminal residues of the chemotaxis inhibitory protein of Staphylococcus aureus are essential for blocking formylated peptide receptor but not C5a receptor. J Immunol 173:5704-5711.

Habermann JK, Roblick UJ, Luke BT, Prieto DA, Finlay WJ, Podust VN, Roman JM, Oevermann E, Schiedeck T, and Homann N, et al. (2006) Increased serum levels of complement C3a anaphylatoxin indicate the presence of colorectal tumors. Gas troenterology 131:1020-1029, quiz 1284.

Hack CE, Nuijens JH, Felt-Bersma RJ, Schreuder WO, Eerenberg-Belmer AJ, Paardekooper J, Bronsveld W, and Thijs LG (1989) Elevated plasma levels of the anaphylatoxins C3a and C4a are associated with a fatal outcome in sepsis. Am J Med 86:20-26.

Hagemann IS, Miller DL, Klco JM, Nikiforovich GV, and Baranski TJ (2008) Structure of the complement factor 5 a receptor-ligand complex studied by disulfide trapping and molecular modeling. $J$ Biol Chem 283:7763-7775.

Hagemann IS, Narzinski KD, Floyd DH, and Baranski TJ (2006) Random mutagenesis of the complement factor $5 \mathrm{a}$ (C5a) receptor $\mathrm{N}$ terminus provides a structural constraint for C5a docking. J Biol Chem 281:36783-36792

Han G, Geng S, Li Y, Chen G, Wang R, Li X, Ma Y, Shen B, and Li Y (2011) $\gamma \delta$ T-cell function in sepsis is modulated by $\mathrm{C} 5$ a receptor signalling. Immunology $\mathbf{1 3 3}$ 340-349.

Haque R, Hwang BY, Appelboom G, Piazza MA, Guo K, and Connolly ES (2011) Alterations in systemic complement component $3 \mathrm{a}$ and $5 \mathrm{a}$ levels in patients with cerebral arteriovenous malformations. J Clin Neurosci 18:1235-1239.

Harada T, Sano M, and Matsunaga T (1992) The effect of anaphylatoxin component on inner ear damage. Acta Otolaryngol 112:265-271.

Haribabu B, Zhelev DV, Pridgen BC, Richardson RM, Ali H, and Snyderman R (1999) Chemoattractant receptors activate distinct pathways for chemotaxis and secretion. Role of G-protein usage. J Biol Chem 274:37087-37092.

Hartmann H, Lübbers B, Casaretto M, Bautsch W, Klos A, and Köhl J (1993) Rapid quantification of $\mathrm{C} 3 \mathrm{a}$ and C5a using a combination of chromatographic and immunoassay procedures. J Immunol Methods 166:35-44.

Hartmann K, Henz BM, Krüger-Krasagakes S, Köhl J, Burger R, Guhl S, Haase I, Lippert U, and Zuberbier T (1997) C3a and C5a stimulate chemotaxis of human mast cells. Blood 89:2863-2870.

Hartmann TN, Leick M, Ewers S, Diefenbacher A, Schraufstatter I, Honczarenko M, and Burger M (2008) Human B cells express the orphan chemokine receptor CRAM-A/B in a maturation-stage-dependent and CCL5-modulated manner. Immunology 125:252-262.

Hasegawa K, Tamari M, Shao C, Shimizu M, Takahashi N, Mao XQ, Yamasaki A, Kamada F, Doi S, and Fujiwara H, et al. (2004) Variations in the C3, C3a receptor, and C5 genes affect susceptibility to bronchial asthma. Hum Genet 115:295-301.

Hashimoto M, Hirota K, Yoshitomi H, Maeda S, Teradaira S, Akizuki S, PrietoMartin P, Nomura T, Sakaguchi N, and Köhl J, et al. (2010) Complement drives Th17 cell differentiation and triggers autoimmune arthritis. J Exp Med 207: 1135-1143.

Heimbach L, Li Z, Berkowitz P, Zhao M, Li N, Rubenstein DS, Diaz LA, and Liu Z (2011) The C5a receptor on mast cells is critical for the autoimmune skin-blistering disease bullous pemphigoid. J Biol Chem 286:15003-15009. 
Heller T, Hennecke M, Baumann U, Gessner JE, zu Vilsendorf AM, Baensch M, Boulay F, Kola A, Klos A, Bautsch W, and Köhl J (1999) Selection of a C5a receptor antagonist from phage libraries attenuating the inflammatory response in immune complex disease and ischemia/reperfusion injury. J Immunol 163:985-994.

Hensens OD, Borris RP, Koupal LR, Caldwell CG, Currie SA, Haidri AA, Homnick CF, Honeycutt SS, Lindenmayer SM, and Schwartz CD, et al. (1991) L-156,602, a C5a antagonist with a novel cyclic hexadepsipeptide structure from Streptomyces sp. MA6348. Fermentation, isolation and structure determination. J Antibiot (Tokyo) 44:249-254.

Higginbottom A, Cain SA, Woodruff TM, Proctor LM, Madala PK, Tyndall JD, Taylor SM, Fairlie DP, and Monk PN (2005) Comparative agonist/antagonist responses in mutant human C5a receptors define the ligand binding site. $J$ Biol Chem 280 : 17831-17840.

Hillenbrand A, Weiss M, Knippschild U, Wolf AM, and Huber-Lang M (2012) Sepsisinduced adipokine change with regard to insulin resistance. Int $J$ Inflamm 2012 : 972368 .

Hoke M, Speidl W, Schillinger M, Minar E, Zehetmayer S, Schönherr M, Wagner O, and Mannhalter C (2012) Polymorphism of the complement 5 gene and cardiovascular outcome in patients with atherosclerosis. Eur J Clin Invest 42:921-926.

Hollmann TJ, Mueller-Ortiz SL, Braun MC, and Wetsel RA (2008) Disruption of the C5a receptor gene increases resistance to acute Gram-negative bacteremia and endotoxic shock: opposing roles of C3a and C5a. Mol Immunol 45:1907-1915.

Honczarenko M, Lu B, Nicholson-Weller A, Gerard NP, Silberstein LE, and Gerard C (2005a) C5L2 receptor is not involved in C3a / C3a-desArg-mediated enhancement of bone marrow hematopoietic cell migration to CXCL12. Leukemia 19:1682-1683, author reply $1684-1685$.

Honczarenko M, Ratajczak MZ, Nicholson-Weller A, and Silberstein LE (2005b) Complement C3a enhances CXCL12 (SDF-1)-mediated chemotaxis of bone marrow hematopoietic cells independently of C3a receptor. J Immunol 175:3698-3706.

Horino K, Nishiura H, Ohsako T, Shibuya Y, Hiraoka T, Kitamura N, and Yamamoto $\mathrm{T}$ (1998) A monocyte chemotactic factor, S19 ribosomal protein dimer, in phagocytic clearance of apoptotic cells. Lab Invest 78:603-617.

Hsu W, Rosenquist GL, Ansari AA, and Gershwin ME (2005) Autoimmunity and tyrosine sulfation. Autoimmun Rev 4:429-435.

Huber-Lang M, Denk S, Fulda S, Erler E, Kalbitz M, Weckbach S, Schneider EM, Weiss M, Kanse SM, and Perl M (2012) Cathepsin D is released after severe tissue trauma in vivo and is capable of generating C5a in vitro. Mol Immunol 50:60-65.

Huber-Lang M, Sarma JV, Rittirsch D, Schreiber H, Weiss M, Flierl M, Younkin E, Schneider M, Suger-Wiedeck H, and Gebhard F, et al. (2005) Changes in the novel orphan, C5a receptor (C5L2), during experimental sepsis and sepsis in humans. $J$ Immunol 174:1104-1110.

Huber-Lang MS, Sarma JV, McGuire SR, Lu KT, Padgaonkar VA, Younkin EM, Guo $\mathrm{RF}$, Weber CH, Zuiderweg ER, Zetoune FS, and Ward PA (2003) Structure-function relationships of human C5a and C5aR. J Immunol 170:6115-6124.

Huber R, Scholze H, Pâques EP, and Deisenhofer J (1980) Crystal structure analysis and molecular model of human C3a anaphylatoxin. Hoppe Seylers $Z$ Physiol Chem 361:1389-1399.

Hueber AJ, Asquith DL, Miller AM, Reilly J, Kerr S, Leipe J, Melendez AJ, and McInnes IB (2010) Mast cells express IL-17A in rheumatoid arthritis synovium. J Immunol 184:3336-3340.

Huey R, Bloor CM, Kawahara MS, and Hugli TE (1983) Potentiation of the anaphylatoxins in vivo using an inhibitor of serum carboxypeptidase N (SCPN). I. Lethality and pathologic effects on pulmonary tissue. Am J Pathol 112:48-60.

Huey R, Erickson BW, Bloor CM, and Hugli TE (1984) Contraction of guinea pig lung by synthetic oligopeptides related to human C3a. Immunopharmacology 8:37-45.

Hugli TE (1975) Human anaphylatoxin (C3a) from the third component of complement. Primary structure. J Biol Chem 250:8293-8301.

Hugli TE (1981) The structural basis for anaphylatoxin and chemotactic functions of C3a, C4a, and C5a. Crit Rev Immunol 1:321-366.

Hugli TE and Erickson BW (1977) Synthetic peptides with the biological activities and specificity of human C3a anaphylatoxin. Proc Natl Acad Sci USA 74: $1826-1830$.

Hugli TE, Gerard C, Kawahara M, Scheetz ME 2nd, Barton R, Briggs S, Koppel G, and Russell S (1981a) Isolation of three separate anaphylatoxins from complementactivated human serum. Mol Cell Biochem 41:59-66.

Hugli TE, Kawahara MS, Unson CG, Molinar-Rode R, and Erickson BW (1983) The active site of human C4a anaphylatoxin. Mol Immunol 20:637-645.

Hugli TE, Morgan WT, and Müller-Eberhard HJ (1975a) Circular dichroism of C3a anaphylatoxin. Effects of $\mathrm{pH}$, heat, guanidinium chloride, and mercaptoethanol on conformation and function. J Biol Chem 250:1479-1483.

Hugli TE and Müller-Eberhard HJ (1978) Anaphylatoxins: C3a and C5a. Adv Immunol 26:1-53.

Hugli TE, Stimler NP, Gerard C, and Moon KE (1981b) Possible role of serum anaphylatoxins in hypersensitivity reactions. Int Arch Allergy Appl Immunol 66 (Suppl 1):113-120.

Hugli TE, Vallota EH, and Müller-Eberhard HJ (1975b) Purification and partial characterization of human and porcine C3a anaphylatoxin. J Biol Chem 250: $1472-1478$

Hunt JR, Martin CB, and Martin BK (2005) Transcriptional regulation of the murine C5a receptor gene: NF-Y is required for basal and LPS induced expression in macrophages and endothelial cells. Mol Immunol 42:1405-1415.

Husmann LK, Yung DL, Hollingshead SK, and Scott JR (1997) Role of putative virulence factors of Streptococcus pyogenes in mouse models of long-term throat colonization and pneumonia. Infect Immun 65:1422-1430.

Hutamekalin P, Takeda K, Tani M, Tsuga Y, Ogawa N, Mizutani N, and Yoshino S (2010) Effect of the C3a-receptor antagonist SB 290157 on anti-OVA polyclonal antibody-induced arthritis. J Pharmacol Sci 112:56-63.

Hüttenrauch F, Pollok-Kopp B, and Oppermann M (2005) G protein-coupled receptor kinases promote phosphorylation and beta-arrestin-mediated internalization of CCR5 homo- and hetero-oligomers. J Biol Chem 280:37503-37515.
Huynh J, Thomas WG, Aguilar MI, and Pattenden LK (2009) Role of helix 8 in G protein-coupled receptors based on structure-function studies on the type 1 angiotensin receptor. Mol Cell Endocrinol 302:118-127.

Ibrahim FB, Pang SJ, and Melendez AJ (2004) Anaphylatoxin signaling in human neutrophils. A key role for sphingosine kinase. J Biol Chem 279:44802-44811.

Ignatius A, Ehrnthaller C, Brenner RE, and Kreja LSchoengraf P, Lisson P, Blakytny R, Recknagel S, Claes L, and Gebhard F, et al. (2011a) The anaphylatoxin receptor $\mathrm{C} 5 \mathrm{aR}$ is present during fracture healing in rats and mediates osteoblast migration in vitro. J Trauma 71:952-960.

Ignatius A, Schoengraf P, Kreja L, Liedert A, Recknagel S, Kandert S, Brenner RE, Schneider M, Lambris JD, and Huber-Lang M (2011b) Complement C3a and C5a modulate osteoclast formation and inflammatory response of osteoblasts in synergism with IL-1 $\beta$. J Cell Biochem 112:2594-2605.

Imakiire K, Uto H, Sato Y, Sasaki F, Mawatari S, Ido A, Shimoda K, Hayashi K, Stuver SO, and Ito Y, et al. (2012) Difference in serum complement component C4a levels between hepatitis $\mathrm{C}$ virus carriers with persistently normal alanine aminotransferase levels or chronic hepatitis C. Mol Med Report 6:259-264.

Ingersoll SA, Martin CB, Barnum SR, and Martin BK (2010) CNS-specific expression of C3a and C5a exacerbate demyelination severity in the cuprizone model. Mol Immunol 48:219-230.

Ingram G, Hakobyan S, Robertson NP, and Morgan BP (2010) Elevated plasma C4a levels in multiple sclerosis correlate with disease activity. $J$ Neuroimmunol 223 : 124-127.

Ippel JH, de Haas CJ, Bunschoten A, van Strijp JA, Kruijtzer JA, Liskamp RM, and Kemmink J (2009) Structure of the tyrosine-sulfated C5a receptor N terminus in complex with chemotaxis inhibitory protein of Staphylococcus aureus. J Biol Chem 284:12363-12372.

Iyer A, Woodruff TM, Wu MC, Stylianou C, Reid RC, Fairlie DP, Taylor SM, and Brown L (2011) Inhibition of inflammation and fibrosis by a complement C5a receptor antagonist in DOCA-salt hypertensive rats. $J$ Cardiovasc Pharmacol 58: 479-486.

Jacob A, Bao L, Brorson J, Quigg RJ, and Alexander JJ (2010a) C3aR inhibition reduces neurodegeneration in experimental lupus. Lupus 19:73-82.

Jacob A, Hack B, Bai T, Brorson JR, Quigg RJ, and Alexander JJ (2010b) Inhibition of C5a receptor alleviates experimental CNS lupus. J Neuroimmunol 221:46-52.

Jacob A, Hack B, Chiang E, Garcia JG, Quigg RJ, and Alexander JJ (2010c) C5a alters blood-brain barrier integrity in experimental lupus. FASEB J 24:1682-1688

Jacobs JW, Rubin JS, Hugli TE, Bogardt RA, Mariz IK, Daniels JS, Daughaday WH, and Bradshaw RA (1978) Purification, characterization, and amino acid sequence of rat anaphylatoxin (C3a). Biochemistry 17:5031-5038.

Jalili A, Shirvaikar N, Marquez-Curtis L, Qiu Y, Korol C, Lee H, Turner AR Ratajczak MZ, and Janowska-Wieczorek A (2010) Fifth complement cascade protein (C5) cleavage fragments disrupt the SDF-1/CXCR4 axis: further evidence that innate immunity orchestrates the mobilization of hematopoietic stem/progenitor cells. Exp Hematol 38:321-332.

Jalink K and Moolenaar WH (2010) G protein-coupled receptors: the inside story. Bioessays 32:13-16.

Jang JH, Clark JD, Li X, Yorek MS, Usachev YM, and Brennan TJ (2010) Nociceptive sensitization by complement C5a and C3a in mouse. Pain 148:343-352.

Jang JH, Liang D, Kido K, Sun Y, Clark DJ, and Brennan TJ (2011) Increased local concentration of complement C5a contributes to incisional pain in mice. J Neuroinflammation 8:80.

Jia N, Semba U, Nishiura H, Kuniyasu A, Nsiama TK, Nishino N, and Yamamoto T (2010) Pivotal advance: interconversion between pure chemotactic ligands and chemoattractant/secretagogue ligands of neutrophil C5a receptor by a single amino acid substitution. J Leukoc Biol 87:965-975.

Jinsmaa Y, Takahashi M, Takahashi M, and Yoshikawa M (2000) Anti-analgesic and anti-amnesic effect of complement C3a. Life Sci 67:2137-2143.

Jinsmaa Y, Takenaka Y, and Yoshikawa M (2001) Designing of an orally active complement C3a agonist peptide with anti-analgesic and anti-amnesic activity. Peptides 22:25-32.

Johswich K and Klos A (2007) C5L2-an anti-inflammatory molecule or a receptor for acylation stimulating protein (C3a-desArg)? Adv Exp Med Biol 598:159-180.

Johswich K, Martin M, Thalmann J, Rheinheimer C, Monk PN, and Klos A (2006) Ligand specificity of the anaphylatoxin C5L2 receptor and its regulation on myeloid and epithelial cell lines. J Biol Chem 281:39088-39095.

Joks R, Drew HP, Castro MB, and Khaneja NM(2008) inventors, Research Foundation of State University of New York, assignee. Plasma C5A levels as an indicator of asthma severity. U.S. patent 7,407,764B2. 2008 Aug 5

Joost P and Methner A (2002) Phylogenetic analysis of 277 human G-protein-coupled receptors as a tool for the prediction of orphan receptor ligands. Genome Biol 3 RESEARCH0063.

Jusko M, Potempa J, Karim AY, Ksiazek M, Riesbeck K, Garred P, Eick S, and Blom AM (2012) A metalloproteinase karilysin present in the majority of Tannerella forsythia isolates inhibits all pathways of the complement system. J Immunol 188: 2338-2349.

Kalant D, Cain SA, Maslowska M, Sniderman AD, Cianflone K, and Monk PN (2003) The chemoattractant receptor-like protein C5L2 binds the C3a des-Arg77/ acylation-stimulating protein. J Biol Chem 278:11123-11129.

Kalant D, MacLaren R, Cui W, Samanta R, Monk PN, Laporte SA, and Cianflone K (2005) C5L2 is a functional receptor for acylation-stimulating protein. J Biol Chem 280:23936-23944.

Kanmura S, Uto H, Sato Y, Kumagai K, Sasaki F, Moriuchi A, Oketani M, Ido A Nagata K, and Hayashi K, et al. (2010) The complement component C3a fragment is a potential biomarker for hepatitis $\mathrm{C}$ virus-related hepatocellular carcinoma. $J$ Gastroenterol 45:459-467.

Kanse SM, Gallenmueller A, Zeerleder S, Stephan F, Rannou O, Denk S, Etscheid M, Lochnit G, Krueger M, and Huber-Lang M (2012) Factor VII-activating protease is activated in multiple trauma patients and generates anaphylatoxin C5a. $J$ Immunol 188:2858-2865. 
Kashem SW, Subramanian H, Collington SJ, Magotti P, Lambris JD, and Ali H (2011) G protein coupled receptor specificity for C3a and compound 48/80-induced degranulation in human mast cells: roles of Mas-related genes MrgX1 and MrgX2. Eur J Pharmacol 668:299-304.

Kawai M, Quincy DA, Lane B, Mollison KW, Luly JR, and Carter GW (1991) Identification and synthesis of a receptor binding site of human anaphylatoxin C5a. $J$ Med Chem 34:2068-2071.

Kawai M, Quincy DA, Lane B, Mollison KW, Or YS, Luly JR, and Carter GW (1992) Structure-function studies in a series of carboxyl-terminal octapeptide analogues of anaphylatoxin C5a. J Med Chem 35:220-223.

Kawatsu R, Sanderson SD, Blanco I, Kendall N, Finch AM, Taylor SM, and Colcher D (1996) Conformationally biased analogs of human C5a mediate changes in vascular permeability. J Pharmacol Exp Ther 278:432-440.

Kershaw EE and Flier JS (2004) Adipose tissue as an endocrine organ. $J$ Clin Endocrinol Metab 89:2548-2556.

Klco JM, Lassere TB, and Baranski TJ (2003) C5a receptor oligomerization. I Disulfide trapping reveals oligomers and potential contact surfaces in a $\mathrm{G}$ proteincoupled receptor. J Biol Chem 278:35345-35353.

Klco JM, Nikiforovich GV, and Baranski TJ (2006) Genetic analysis of the first and third extracellular loops of the C5a receptor reveals an essential WXFG motif in the first loop. J Biol Chem 281:12010-12019.

Klco JM, Wiegand CB, Narzinski K, and Baranski TJ (2005) Essential role for the second extracellular loop in C5a receptor activation. Nat Struct Mol Biol 12 $320-326$.

Klos A, Bank S, Gietz C, Bautsch W, Köhl J, Burg M, and Kretzschmar T (1992) C3a receptor on dibutyryl-cAMP-differentiated U937 cells and human neutrophils: the human C3a receptor characterized by functional responses and 125I-C3a binding. Biochemistry 31:11274-11282.

Klos A, Ihrig V, Messner M, Grabbe J, and Bitter-Suermann D (1988) Detection of native human complement components C3 and C5 and their primary activation peptides C3a and C5a (anaphylatoxic peptides) by ELISAs with monoclonal antibodies. J Immunol Methods 111:241-252.

Klos A, Tenner AJ, Johswich KO, Ager RR, Reis ES, and Köhl J (2009) The role of the anaphylatoxins in health and disease. Mol Immunol 46:2753-2766.

Köhl J, Casaretto M, Gier M, Karwath G, Gietz C, Bautsch W, Saunders D, and Bitter-Suermann D (1990) Reevaluation of the C3a active site using short synthetic C3a analogues. Eur J Immunol 20:1463-1468.

Koistinen HA, Vidal H, Karonen SL, Dusserre E, Vallier P, Koivisto VA, and Ebeling P (2001) Plasma acylation stimulating protein concentration and subcutaneous adipose tissue C3 mRNA expression in nondiabetic and type 2 diabetic men. Arterioscler Thromb Vasc Biol 21:1034-1039.

Konteatis ZD, Siciliano SJ, Van Riper G, Molineaux CJ, Pandya S, Fischer P, Rosen H, Mumford RA, and Springer MS (1994) Development of C5a receptor antagonists. Differential loss of functional responses. J Immunol 153:4200-4205.

Koski P, Rhen M, Kantele J, and Vaara M (1989) Isolation, cloning, and primary structure of a cationic $16-\mathrm{kDa}$ outer membrane protein of Salmonella typhimurium. J Biol Chem 264:18973-18980.

Kourtzelis I, Markiewski MM, Doumas M, Rafail S, Kambas K, Mitroulis I, Panagoutsos S, Passadakis P, Vargemezis V, and Magotti P, et al. (2010) Complement anaphylatoxin C5a contributes to hemodialysis-associated thrombosis. Blood 116 $631-639$.

Kretzschmar T, Pohl M, Casaretto M, Przewosny M, Bautsch W, Klos A, Saunders D, and Köhl J (1992) Synthetic peptides as antagonists of the anaphylatoxin C3a. Eur $J$ Biochem 210:185-191.

Krishnan V, Xu Y, Macon K, Volanakis JE, and Narayana SV (2009) The structure of $\mathrm{C} 2 \mathrm{~b}$, a fragment of complement component C2 produced during C3 convertase formation. Acta Crystallogr D Biol Crystallogr 65:266-274.

Kristiansen K (2004) Molecular mechanisms of ligand binding, signaling, and regulation within the superfamily of G-protein-coupled receptors: molecular modeling and mutagenesis approaches to receptor structure and function. Pharmacol Ther 103:21-80.

Lagane B, Ballet S, Planchenault T, Balabanian K, Le Poul E, Blanpain C, Percherancier Y, Staropoli I, Vassart G, and Oppermann M, et al. (2005) Mutation of the DRY motif reveals different structural requirements for the CC chemokine receptor 5-mediated signaling and receptor endocytosis. Mol Pharmacol 67: 1966-1976.

Lajoie S, Lewkowich IP, Suzuki Y, Clark JR, Sproles AA, Dienger K, Budelsky AL, and Wills-Karp M (2010) Complement-mediated regulation of the IL-17A axis is a central genetic determinant of the severity of experimental allergic asthma. Nat Immunol 11:928-935.

Lalli PN, Strainic MG, Yang M, Lin F, Medof ME, and Heeger PS (2008) Locally produced C5a binds to T cell-expressed C5aR to enhance effector T-cell expansion by limiting antigen-induced apoptosis. Blood 112:1759-1766.

Langkabel P, Zwirner J, and Oppermann M (1999) Ligand-induced phosphorylation of anaphylatoxin receptors $\mathrm{C} 3 \mathrm{aR}$ and $\mathrm{C} 5 \mathrm{aR}$ is mediated by " $\mathrm{G}$ protein-coupled receptor kinases. Eur J Immunol 29:3035-3046.

Langone JJ, Das C, Bennett D, and Terman DS (1984) Generation of human C3a, C4a, and C5a anaphylatoxins by protein A of Staphylococcus aureus and immobilized protein A reagents used in serotherapy of cancer. $J$ Immunol 133: $1057-1063$.

Lanza TJ, Durette PL, Rollins T, Siciliano S, Cianciarulo DN, Kobayashi SV, Caldwell CG, Springer MS, and Hagmann WK (1992) Substituted 4,6-diaminoquinolines as inhibitors of C5a receptor binding. J Med Chem 35:252-258.

Lappas M (2011) Lower circulating levels of complement split proteins C3a and C4a in maternal plasma of women with gestational diabetes mellitus. Diabet Med 28: 906-911.

Larkin MA, Blackshields G, Brown NP, Chenna R, McGettigan PA, McWilliam H Valentin F, Wallace IM, Wilm A, and Lopez R, et al. (2007) Clustal W and Clustal X version 2.0. Bioinformatics 23:2947-2948.
Lee DK, George SR, Cheng R, Nguyen T, Liu Y, Brown M, Lynch KR, and O'Dowd BF (2001) Identification of four novel human $\mathrm{G}$ protein-coupled receptors expressed in the brain. Brain Res Mol Brain Res 86:13-22

Lee H, Whitfeld PL, and Mackay CR (2008) Receptors for complement C5a. The importance of C5aR and the enigmatic role of C5L2. Immunol Cell Biol 86 153-160.

Lee HM, Wu W, Wysoczynski M, Liu R, Zuba-Surma EK, Kucia M, Ratajczak J, and Ratajczak MZ (2009) Impaired mobilization of hematopoietic stem/progenitor cells in C5-deficient mice supports the pivotal involvement of innate immunity in this process and reveals novel promobilization effects of granulocytes. Leukemia 23:2052-2062.

Lee IN, Chen CH, Sheu JC, Lee HS, Huang GT, Chen DS, Yu CY, Wen CL, Lu FJ, and Chow LP (2006a) Identification of complement C3a as a candidate biomarker in human chronic hepatitis $\mathrm{C}$ and HCV-related hepatocellular carcinoma using a proteomics approach. Proteomics 6:2865-2873.

Lee JS, Frevert CW, Wurfel MM, Peiper SC, Wong VA, Ballman KK, Ruzinski JT, Rhim JS, Martin TR, and Goodman RB (2003) Duffy antigen facilitates movement of chemokine across the endothelium in vitro and promotes neutrophil transmigration in vitro and in vivo. $J$ Immunol 170:5244-5251.

Lee SH, Rhim T, Choi YS, Min JW, Kim SH, Cho SY, Paik YK, and Park CS (2006b) Complement $\mathrm{C} 3 \mathrm{a}$ and $\mathrm{C} 4 \mathrm{a}$ increased in plasma of patients with aspirin-induced asthma. Am J Respir Crit Care Med 173:370-378.

Leick M, Catusse J, Follo M, Nibbs RJ, Hartmann TN, Veelken H, and Burger M (2010) CCL19 is a specific ligand of the constitutively recycling atypical human chemokine receptor CRAM-B. Immunology 129:536-546.

Leung LL, Nishimura T, and Myles T (2008) Regulation of tissue inflammation by thrombin-activatable carboxypeptidase B (or TAFI). Adv Exp Med Biol 632:61-69. Levin Y, Skidgel RA, and Erdös EG (1982) Isolation and characterization of the subunits of human plasma carboxypeptidase N (kininase i). Proc Natl Acad Sci USA 79:4618-4622.

Levoye A, Balabanian K, Baleux F, Bachelerie F, and Lagane B (2009) CXCR7 heterodimerizes with CXCR4 and regulates CXCL12-mediated G protein signaling. Blood 113:6085-6093.

Lewis AG, Köhl G, Ma Q, Devarajan P, and Köhl J (2008) Pharmacological targeting of C5a receptors during organ preservation improves kidney graft survival. Clin Exp Immunol 153:117-126.

Li K, Anderson KJ, Peng Q, Noble A, Lu B, Kelly AP, Wang N, Sacks SH, and Zhou W (2008) Cyclic AMP plays a critical role in C3a-receptor-mediated regulation of dendritic cells in antigen uptake and T-cell stimulation. Blood 112:5084-5094.

Li Q, Peng Q, Xing G, Li K, Wang N, Farrar CA, Meader L, Sacks SH, and Zhou W (2010) Deficiency of C5aR prolongs renal allograft survival. J Am Soc Nephrol 21: 1344-1353.

Liang S, Krauss JL, Domon H, McIntosh ML, Hosur KB, Qu H, Li F, Tzekou A Lambris JD, and Hajishengallis G (2011) The C5a receptor impairs IL-12dependent clearance of Porphyromonas gingivalis and is required for induction of periodontal bone loss. J Immunol 186:869-877.

Lienenklaus S, Ames RS, Tornetta MA, Sarau HM, Foley JJ, Crass T, Sohns B, Raffetseder U, Grove M, and Hölzer A, et al. (1998) Human anaphylatoxin C4a is a potent agonist of the guinea pig but not the human C3a receptor. J Immunol 161: 2089-2093.

Liu B, Wei L, Meyerle C, and Tuo JSen HN, Li Z, Chakrabarty S, Agron E, Chan CC, and Klein ML, et al. (2011a) Complement component C5a promotes expression of IL-22 and IL-17 from human T cells and its implication in age-related macular degeneration. J Transl Med 9:1-12

Liu F, Gou R, Huang J, and Fu P (2011b) The effect of C3a, C5a and their receptor antagonists on the expression of beta-catenin in renal tubular cells [article in Chinese]. Sichuan Da Xue Xue Bao Yi Xue Ban 42:74-77.

Liu J, Lin F, Strainic MG, An F, Miller RH, Altuntas CZ, Heeger PS, Tuohy VK, and Medof ME (2008) IFN-gamma and IL-17 production in experimental autoimmune encephalomyelitis depends on local APC-T cell complement production. $J$ Immunol 180:5882-5889.

Liu ZJ, Yang YJ, Jiang L, Xu YC, Wang AX, Du GH, and Gao JM (2011c) Tyrosine sulfation in N-terminal domain of human C5a receptor is necessary for binding of chemotaxis inhibitory protein of Staphylococcus aureus. Acta Pharmacol Sin 32 1038-1044.

Locati M, Torre YM, Galliera E, Bonecchi R, Bodduluri H, Vago G, Vecchi A and Mantovani A (2005) Silent chemoattractant receptors: D6 as a decoy and scavenger receptor for inflammatory CC chemokines. Cytokine Growth Factor Rev 16:679-686.

Lohse MJ, Benovic JL, Codina J, Caron MG, and Lefkowitz RJ (1990) $\beta$-Arrestin: a protein that regulates $\beta$-adrenergic receptor function. Science 248:1547-1550.

Lu ZX, Fok KF, Erickson BW, and Hugli TE (1984) Conformational analysis of $\mathrm{COOH}$-terminal segments of human C3a. Evidence of ordered conformation in an active 21-residue peptide. J Biol Chem 259:7367-7370.

Luo Y, Zeng Q, Glisson JR, Jackwood MW, Cheng IH, and Wang C (1999) Sequence analysis of Pasteurella multocida major outer membrane protein $(\mathrm{OmpH})$ and application of synthetic peptides in vaccination of chickens against homologous strain challenge. Vaccine 17:821-831.

Lynch AM, Gibbs RS, Murphy JR, Giclas PC, Salmon JE, and Holers VM (2011) Early elevations of the complement activation fragment C3a and adverse pregnancy outcomes. Obstet Gynecol 117:75-83.

Machalińska A, Dziedziejko V, Mozolewska-Piotrowska K, Karczewicz D, Wiszniewska B, and Machaliński B (2009) Elevated plasma levels of C3a complement compound in the exudative form of age-related macular degeneration. Ophthalmic Res 42:54-59.

Mack WJ, Ducruet AF, Hickman ZL, Garrett MC, Albert EJ, Kellner CP, Mocco J, and Connolly ES Jr. (2007) Early plasma complement C3a levels correlate with functional outcome after aneurysmal subarachnoid hemorrhage. Neurosurgery 61 255-260, discussion 260-261. 
MacLaren R, Cui W, and Cianflone K (2008) Adipokines and the immune system: an adipocentric view. Adv Exp Med Biol 632:1-21.

Magen E, Feldman A, Cohen Z, Alon DB, Linov L, Mishal J, and Schlezinger M (2010) Potential link between C3a, C3b and endothelial progenitor cells in resistant hypertension. Am J Med Sci 339:415-419.

Maher SG, McDowell DT, Collins BC, Muldoon C, Gallagher WM, and Reynolds JV (2011) Serum proteomic profiling reveals that pretreatment complement protein levels are predictive of esophageal cancer patient response to neoadjuvant chemoradiation. Ann Surg 254:809-816, discussion 816-817.

Malmsten M and Schmidtchen A (2007) Antimicrobial C3a-biology, biophysics, and evolution. Adv Exp Med Biol 598:141-158.

Mamane Y, Chung Chan C, Lavallee G, Lavallee G, Morin N, Xu LJ, Huang J, Gordon R, Thomas W, and Lamb J, et al. (2009) The C3a anaphylatoxin receptor is a key mediator of insulin resistance and functions by modulating adipose tissue macrophage infiltration and activation. Diabetes 58:2006-2017.

Manabe I (2011) Chronic inflammation links cardiovascular, metabolic and renal diseases. Circ J 75:2739-2748.

Manthey HD, Thomas AC, Shiels IA, Zernecke A, Woodruff TM, Rolfe B, and Taylor $\mathrm{SM}$ (2011) Complement C5a inhibition reduces atherosclerosis in $\mathrm{ApoE}^{-1-}$ mice. FASEB J 25:2447-2455.

Marc MM, Korosec P, Kosnik M, Kern I, Flezar M, Suskovic S, and Sorli J (2004) Complement factors c3a, c4a, and c5a in chronic obstructive pulmonary disease and asthma. Am J Respir Cell Mol Biol 31:216-219.

Marc MM, Kristan SS, Rozman A, Kern I, Flezar M, Kosnik M, and Korosec P (2010) Complement factor C5a in acute exacerbation of chronic obstructive pulmonary disease. Scand J Immunol 71:386-391.

Marcil M, Vu H, Cui W, Dastani Z, Engert JC, Gaudet D, Castro-Cabezas M, Sniderman AD, Genest J Jr, and Cianflone K (2006) Identification of a novel C5L2 variant (S323I) in a French Canadian family with familial combined hyperlipemia. Arterioscler Thromb Vasc Biol 26:1619-1625.

Martin CB, Ingersoll SA, and Martin BK (2007a) Regulation of the C5a receptor promoter in glial cells: minimal dependence upon the CCAAT element in astrocytes. Mol Immunol 44:713-721.

Martin CB, Ingersoll SA, and Martin BK (2007b) Transcriptional control of the C3a receptor gene in glial cells: dependence upon AP-1 but not Ets. Mol Immunol 44: $703-712$.

Martin CB and Martin BK (2005) Characterization of the murine C3a receptor enhancer-promoter: expression control by an activator protein 1 sequence and an Ets-like site. J Immunol 175:3123-3132.

Martin U, Bock D, Arseniev L, Tornetta MA, Ames RS, Bautsch W, Köhl J, Ganser A, and Klos A (1997) The human C3a receptor is expressed on neutrophils and monocytes, but not on B or T lymphocytes. J Exp Med 186:199-207.

Martinus RD and Cook CJ (2011) The effect of complement C5a on mitochondrial functions of PC12 cells. Neuroreport 22:581-585.

Maruo K, Akaike T, Ono T, Okamoto T, and Maeda H (1997) Generation of anaphylatoxins through proteolytic processing of C3 and C5 by house dust mite protease. J Allergy Clin Immunol 100:253-260.

Maslowska M, Wang HW, and Cianflone K (2005) Novel roles for acylation stimulating protein/C3adesArg: a review of recent in vitro and in vivo evidence. Vitam Horm 70:309-332.

Mathieu MC, Sawyer N, Greig GM, Hamel M, Kargman S, Ducharme Y, Lau CK Friesen RW, O'Neill GP, Gervais FG, and Therien AG (2005) The C3a receptor antagonist SB 290157 has agonist activity. Immunol Lett 100:139-145.

Matsubara S, Yamamoto T, Tsuruta T, Takagi K, and Kambara T (1991) Complement C4-derived monocyte-directed chemotaxis-inhibitory factor. A molecular mechanism to cause polymorphonuclear leukocyte-predominant infiltration in rheumatoid arthritis synovial cavities. Am J Pathol 138:1279-1291.

Matsumoto ML, Narzinski K, Kiser PD, Nikiforovich GV, and Baranski TJ (2007a) A comprehensive structure-function map of the intracellular surface of the human C5a receptor. I. Identification of critical residues. J Biol Chem 282:3105-3121.

Matsumoto ML, Narzinski K, Nikiforovich GV, and Baranski TJ (2007b) A comprehensive structure-function map of the intracellular surface of the human C5a receptor. II. Elucidation of $\mathrm{G}$ protein specificity determinants. J Biol Chem 282: 3122-3133.

Matthan NR, Cianflone K, Lichtenstein AH, Ausman LM, Jauhiainen M, and Jones PJ (2001) Hydrogenated fat consumption affects acylation-stimulating protein levels and cholesterol esterification rates in moderately hypercholesterolemic women. J Lipid Res 42:1841-1848.

Melendez AJ and Ibrahim FB (2004) Antisense knockdown of sphingosine kinase 1 in human macrophages inhibits $\mathrm{C} 5$ a receptor-dependent signal transduction, $\mathrm{Ca}^{2+}$ signals, enzyme release, cytokine production, and chemotaxis. J Immunol 173: $1596-1603$

Melillo D, Sfyroera G, De Santis R, Graziano R, Marino R, Lambris JD, and Pinto MR (2006) First identification of a chemotactic receptor in an invertebrate species: structural and functional characterization of Ciona intestinalis C3a receptor. $J$ Immunol 177:4132-4140.

Mery L and Boulay F (1994) The NH2-terminal region of C5aR but not that of FPR is critical for both protein transport and ligand binding. J Biol Chem 269:3457-3463.

Middleton J, Neil S, Wintle J, Clark-Lewis I, Moore H, Lam C, Auer M, Hub E, and Rot A (1997) Transcytosis and surface presentation of IL-8 by venular endothelial cells. Cell 91:385-395.

Delisle Milton RC, Milton SC, and Chamberlin AR (2011) Improving the Fmoc solid phase synthesis of the cyclic hexapeptide complement C5a antagonist, PMX205. Int $J$ Pept Res Ther 17:337-342.

Mizuno M, Blanchin S, Gasque P, Nishikawa K, and Matsuo S (2007) High levels of complement C3a receptor in the glomeruli in lupus nephritis. Am J Kidney Dis 49 598-606.

Mizutani N, Goshima H, Nabe T, and Yoshino S (2012) Establishment and characterization of a murine model for allergic asthma using allergen-specific IgE monoclonal antibody to study pathological roles of IgE. Immunol Lett 141:235-245.
Mizutani N, Nabe T, and Yoshino S (2009) Complement C3a regulates late asthmatic response and airway hyperresponsiveness in mice. J Immunol 183:4039-4046.

Mocco J, Mack WJ, Ducruet AF, Sosunov SA, Sughrue ME, Hassid BG, Nair MN, Laufer I, Komotar RJ, and Claire M, et al. (2006) Complement component C3 mediates inflammatory injury following focal cerebral ischemia. Circ Res 99: 209-217.

Moll G, Jitschin R, von Bahr L, Rasmusson-Duprez I, Sundberg B, Lönnies L, Elgue G, Nilsson-Ekdahl K, Mougiakakos D, and Lambris JD, et al. (2011) Mesenchyma stromal cells engage complement and complement receptor bearing innate effector cells to modulate immune responses. PLoS ONE 6:e21703.

Möller T, Nolte C, Burger R, Verkhratsky A, and Kettenmann H (1997) Mechanisms of C5a and C3a complement fragment-induced $\left[\mathrm{Ca}^{2+}\right]$ i signaling in mouse microglia. J Neurosci 17:615-624.

Mollison KW, Mandecki W, Zuiderweg ER, Fayer L, Fey TA, Krause RA, Conway RG, Miller L, Edalji RP, and Shallcross MA, et al. (1989) Identification of receptorbinding residues in the inflammatory complement protein C5a by site-directed mutagenesis. Proc Natl Acad Sci USA 86:292-296.

Mondino BJ, Sidikaro Y, Mayer FJ, and Sumner HL (1990) Inflammatory mediators in the vitreous humor of AIDS patients with retinitis. Invest Ophthalmol Vis Sci 31:798-804.

Mondino BJ, Sidikaro Y, and Sumner H (1988) Anaphylatoxin levels in human vitreous humor. Invest Ophthalmol Vis Sci 29:1195-1198.

Mondino BJ and Sumner HL (1990) Generation of complement-derived anaphylatoxins in normal human donor corneas. Invest Ophthalmol Vis Sci 31:1945-1949.

Monk PN, Barker MD, Partridge LJ, and Pease JE(1995) Mutation of glutamate 199 of the human C5a receptor defines a binding site for ligand distinct from the receptor N terminus. J Biol Chem 270:16625-16629.

Monk PN and Partridge LJ (1993) Characterization of a complement-fragment-C5astimulated calcium-influx mechanism in U937 monocytic cells. Biochem $J$ 295: 679-684.

Monk PN, Pease JE, and Barker MD (1994) C5a stimulus-secretion coupling in rat basophilic leukaemia (RBL-2H3) cells transfected with the human C5a receptor is mediated by pertussis and cholera toxin-sensitive $\mathrm{G}$ proteins. Biochem Mol Biol Int 32:13-20.

Monk PN, Scola AM, Madala P, and Fairlie DP (2007) Function, structure and therapeutic potential of complement C5a receptors. Br J Pharmacol 152:429-448. Moon KE, Gorski JP, and Hugli TE (1981) Complete primary structure of human C4a anaphylatoxin. J Biol Chem 256:8685-8692.

Morgan M, Bulmer AC, Woodruff TM, Proctor LM, Williams HM, Stocks SZ, Pollitt S, Taylor SM, and Shiels IA (2008) Pharmacokinetics of a C5a receptor antagonist in the rat after different sites of enteral administration. Eur J Pharm Sci 33:390-398.

Moxley G and Ruddy S (1985) Elevated C3 anaphylatoxin levels in synovial fluids from patients with rheumatoid arthritis. Arthritis Rheum 28:1089-1095.

Mueller-Ortiz SL, Hollmann TJ, Haviland DL, and Wetsel RA (2006) Ablation of the complement C3a anaphylatoxin receptor causes enhanced killing of Pseudomonas aeruginosa in a mouse model of pneumonia. Am J Physiol Lung Cell Mol Physiol 291:L157-L165.

Mullick A, Tremblay J, Leon Z, and Gros P (2011) A novel role for the fifth component of complement (C5) in cardiac physiology. PLoS ONE 6:e22919.

Murakami Y, Yamamoto T, Imamichi T, and Nagasawa S (1993) Cellular responses of guinea-pig macrophages to $\mathrm{C} 4 \mathrm{a}$; inhibition of $\mathrm{C} 3 \mathrm{a}$-induced $\mathrm{O} 2$ - generation by C4a. Immunol Lett 36:301-304.

Murray I, Havel PJ, Sniderman AD, and Cianflone K (2000) Reduced body weight, adipose tissue, and leptin levels despite increased energy intake in female mice lacking acylation-stimulating protein. Endocrinology 141:1041-1049.

Murray I, Köhl J, and Cianflone K (1999a) Acylation-stimulating protein (ASP): structure-function determinants of cell surface binding and triacylglycerol synthetic activity. Biochem $J$ 342:41-48.

Murray I, Parker RA, Kirchgessner TG, Tran J, Zhang ZJ, Westerlund J, and Cianflone K (1997) Functional bioactive recombinant acylation stimulating protein is distinct from C3a anaphylatoxin. J Lipid Res 38:2492-2501.

Murray I, Sniderman AD, and Cianflone K (1999b) Enhanced triglyceride clearance with intraperitoneal human acylation stimulating protein in C57BL/6 mice. Am J Physiol 277:E474-E480.

Murray I, Sniderman AD, and Cianflone K (1999c) Mice lacking acylation stimulating protein (ASP) have delayed postprandial triglyceride clearance. J Lipid Res 40:1671-1676.

Murray I, Sniderman AD, Havel PJ, and Cianflone K (1999d) Acylation stimulating protein (ASP) deficiency alters postprandial and adipose tissue metabolism in male mice. $J$ Biol Chem 274:36219-36225.

Muto M, Mashimo M, Urabe K, Suzuki T, and Sasazuki T (1991) Correlation between HLA-A2-Bw46-DRw8 haplotype and increased levels of complement components (C4 and C4a) in patients with psoriatic arthritis. Arch Dermatol Res 283:347-349

Naik N, Giannini E, Brouchon L, and Boulay F (1997) Internalization and recycling of the C5a anaphylatoxin receptor: evidence that the agonist-mediated internalization is modulated by phosphorylation of the C-terminal domain. J Cell Sci 110:2381-2390

Nakae H, Endo S, Inada K, and Yoshida M (1996) Chronological changes in the complement system in sepsis. Surg Today 26:225-229.

Nettesheim DG, Edalji RP, Mollison KW, Greer J, and Zuiderweg ER (1988) Secondary structure of complement component C3a anaphylatoxin in solution as determined by NMR spectroscopy: differences between crystal and solution conformations. Proc Natl Acad Sci USA 85:5036-5040.

Nezlin R and Freywald A (1992) Complexes of IgG molecules and C3a and C4a complement components in human serum. Eur J Immunol 22:1955-1957.

Nibbs R, Graham G, and Rot A (2003) Chemokines on the move: control by the chemokine "interceptors" Duffy blood group antigen and D6. Semin Immunol $\mathbf{1 5}$ 287-294.

Nibbs RJ, Wylie SM, Pragnell IB, and Graham GJ (1997) Cloning and characterization of a novel murine beta chemokine receptor, D6. Comparison to three other 
related macrophage inflammatory protein-1alpha receptors, CCR-1, CCR-3, and CCR-5. J Biol Chem 272:12495-12504.

Nijs J, Van Oosterwijck J, Meeus M, Lambrecht L, Metzger K, Frémont M, and Paul L (2010) Unravelling the nature of postexertional malaise in myalgic encephalomyelitis/chronic fatigue syndrome: the role of elastase, complement C4a and interleukin-1beta. J Intern Med 267:418-435.

Nikiforovich GV and Baranski TJ (2012) Structural mechanisms of constitutive activation in the C5a receptors with mutations in the extracellular loops: molecular modeling study. Proteins 80:71-80.

Nikiforovich GV, Marshall GR, and Baranski TJ (2008) Modeling molecular mechanisms of binding of the anaphylatoxin C5a to the C5a receptor. Biochemistry 47: 3117-3130.

Nikiforovich GV, Marshall GR, and Baranski TJ (2011) Simplified modeling approach suggests structural mechanisms for constitutive activation of the C5a receptor. Proteins 79:787-802.

Nilsson G, Johnell M, Hammer CH, Tiffany HL, Nilsson K, Metcalfe DD, Siegbahn A, and Murphy PM (1996) C3a and C5a are chemotaxins for human mast cells and act through distinct receptors via a pertussis toxin-sensitive signal transduction pathway. J Immunol 157:1693-1698.

Nishimura T, Horino K, Nishiura H, Shibuya Y, Hiraoka T, Tanase S, and Yamamoto $\mathrm{T}$ (2001) Apoptotic cells of an epithelial cell line, AsPC-1, release monocyte chemotactic S19 ribosomal protein dimer. J Biochem 129:445-454.

Nishimura T, Myles T, Piliponsky AM, Kao PN, Berry GJ, and Leung LL (2007) Thrombin-activatable procarboxypeptidase B regulates activated complement C5a in vivo. Blood 109:1992-1997.

Nishiura H, Chen J, Ota Y, Semba U, Higuchi H, Nakashima T, and Yamamoto T (2010a) Base of molecular mimicry between human ribosomal protein S19 dimer and human C5a anaphylatoxin. Int Immunopharmacol 10:1541-1547.

Nishiura H, Shibuya Y, Matsubara S, Tanase S, Kambara T, and Yamamoto T (1996) Monocyte chemotactic factor in rheumatoid arthritis synovial tissue. Probably a cross-linked derivative of S19 ribosomal protein. J Biol Chem 271:878-882.

Nishiura H, Shibuya Y, and Yamamoto T (1998) S19 ribosomal protein cross-linked dimer causes monocyte-predominant infiltration by means of molecular mimicry to complement C5a. Lab Invest 78:1615-1623.

Nishiura H, Tanase S, Shibuya Y, Futa N, Sakamoto T, Higginbottom A, Monk P, Zwirner J, and Yamamoto T (2005) S19 ribosomal protein dimer augments metalinduced apoptosis in a mouse fibroblastic cell line by ligation of the C5a receptor. $J$ Cell Biochem 94:540-553.

Nishiura H, Tokita K, Li Y, Harada K, Woodruff TM, Taylor SM, Nsiama TK, Nishino $\mathrm{N}$, and Yamamoto $\mathrm{T}(2010 \mathrm{~b})$ The role of the ribosomal protein S19 C-terminus in $\mathrm{Gi}$ protein-dependent alternative activation of p38 MAP kinase via the C5a receptor in HMC-1 cells. Apoptosis 15:966-981.

Nishiura H, Zhao R, and Yamamoto T (2011) The role of the ribosomal protein S19 Cterminus in altering the chemotaxis of leucocytes by causing functional differences in the C5a receptor response. J Biochem 150:271-277.

Nitta H, Imamura T, Wada Y, Irie A, Kobayashi H, Okamoto K, and Baba H (2008) Production of C5a by ASP, a serine protease released from Aeromonas sobria. $J$ Immunol 181:3602-3608.

Nordahl EA, Rydengård V, Nyberg P, Nitsche DP, Mörgelin M, Malmsten M, Björck $\mathrm{L}$, and Schmidtchen A (2004) Activation of the complement system generates antibacterial peptides. Proc Natl Acad Sci USA 101:16879-16884.

Norgauer J, Dobos G, Kownatzki E, Dahinden C, Burger R, Kupper R, and Gierschik $\mathrm{P}$ (1993) Complement fragment C3a stimulates $\mathrm{Ca}^{2+}$ influx in neutrophils via a pertussis-toxin-sensitive G protein. Eur J Biochem 217:289-294.

Oda T, Kojima Y, Akaike T, Ijiri S, Molla A, and Maeda H (1990) Inactivation of chemotactic activity of C5a by the serratial 56-kilodalton protease. Infect Immun 58:1269-1272.

Oda Y, Tokita K, Ota Y, Li Y, Taniguchi K, Nishino N, Takagi K, Yamamoto T, and Nishiura H (2008) Agonistic and antagonistic effects of C5a-chimera bearing S19 ribosomal protein tail portion on the C5a receptor of monocytes and neutrophils, respectively. $J$ Biochem 144:371-381.

Ohinata K, Inui A, Asakawa A, Wada K, Wada E, and Yoshikawa M (2002) Albutensin A and complement C3a decrease food intake in mice. Peptides 23:127-133. Ohinata K, Suetsugu K, Fujiwara Y, and Yoshikawa M (2007) Suppression of food intake by a complement C3a agonist [Trp5]-oryzatensin(5-9). Peptides 28:602-606.

Ohinata K, Takagi K, Biyajima K, Kaneko K, Miyamoto C, Asakawa A, Eguchi N, Urade Y, Inui A, and Yoshikawa M (2009) Complement C5a stimulates food intake via a prostaglandin $\mathrm{D}(2)$ - and neuropeptide Y-dependent mechanism in mice. Prostaglandins Other Lipid Mediat 90:81-84.

Ohinata K and Yoshikawa M (2008) Food intake regulation by central complement system. Adv Exp Med Biol 632:35-46.

Ohno M, Hirata T, Enomoto M, Araki T, Ishimaru H, and Takahashi TA (2000) A putative chemoattractant receptor, C5L2, is expressed in granulocyte and immature dendritic cells, but not in mature dendritic cells. Mol Immunol 37:407-412.

Ohta R, Torii Y, Imai M, Kimura H, Okada N, and Ito Y (2011) Serum concentrations of complement anaphylatoxins and proinflammatory mediators in patients with 2009 H1N1 influenza. Microbiol Immunol 55:191-198.

Oikonomopoulou K, Ricklin D, Ward PA, and Lambris JD (2012) Interactions between coagulation and complement-their role in inflammation. Semin Immunopathol 34:151-165.

Okinaga S, Slattery D, Humbles A, Zsengeller Z, Morteau O, Kinrade MB, Brodbeck RM, Krause JE, Choe HR, Gerard NP, and Gerard C (2003) C5L2, a nonsignaling C5A binding protein. Biochemistry 42:9406-9415.

Oksjoki R, Laine P, Helske S, Vehmaan-Kreula P, Mäyränpää MI, Gasque P, Kovanen PT, and Pentikäinen MO (2007) Receptors for the anaphylatoxins C3a and C5a are expressed in human atherosclerotic coronary plaques. Atherosclerosis 195:90-99

Oliveira L, Paiva AC, Sander C, and Vriend G (1994) A common step for signal transduction in G protein-coupled receptors. Trends Pharmacol Sci 15:170-172.
Onat A, Can G, Rezvani R, and Cianflone K (2011) Complement C3 and cleavage products in cardiometabolic risk. Clin Chim Acta 412:1171-1179.

Oppermann M and Götze O (1994) Plasma clearance of the human C5a anaphylatoxin by binding to leucocyte C5a receptors. Immunology 82:516-521.

Oppermann M, Raedt U, Hebell T, Schmidt B, Zimmermann B, and Götze O (1993) Probing the human receptor for $\mathrm{C} 5 \mathrm{a}$ anaphylatoxin with site-directed antibodies. Identification of a potential ligand binding site on the NH2-terminal domain. $J$ Immunol 151:3785-3794.

Otto M, Hawlisch H, Monk PN, Müller M, Klos A, Karp CL, and Köhl J (2004) C5a mutants are potent antagonists of the C5a receptor (CD88) and of C5L2: position 69 is the locus that determines agonism or antagonism. J Biol Chem 279:142-151. Ottonello L, Corcione A, Tortolina G, Airoldi I, Albesiano E, Favre A, D'Agostino R, Malavasi F, Pistoia V, and Dallegri F (1999) rC5a directs the in vitro migration of human memory and naive tonsillar B lymphocytes: implications for B cell trafficking in secondary lymphoid tissues. J Immunol 162:6510-6517.

Ouchi N, Parker JL, Lugus JJ, and Walsh K (2011) Adipokines in inflammation and metabolic disease. Nat Rev Immunol 11:85-97.

Paglialunga S, Fisette A, Munkonda M, Gao Y, Richard D, and Cianflone K (2010) The effects of acylation stimulating protein supplementation VS antibody neutralization on energy expenditure in wildtype mice. BMC Physiol 10:4.

Paglialunga S, Schrauwen P, Roy C, Moonen-Kornips E, Lu H, Hesselink MK Deshaies Y, Richard D, and Cianflone K (2007) Reduced adipose tissue triglyceride synthesis and increased muscle fatty acid oxidation in C5L2 knockout mice. $J$ Endocrinol 194:293-304.

Palmer E, Gray LC, Stott M, Bowen DJ, and van den Berg CW (2012) Roles of promoter and $3^{\prime}$ untranslated motifs in expression of the human C5a receptor. Mol Immunol 52:88-95.

Pâques EP, Scholze H, and Huber R (1980) Purification and crystallization of human anaphylatoxin, C3a. Hoppe Seylers $Z$ Physiol Chem 361:977-980.

Paral D, Sohns B, Crass T, Grove M, Köhl J, Klos A, and Bautsch W (1998) Genomic organization of the human C3a receptor. Eur J Immunol 28:2417-2423.

Pasupuleti M, Walse B, Nordahl EA, Mörgelin M, Malmsten M, and Schmidtchen A (2007) Preservation of antimicrobial properties of complement peptide C3a, from invertebrates to humans. J Biol Chem 282:2520-2528.

Pasupuleti M, Walse B, Svensson B, Malmsten M, and Schmidtchen A (2008) Rational design of antimicrobial C3a analogues with enhanced effects against Staphylococci using an integrated structure and function-based approach. Biochemistry 47:9057-9070.

Patel SN, Berghout J, Lovegrove FE, Ayi K, Conroy A, Serghides L, Min-oo G, Gowda DC, Sarma JV, and Rittirsch D, et al. (2008) C5 deficiency and C5a or C5aR blockade protects against cerebral malaria. J Exp Med 205:1133-1143.

Peake P and Shen Y (2010) Factor H binds to the N-terminus of adiponectin and modulates complement activation. Biochem Biophys Res Commun 397:361-366.

Peake PW, Shen Y, Walther A, and Charlesworth JA (2008) Adiponectin binds C1q and activates the classical pathway of complement. Biochem Biophys Res Commun 367:560-565.

Pease JE and Barker MD (1993) N-linked glycosylation of the C5a receptor. Biochem Mol Biol Int 31:719-726.

Pease JE, Burton DR, and Barker MD (1994) Generation of chimeric C5a/formyl peptide receptors: towards the identification of the human C5a receptor binding site. Eur J Immunol 24:211-215.

Peng Q, Li K, Sacks SH, and Zhou W (2009a) The role of anaphylatoxins C3a and C5a in regulating innate and adaptive immune responses. Inflamm Allergy Drug Targets 8:236-246.

Peng Q, Li K, Wang N, Li Q, Asgari E, Lu B, Woodruff TM, Sacks SH, and Zhou W (2009b) Dendritic cell function in allostimulation is modulated by C5aR signaling. $J$ Immunol 183:6058-6068.

Perl M, Denk S, Kalbitz M, and Huber-Lang M (2012) Granzyme B: a new crossroad of complement and apoptosis. Adv Exp Med Biol 946:135-146.

Persson L, Borén J, Robertson AK, Wallenius V, Hansson GK, and Pekna M (2004) Lack of complement factor $\mathrm{C} 3$, but not factor B, increases hyperlipidemia and atherosclerosis in apolipoprotein E-/- low-density lipoprotein receptor-/- mice. Arterioscler Thromb Vasc Biol 24:1062-1067.

Péterfy H, Tóth G, Pecht I, and Erdei A (2008) C3a-derived peptide binds to the type I FcepsilonR and inhibits proximal-coupling signal processes and cytokine secretion by mast cells. Int Immunol 20:1239-1245.

Pettersen EF, Goddard TD, Huang CC, Couch GS, Greenblatt DM, Meng EC, and Ferrin TE (2004) UCSF Chimera-a visualization system for exploratory research and analysis. J Comput Chem 25:1605-1612.

Pfeifer PH, Brems JJ, Brunson M, and Hugli TE (2000) Plasma C3a and C4a levels in liver transplant recipients: a longitudinal study. Immunopharmacology 46:163-174 Pinto MR, Chinnici CM, Kimura Y, Melillo D, Marino R, Spruce LA, De Santis R, Parrinello N, and Lambris JD (2003) CiC3-1a-mediated chemotaxis in the deuterostome invertebrate Ciona intestinalis (Urochordata). J Immunol 171: $5521-5528$

Pinto MR, Melillo D, Giacomelli S, Sfyroera G, and Lambris JD (2007) Ancient origin of the complement system: emerging invertebrate models. Adv Exp Med Biol 598: 372-388.

Pollok-Kopp B, Hüttenrauch F, Rethorn S, and Oppermann M (2007) Dynamics of protein kinase C-mediated phosphorylation of the complement C5a receptor on serine 334. J Biol Chem 282:4345-4353.

Postma B, Kleibeuker W, Poppelier MJ, Boonstra M, Van Kessel KP, Van Strijp JA and de Haas CJ (2005) Residues 10-18 within the C5a receptor N terminus compose a binding domain for chemotaxis inhibitory protein of Staphylococcus aureus. J Biol Chem 280:2020-2027.

Postma B, Poppelier MJ, van Galen JC, Prossnitz ER, van Strijp JA, de Haas CJ, and van Kessel KP (2004) Chemotaxis inhibitory protein of Staphylococcus aureus binds specifically to the C5a and formylated peptide receptor. J Immunol 172: 6994-7001. 
Poursharifi P, Lapointe M, Petrin D, Devost D, Gauvreau D, Hebert TE, and Cianflone K (2012) C5L2 and C5aR interaction in adipocytes and macrophages: Insights into adipoimmunology. Cell Signal doi.org/10.1016/j.cellsig. 2012.12.010

Powers JP, Dairaghi DJ, and Jaen JC (2011) Advances in the discovery of C5a receptor antagonists. Annu Rep Med Chem 46:171-186.

Proctor LM, Woodruff TM, Sharma P, Shiels IA, and Taylor SM (2006) Transdermal pharmacology of small molecule cyclic C5a antagonists. Adv Exp Med Biol 586: 329-345.

Prokopec KE, Berntson L, Öman A, and Kleinau S (2012) Up regulated complement and fc receptors in juvenile idiopathic arthritis and correlation with disease phenotype. J Clin Immunol 32:540-550.

Prossnitz ER, Gilbert TL, Chiang S, Campbell JJ, Qin S, Newman W, Sklar LA, and Ye RD (1999) Multiple activation steps of the $\mathrm{N}$-formyl peptide receptor. Biochemistry 38:2240-2247.

Qu H, Ricklin D, and Lambris JD (2009) Recent developments in low molecular weight complement inhibitors. Mol Immunol 47:185-195.

Rabiet MJ, Huet E, and Boulay F (2008) Complement component 5a receptor oligomerization and homologous receptor down-regulation. $J$ Biol Chem 283 31038-31046.

Rabiet MJ, Macari L, Dahlgren C, and Boulay F (2011) N-formyl peptide receptor 3 (FPR3) departs from the homologous FPR2/ALX receptor with regard to the major processes governing chemoattractant receptor regulation, expression at the cell surface, and phosphorylation. J Biol Chem 286:26718-26731.

Raby AC, Holst B, Davies J, Colmont C, Laumonnier Y, Coles B, Shah S, Hall J, Topley N, and Köhl J, et al. (2011) TLR activation enhances C5a-induced proinflammatory responses by negatively modulating the second C5a receptor, C5L2. Eur J Immunol 41:2741-2752.

Raffetseder U, Röper D, Mery L, Gietz C, Klos A, Grötzinger J, Wollmer A, Boulay F, Köhl J, and Bautsch W (1996) Site-directed mutagenesis of conserved charged residues in the helical region of the human C5a receptor. Arg2O6 determines highaffinity binding sites of C5a receptor. Eur J Biochem 235:82-90.

Ramos TN, Wohler JE, and Barnum SR (2009) Deletion of both the C3a and C5a receptors fails to protect against experimental autoimmune encephalomyelitis. Neurosci Lett 467:234-236.

Randolph-Habecker JR, Rahill B, Torok-Storb B, Vieira J, Kolattukudy PE, Rovin $\mathrm{BH}$, and Sedmak DD (2002) The expression of the cytomegalovirus chemokine receptor homolog US28 sequesters biologically active CC chemokines and alters IL8 production. Cytokine 19:37-46.

Ratajczak MZ, Kim C, Wu W, Shin DM, Bryndza E, Kucia M, and Ratajczak J (2012) The role of innate immunity in trafficking of hematopoietic stem cells-an emerging link between activation of complement cascade and chemotactic gradients of bioactive sphingolipids. Adv Exp Med Biol 946:37-54.

Ratajczak MZ, Kim CH, Wojakowski W, Janowska-Wieczorek A, Kucia M, and Ratajczak J (2010) Innate immunity as orchestrator of stem cell mobilization. Leukemia 24:1667-1675.

Reca R, Mastellos D, Majka M, Marquez L, Ratajczak J, Franchini S, Glodek A, Honczarenko M, Spruce LA, and Janowska-Wieczorek A, et al. (2003) Functional receptor for $\mathrm{C} 3 \mathrm{a}$ anaphylatoxin is expressed by normal hematopoietic stem/ progenitor cells, and C3a enhances their homing-related responses to SDF-1. Blood 101:3784-3793.

Rees-Roberts D, Mullen LM, Gounaris K, and Selkirk ME (2010) Inactivation of the complement anaphylatoxin C5a by secreted products of parasitic nematodes. Int $J$ Parasitol 40:527-532.

Reis ES, Chen H, Sfyroera G, Monk PN, Köhl J, Ricklin D, and Lambris JD (2012) C5a receptor-dependent cell activation by physiological concentrations of desarginated C5a: insights from a novel label-free cellular assay. $J$ Immunol 189 $4797-4805$

Revollo I, Nishiura H, Shibuya Y, Oda Y, Nishino N, and Yamamoto T (2005) Agonist and antagonist dual effect of the cross-linked S19 ribosomal protein dimer in the C5a receptor-mediated respiratory burst reaction of phagocytic leukocytes. Inflamm Res 54:82-90.

Richani K, Soto E, Romero R, Espinoza J, Chaiworapongsa T, Nien JK, Edwin S, Kim YM, Hong JS, and Mazor M (2005) Normal pregnancy is characterized by systemic activation of the complement system. J Matern Fetal Neonatal Med 17:239-245.

Ricklin D and Lambris JD (2007) Complement-targeted therapeutics. Nat Biotechnol 25:1265-1275.

Rittirsch D, Flierl MA, Nadeau BA, Day DE, Huber-Lang M, Mackay CR, Zetoune FS, Gerard NP, Cianflone K, and Köhl J, et al. (2008) Functional roles for C5a receptors in sepsis. Nat Med 14:551-557.

Rosenquist GL and Nicholas HB Jr (1993) Analysis of sequence requirements for protein tyrosine sulfation. Protein Sci 2:215-222.

Rovati GE, Capra V, and Neubig RR (2007) The highly conserved DRY motif of class A G protein-coupled receptors: beyond the ground state. Mol Pharmacol 71: 959-964.

Roy C, Roy MC, Gauvreau D, Poulin AM, Tom FQ, Timofeeva E, Richard D, and Cianflone K (2011) Acute injection of ASP in the third ventricle inhibits food intake and locomotor activity in rats. Am J Physiol Endocrinol Metab $\mathbf{3 0 1}$ E232-E241.

Rua-Figueroa I, Arencibia-Mireles O, Elvira M, Erausquin C, Ojeda S, Francisco F, Naranjo A, Rodríguez-Gallego C, Garcia-Laorden I, Rodríguez-Perez J, and Rodríguez-Lozano C (2010) Factors involved in the progress of preclinical atherosclerosis associated with systemic lupus erythematosus: a 2-year longitudinal study. Ann Rheum Dis 69:1136-1139.

Ruan BH, Li X, Winkler AR, Kuai J, Greco RM, Nocka KH, Fitz LJ, Wright JF, Pittman DD, and Tan XY, et al. (2010) Complement C3a, CpG oligos, and DNA/C3a complex stimulate IFN- $\alpha$ production in a receptor for advanced glycation end product-dependent manner. J Immunol 185:4213-4222.
Rutkowski MJ, Sughrue ME, Kane AJ, Ahn BJ, Fang S, and Parsa AT (2010a) The complement cascade as a mediator of tissue growth and regeneration. Inflamm Res 59:897-905.

Rutkowski MJ, Sughrue ME, Kane AJ, Mills SA, and Parsa AT (2010b) Cancer and the complement cascade. Mol Cancer Res 8:1453-1465.

Rynkowski MA, Kim GH, Garrett MC, Zacharia BE, Otten ML, Sosunov SA, Komotar RJ, Hassid BG, Ducruet AF, Lambris JD, and Connolly ES (2009) C3a receptor antagonist attenuates brain injury after intracerebral hemorrhage. J Cereb Blood Flow Metab 29:98-107.

Sacks SH (2010) Complement fragments C3a and C5a: the salt and pepper of the immune response. Eur $J$ Immunol 40:668-670.

Saleh J, Al-Riyami HD, Chaudhary TA, and Cianflone K (2008) Cord blood ASP is predicted by maternal lipids and correlates with fetal birth weight. Obesity (Silver Spring) 16:1193-1198.

Saleh J, Cianflone K, Chaudhary T, Al-Riyami H, Al-Abri AR, and Bayoumi R (2007) Increased plasma acylation-stimulating protein correlates with hyperlipidemia at late gestation. Obesity (Silver Spring) 15:646-652.

Sanderson SD, Kirnarsky L, Sherman SA, Ember JA, Finch AM, and Taylor SM (1994) Decapeptide agonists of human C5a: the relationship between conformation and spasmogenic and platelet aggregatory activities. J Med Chem 37:3171-3180.

Sanganee HJ, Baxter A, Barber S, Brown AJ, Grice D, Hunt F, King S, Laughton D, Pairaudeau G, and Thong B, et al. (2009) Discovery of small molecule human C5a receptor antagonists. Bioorg Med Chem Lett 19:1143-1147.

Sato T, Miwa T, Akatsu H, Matsukawa N, Obata K, Okada N, Campbell W, and Okada H (2000) Pro-carboxypeptidase $\mathrm{R}$ is an acute phase protein in the mouse, whereas carboxypeptidase $\mathrm{N}$ is not. J Immunol 165:1053-1058.

Savarese TM and Fraser CM (1992) In vitro mutagenesis and the search for structure-function relationships among $\mathrm{G}$ protein-coupled receptors. Biochem $J$ 283:1-19.

Sayah S, Jauneau AC, Patte C, Tonon MC, Vaudry H, and Fontaine M (2003) Two different transduction pathways are activated by C3a and C5a anaphylatoxins on astrocytes. Brain Res Mol Brain Res 112:53-60.

Schaefer M, Konrad S, Thalmann J, Rheinheimer C, Johswich K, Sohns B, and Klos A (2005) The transcription factors AP-1 and Ets are regulators of C3a receptor expression. J Biol Chem 280:42113-42123.

Scheer A, Fanelli F, Costa T, De Benedetti PG, and Cotecchia S (1996) Constitutively active mutants of the alpha 1B-adrenergic receptor: role of highly conserved polar amino acids in receptor activation. EMBO J 15:3566-3578.

Schnatbaum K, Locardi E, Scharn D, Richter U, Hawlisch H, Knolle J, and Polakowski T (2006) Peptidomimetic C5a receptor antagonists with hydrophobic substitutions at the C-terminus: increased receptor specificity and in vivo activity. Bioorg Med Chem Lett 16:5088-5092.

Schraufstatter IU, Discipio RG, Zhao M, and Khaldoyanidi SK (2009) C3a and C5a are chemotactic factors for human mesenchymal stem cells, which cause prolonged ERK1/2 phosphorylation. J Immunol 182:3827-3836.

Schraufstatter IU, Trieu K, Sikora L, Sriramarao P, and DiScipio R (2002) Complement c3a and c5a induce different signal transduction cascades in endothelial cells. J Immunol 169:2102-2110.

Scola AM, Higginbottom A, Partridge LJ, Reid RC, Woodruff T, Taylor SM, Fairlie DP, and Monk PN (2007) The role of the N-terminal domain of the complement fragment receptor C5L2 in ligand binding. J Biol Chem 282:3664-3671.

Scola AM, Johswich KO, Morgan BP, Klos A, and Monk PN (2009) The human complement fragment receptor, C5L2, is a recycling decoy receptor. Mol Immunol 46:1149-1162.

Scully CC, Blakeney JS, Singh R, Hoang HN, Abbenante G, Reid RC, and Fairlie DP (2010) Selective hexapeptide agonists and antagonists for human complement C3a receptor. $J$ Med Chem 53:4938-4948.

Semba U, Chen J, Ota Y, Jia N, Arima H, Nishiura H, and Yamamoto T (2010) A plasma protein indistinguishable from ribosomal protein S19: conversion to a monocyte chemotactic factor by a factor XIIIa-catalyzed reaction on activated platelet membrane phosphatidylserine in association with blood coagulation. Am J Pathol 176:1542-1551.

Sergeev IuV, Reznikov IuP, Lobanova EV, and Pimenova NS (1989). Atopic dermatitis. II. The status of complement proteins and the pathogenetic role of anaphylatoxins C4a, C3a and C5a [article in Russian]. Vestn Dermatol Venerol 4:4-7.

Settmacher B, Rheinheimer C, Hamacher H, Ames RS, Wise A, Jenkinson L, Bock D, Schaefer M, Köhl J, and Klos A (2003) Structure-function studies of the C3areceptor: C-terminal serine and threonine residues which influence receptor internalization and signaling. Eur J Immunol 33:920-927.

Shagdarsuren E, Bidzhekov K, Mause SF, Simsekyilmaz S, Polakowski T, Hawlisch $\mathrm{H}$, Gessner JE, Zernecke A, and Weber C (2010) C5a receptor targeting in neointima formation after arterial injury in atherosclerosis-prone mice. Circulation 122:1026-1036

Sherry ST, Ward MH, Kholodov M, Baker JB, Phan L, Smigielski EM, and Sirotkin K (2001) dbSNP: the NCBI database of genetic variation. Nucleic Acids Res 29 308-311.

Sheth B, Banks P, Burton DR, and Monk PN (1991) The regulation of actin polymerization in differentiating U937 cells correlates with increased membrane levels of the pertussis-toxin-sensitive G-protein Gi2. Biochem $J$ 275:809-811.

Shibuya Y, Shiokawa M, Nishiura H, Nishimura T, Nishino N, Okabe H, Takagi K, and Yamamoto T (2001) Identification of receptor-binding sites of monocyte chemotactic S19 ribosomal protein dimer. Am J Pathol 159:2293-2301.

Shinjyo N, Ståhlberg A, Dragunow M, Pekny M, and Pekna M (2009) Complementderived anaphylatoxin C3a regulates in vitro differentiation and migration of neural progenitor cells. Stem Cells 27:2824-2832.

Shoemaker RC, Giclas PC, Crowder C, House D, and Glovsky MM (2008) Complement split products $\mathrm{C} 3 \mathrm{a}$ and $\mathrm{C} 4 \mathrm{a}$ are early markers of acute lyme disease in tick bite patients in the United States. Int Arch Allergy Immunol 146:255-261. 
Short AJ, Paczkowski NJ, Vogen SM, Sanderson SD, and Taylor SM (1999) Response-selective C5a agonists: differential effects on neutropenia and hypotension in the rat. $\mathrm{Br} J$ Pharmacol 128:511-514.

Shrestha A, Shi L, Tanase S, Tsukamoto M, Nishino N, Tokita K, and Yamamoto T (2004) Bacterial chaperone protein, Skp, induces leukocyte chemotaxis via C5a receptor. Am J Pathol 164:763-772.

Shrestha A, Shiokawa M, Nishimura T, Nishiura H, Tanaka Y, Nishino N, Shibuya $\mathrm{Y}$, and Yamamoto T (2003) Switch moiety in agonist/antagonist dual effect of S19 ribosomal protein dimer on leukocyte chemotactic C5a receptor. Am J Pathol 162: 1381-1388.

Siciliano SJ, Rollins TE, and Springer MS (1990) Interaction between the C5a receptor and Gi in both the membrane-bound and detergent-solubilized states. $J$ Biol Chem 265:19568-19574.

Skeie JM, Fingert JH, Russell SR, Stone EM, and Mullins RF (2010) Complement component C5a activates ICAM-1 expression on human choroidal endothelial cells. Invest Ophthalmol Vis Sci 51:5336-5342.

Skokowa J, Ali SR, Felda O, Kumar V, Konrad S, Shushakova N, Schmidt RE, Piekorz RP, Nürnberg B, and Spicher K, et al. (2005) Macrophages induce the inflammatory response in the pulmonary Arthus reaction through $\mathrm{G}$ alpha i2 activation that controls $\mathrm{C} 5 \mathrm{aR}$ and $\mathrm{Fc}$ receptor cooperation. J Immunol 174: 3041-3050.

Smith MA, Gerrie LM, Dunbar B, and Fothergill JE (1982) Primary structure of bovine complement activation fragment $\mathrm{C} 4 \mathrm{a}$, the third anaphylatoxin. Purification and complete amino acid sequence. Biochem $J$ 207:253-260.

Sniderman A, Teng B, Genest J, Cianflone K, Wacholder S, and Kwiterovich P Jr (1985) Familial aggregation and early expression of hyperapobetalipoproteinemia. Am J Cardiol 55:291-295.

Sniderman AD and Cianflone K (1994) The adipsin-ASP pathway and regulation of adipocyte function. Ann Med 26:388-393.

Sniderman AD, Cianflone KM, and Eckel RH (1991) Levels of acylation stimulating protein in obese women before and after moderate weight loss. Int $J$ Obes 15: 333-336.

Solassol J, Rouanet P, Lamy PJ, Allal C, Favre G, Maudelonde T, and Mangé A (2010) Serum protein signature may improve detection of ductal carcinoma in situ of the breast. Oncogene 29:550-560.

Sonesson A, Ringstad L, Nordahl EA, Malmsten M, Mörgelin M, and Schmidtchen A (2007) Antifungal activity of C3a and C3a-derived peptides against Candida. Biochim Biophys Acta 1768:346-353.

Song JJ, Hwang I, Cho KH, Garcia MA, Kim AJ, Wang TH, Lindstrom TM, Lee AT, Nishimura T, and Zhao L, et al.; Consortium for the Longitudinal Evaluation of African Americans with Early Rheumatoid Arthritis (CLEAR) Registry (2011) Plasma carboxypeptidase B downregulates inflammatory responses in autoimmune arthritis. J Clin Invest 121:3517-3527.

Speidl WS, Kastl SP, Hutter R, Katsaros KM, Kaun C, Bauriedel G, Maurer G, Huber K, Badimon JJ, and Wojta J (2011) The complement component C5a is present in human coronary lesions in vivo and induces the expression of MMP-1 and MMP-9 in human macrophages in vitro. FASEB $J$ 25:35-44.

Stokowska A, Olsson S, Holmegaard L, Jood K, Blomstrand C, Jern C, and Pekna M (2011) Plasma C3 and C3a levels in cryptogenic and large-vessel disease stroke: associations with outcome. Cerebrovasc Dis 32:114-122.

Stöve S, Klos A, Bautsch W, and Köhl J (1995) Re-evaluation of the storage conditions for blood samples which are used for determination of complement activation. $J$ Immunol Methods 182:1-5.

Stöve S, Welte T, Wagner TO, Kola A, Klos A, Bautsch W, and Köhl J (1996) Circulating complement proteins in patients with sepsis or systemic inflammatory response syndrome. Clin Diagn Lab Immunol 3:175-183.

Strachan AJ, Shiels IA, Reid RC, Fairlie DP, and Taylor SM (2001) Inhibition of immune-complex mediated dermal inflammation in rats following either oral or topical administration of a small molecule C5a receptor antagonist. $\mathrm{Br} \mathrm{J}$ Phar macol 134:1778-1786.

Strachan AJ, Woodruff TM, Haaima G, Fairlie DP, and Taylor SM (2000) A new small molecule C5a receptor antagonist inhibits the reverse-passive Arthus reaction and endotoxic shock in rats. J Immunol 164:6560-6565.

Strainic MG, Liu J, Huang D, An F, Lalli PN, Muqim N, Shapiro VS, Dubyak GR, Heeger PS, and Medof ME (2008) Locally produced complement fragments C5a and C3a provide both costimulatory and survival signals to naive $\mathrm{CD} 4^{+} \mathrm{T}$ cells. $\mathrm{Im}$ munity 28:425-435.

Strey CW, Siegmund B, Rosenblum S, Marquez-Pinilla RM, Oppermann E, HuberLang M, Lambris JD, and Bechstein WO (2009) Complement and neutrophil function changes after liver resection in humans. World $J$ Surg 33:2635-2643.

Stricker RB, Savely VR, Motanya NC, and Giclas PC (2009) Complement split products c3a and c4a in chronic lyme disease. Scand J Immunol 69:64-69.

Subramanian H, Kashem SW, Collington SJ, Qu H, Lambris JD, and Ali H (2011) PMX-53 as a dual CD88 antagonist and an agonist for Mas-related gene 2 (MrgX2) in human mast cells. Mol Pharmacol 79:1005-1013.

Sumichika H, Sakata K, Sato N, Takeshita S, Ishibuchi S, Nakamura M, Kamahori T, Ehara S, Itoh K, and Ohtsuka T, et al. (2002) Identification of a potent and orally active non-peptide C5a receptor antagonist. J Biol Chem 277:49403-49407.

Sun J, Ember JA, Chao TH, Fukuoka Y, Ye RD, and Hugli TE (1999) Identification of ligand effector binding sites in transmembrane regions of the human G proteincoupled C3a receptor. Protein Sci 8:2304-2311.

Sun S, Guo Y, Zhao G, Zhou X, Li J, Hu J, Yu H, Chen Y, Song H, and Qiao F, et al. (2011) Complement and the alternative pathway play an important role in LPS/DGalN-induced fulminant hepatic failure. PLoS ONE 6:e26838.

Surgand JS, Rodrigo J, Kellenberger E, and Rognan D (2006) A chemogenomic analysis of the transmembrane binding cavity of human G-protein-coupled receptors. Proteins 62:509-538.

Suvorova ES, Gripentrog JM, Oppermann M, and Miettinen HM (2008) Role of the carboxyl terminal di-leucine in phosphorylation and internalization of C5a receptor. Biochim Biophys Acta 1783:1261-1270.
Takabayashi T, Vannier E, Clark BD, Margolis NH, Dinarello CA, Burke JF, and Gelfand JA (1996) A new biologic role for C3a and C3a desArg: regulation of TNF-alpha and IL-1 beta synthesis. J Immunol 156:3455-3460.

Takahashi M, Moriguchi S, Suganuma H, Shiota A, Tani F, Usui H, Kurahashi K, Sasaki R, and Yoshikawa M (1997) Identification of casoxin C, an ileumcontracting peptide derived from bovine kappa-casein, as an agonist for C3a receptors. Peptides 18:329-336.

Takematsu H, Ohkohchi K, and Tagami H (1986) Demonstration of anaphylatoxins $\mathrm{C} 3 \mathrm{a}, \mathrm{C} 4 \mathrm{a}$ and $\mathrm{C} 5 \mathrm{a}$ in the scales of psoriasis and inflammatory pustular dermatoses. Br J Dermatol 114:1-6.

Tang Z, Lu B, Hatch E, Sacks SH, and Sheerin NS (2009) C3a mediates epithelial-tomesenchymal transition in proteinuric nephropathy. J Am Soc Nephrol 20 593-603.

Taylor SM, Finch AM, Heron AE, Brown LC, and Florin TH (1994) Reversibility of tachyphylaxis to C5A in guinea pig tissues, perfused human placental lobule, and umbilical artery. Inflammation 18:645-657.

Taylor SM, Sherman SA, Kirnarsky L, and Sanderson SD (2001) Development of response-selective agonists of human $\mathrm{C5a}$ anaphylatoxin: conformational, biological, and therapeutic considerations. Curr Med Chem 8:675-684.

Tayman C, Tonbul A, Kahveci H, Uysal S, Koseoğlu B, Tatli MM, and Dilmen U (2011) C5a, a complement activation product, is a useful marker in predicting the severity of necrotizing enterocolitis. Tohoku J Exp Med 224:143-150.

Tegla CA, Cudrici C, Patel S, Trippe R 3rd, Rus V, Niculescu F, and Rus H (2011) Membrane attack by complement: the assembly and biology of terminal complement complexes. Immunol Res 51:45-60.

Terado T, Okamura K, Ohta Y, Shin DH, Smith SL, Hashimoto K, Takemoto T, Nonaka MI, Kimura H, Flajnik MF, and Nonaka M (2003) Molecular cloning of C4 gene and identification of the class III complement region in the shark MHC. $J$ Immunol 171:2461-2466.

Terui T, Takematsu H, Kato T, Ohkohchi K, and Tagami H (1987) Plasma anaphylatoxin concentrations in inflammatory skin diseases. Tohoku J Exp Med 151: 245-252.

Thomas WG, Baker KM, Motel TJ, and Thekkumkara TJ (1995) Angiotensin II receptor endocytosis involves two distinct regions of the cytoplasmic tail. A role for residues on the hydrophobic face of a putative amphipathic helix. J Biol Chem $\mathbf{2 7 0}$ : 22153-22159.

Thurman JM, Lenderink AM, Royer PA, Coleman KE, Zhou J, Lambris JD, Nemenoff RA, Quigg RJ, and Holers VM (2007) C3a is required for the production of CXC chemokines by tubular epithelial cells after renal ishemia/reperfusion. J Immunol 178:1819-1828.

Tokodai K, Goto M, Inagaki A, Imura T, Nakanishi W, and Satomi S (2011) Expression of receptors for anaphylatoxins $\mathrm{C} 3 \mathrm{a}$ and $\mathrm{C} 5 \mathrm{a}$ on rat islet preparations. Transplant Proc 43:3179-3180.

Tornetta MA, Foley JJ, Sarau HM, and Ames RS (1997) The mouse anaphylatoxin C3a receptor: molecular cloning, genomic organization, and functional expression. $J$ Immunol 158:5277-5282.

Toth MJ, Huwyler L, Boyar WC, Braunwalder AF, Yarwood D, Hadala J, Haston WO, Sills MA, Seligmann B, and Galakatos N (1994) The pharmacophore of the human C5a anaphylatoxin. Protein Sci 3:1159-1168.

Tsuboi N, Ernandez T, Li X, Nishi H, Cullere X, Mekala D, Hazen M, Köhl J, Lee DM, and Mayadas TN (2011) Regulation of human neutrophil Fc $\gamma$ receptor IIa by C5a receptor promotes inflammatory arthritis in mice. Arthritis Rheum 63:467-478.

Tsuji RF, Magae J, Nagai K, and Yamasaki M (1992a) Effects of L-156,602, a C5a receptor antagonist, on mouse experimental models of inflammation. Biosci Biotechnol Biochem 56:2034-2036.

Tsuji RF, Uramoto M, Koshino H, Tsuji NM, Magae J, Nagai K, and Yamasaki M (1992b) Preferential suppression of delayed-type hypersensitivity by L-156,602 a C5a receptor antagonist. Biosci Biotechnol Biochem 56:1686-1689.

Tsuji RF, Yamakoshi J, Uramoto M, Koshino H, Saito M, Kikuchi M, and Masuda T (1995) Anti-inflammatory effects and specificity of L-156,602: comparison of effects on concanavalin A and zymosan-induced footpad edema, and contact sensitivity response. Immunopharmacology 29:79-87.

Tsuruta T, Yamamoto T, Matsubara S, Nagasawa S, Tanase S, Tanaka J, Takagi K, and Kambara T (1993) Novel function of C4a anaphylatoxin. Release from monocytes of protein which inhibits monocyte chemotaxis. Am J Pathol 142:1848-1857.

Tyndall JD, Pfeiffer B, Abbenante G, and Fairlie DP (2005) Over one hundred peptide-activated $\mathrm{G}$ protein-coupled receptors recognize ligands with turn structure. Chem Rev 105:793-826.

van der Pals J, Koul S, Andersson P, Götberg M, Ubachs JF, Kanski M, Arheden H, Olivecrona GK, Larsson B, and Erlinge D (2010) Treatment with the C5a receptor antagonist $\mathrm{ADC}-1004$ reduces myocardial infarction in a porcine ischemiareperfusion model. BMC Cardiovasc Disord 10:45

Van Lith LH, Oosterom J, Van Elsas A, and Zaman GJ (2009) C5a-stimulated recruitment of beta-arrestin2 to the nonsignaling 7-transmembrane decoy receptor C5L2. J Biomol Screen 14:1067-1075.

van Oostrom AJ, van Dijk H, Verseyden C, Sniderman AD, Cianflone K, Rabelink TJ, and Castro Cabezas M (2004) Addition of glucose to an oral fat load reduces postprandial free fatty acids and prevents the postprandial increase in complement component 3. Am J Clin Nutr 79:510-515.

Vanek M, Hawkins LD, and Gusovsky F (1994) Coupling of the C5a receptor to Gi in U-937 cells and in cells transfected with C5a receptor cDNA. Mol Pharmacol 46: 832-839.

Veneskoski M, Turunen SP, Kummu O, Nissinen A, Rannikko S, Levonen AL, and Hörkkö S (2011) Specific recognition of malondialdehyde and malondialdehyde acetaldehyde adducts on oxidized LDL and apoptotic cells by complement anaphylatoxin C3a. Free Radic Biol Med 51:834-843.

Venkatesha RT, Berla Thangam E, Zaidi AK, and Ali H (2005) Distinct regulation of C3a-induced MCP-1/CCL2 and RANTES/CCL5 production in human mast cells by extracellular signal regulated kinase and PI3 kinase. Mol Immunol 42: $581-587$. 
Vibhuti A, Gupta K, Subramanian H, Guo Q, and Ali H (2011) Distinct and shared roles of $\beta$-arrestin- 1 and $\beta$-arrestin- 2 on the regulation of $\mathrm{C} 3$ a receptor signaling in human mast cells. PLoS ONE 6:e19585.

Vieyra M, Leisman S, Raedler H, Kwan WH, Yang M, Strainic MG, Medof ME, and Heeger PS (2011) Complement regulates CD4 T-cell help to CD8 T cells required for murine allograft rejection. Am J Pathol 179:766-774.

Vlattas I, Sytwu II, Dellureficio J, Stanton J, Braunwalder AF, Galakatos N, Kramer R, Seligmann B, Sills MA, and Wasvary J (1994) Identification of a receptorbinding region in the core segment of the human anaphylatoxin C5a. J Med Chem 37:2783-2790.

Vogen SM, Finch AM, Wadi SK, Thatcher J, Monk PN, Taylor SM, and Sanderson SD (1999a) The influence of Lys68 in decepeptide agonists of C5a on C5a receptor binding, activation and selectivity. J Pept Res 53:8-17.

Vogen SM, Prakash O, Kirnarsky L, Sanderson SD, and Sherman SA (1999b) Determination of structural elements related to the biological activities of a potent decapeptide agonist of human C5a anaphylatoxin. J Pept Res 54:74-84.

von Köckritz-Blickwede M, Konrad S, Foster S, Gessner JE, and Medina E (2010) Protective role of complement C5a in an experimental model of Staphylococcus aureus bacteremia. J Innate Immun 2:87-92

Wagner JL and Hugli TE (1984) Radioimmunoassay for anaphylatoxins: a sensitive method for determining complement activation products in biological fluids. Anal Biochem 136:75-88.

Walton TA, Sandoval CM, Fowler CA, Pardi A, and Sousa MC (2009) The cavitychaperone Skp protects its substrate from aggregation but allows independent folding of substrate domains. Proc Natl Acad Sci USA 106:1772-1777.

Walton TA and Sousa MC (2004) Crystal structure of Skp, a prefoldin-like chaperone that protects soluble and membrane proteins from aggregation. Mol Cell $\mathbf{1 5}$ 367-374.

Wang M, Krauss JL, Domon H, Hosur KB, Liang S, Magotti P, Triantafilou M, Triantafilou K, Lambris JD, and Hajishengallis G (2010) Microbial hijacking of complement-toll-like receptor crosstalk. Sci Signal 3:ra11.

Wang W, Hendriks DF, and Scharpé SS (1994) Carboxypeptidase U, a plasma carboxypeptidase with high affinity for plasminogen. J Biol Chem 269:15937-15944.

Ward PA and Zvaifler NJ (1971) Complement-derived leukotactic factors in inflammatory synovial fluids of humans. J Clin Invest 50:606-616.

Waterhouse AM, Procter JB, Martin DM, Clamp M, and Barton GJ (2009) Jalview Version 2-a multiple sequence alignment editor and analysis workbench. Bioinformatics 25:1189-1191.

Waters SM, Brodbeck RM, Steflik J, Yu J, Baltazar C, Peck AE, Severance D, Zhang LY, Currie K, and Chenard BL, et al. (2005) Molecular characterization of the gerbil $\mathrm{C} 5 \mathrm{a}$ receptor and identification of a transmembrane domain $\mathrm{V}$ amino acid that is crucial for small molecule antagonist interaction. $J$ Biol Chem 280 : 40617-40623.

Weaver DJ Jr, Reis ES, Pandey MK, Köhl G, Harris N, Gerard C, and Köhl J (2010) C5a receptor-deficient dendritic cells promote induction of Treg and Th17 cells. Eur J Immunol 40:710-721.

Weber M, Blair E, Simpson CV, O'Hara M, Blackburn PE, Rot A, Graham GJ, and Nibbs RJ (2004) The chemokine receptor D6 constitutively traffics to and from the cell surface to internalize and degrade chemokines. Mol Biol Cell 15: $2492-2508$

Welch TR, Frenzke M, Carroll MC, and Witte DP (2001) Evidence or a role for C4 in modulating interstitial inflammation in experimental glomerulonephritis. Clin Immunol 101:366-370.

Wenderfer SE, Wang H, Ke B, Wetsel RA, and Braun MC (2009) C3a receptor deficiency accelerates the onset of renal injury in the MRL/lpr mouse. Mol Immunol 46:1397-1404

Werfel T, Kirchhoff K, Wittmann M, Begemann G, Kapp A, Heidenreich F, Götze O, and Zwirner J (2000) Activated human T lymphocytes express a functional C3a receptor. J Immunol 165:6599-6605.

Wetsel RA, Kildsgaard J, Zsigmond E, Liao W, and Chan L (1999) Genetic deficiency of acylation stimulating protein (ASP(C3ades-Arg)) does not cause hyperapobetalipoproteinemia in mice. J Biol Chem 274:19429-19433.

Wexler DE, Chenoweth DE, and Cleary PP (1985) Mechanism of action of the group A streptococcal C5a inactivator. Proc Natl Acad Sci USA 82:8144-8148.

White RT, Damm D, Hancock N, Rosen BS, Lowell BB, Usher P, Flier JS, and Spiegelman BM (1992) Human adipsin is identical to complement factor D and is expressed at high levels in adipose tissue. J Biol Chem 267:9210-9213.

Wild G, Watkins J, Ward AM, Hughes P, Hume A, and Rowell NR (1990) C4a anaphylatoxin levels as an indicator of disease activity in systemic lupus erythematosus. Clin Exp Immunol 80:167-170.

Wilden U, Wüst E, Weyand I, and Kühn H (1986) Rapid affinity purification of retinal arrestin (48 $\mathrm{kDa}$ protein) via its light-dependent binding to phosphorylated rhodopsin. FEBS Lett 207:292-295.

Wilken HC, Götze O, Werfel T, and Zwirner J (1999) C3a(desArg) does not bind to and signal through the human C3a receptor. Immunol Lett 67:141-145.

Williamson MP and Madison VS (1990) Three-dimensional structure of porcine C5adesArg from 1H nuclear magnetic resonance data. Biochemistry 29:2895-2905.

Wills-Karp M (2007) Complement activation pathways: a bridge between innate and adaptive immune responses in asthma. Proc Am Thorac Soc 4:247-251.

Wingrove JA, DiScipio RG, Chen Z, Potempa J, Travis J, and Hugli TE (1992) Activation of complement components $\mathrm{C} 3$ and C5 by a cysteine proteinase (gingipain1) from Porphyromonas (Bacteroides) gingivalis. J Biol Chem 267:18902-18907.

Wong AK, Taylor SM, and Fairlie DP (1999) Development of C5a receptor antagonists. IDrugs 2:686-693.

Woodruff TM, Costantini KJ, Crane JW, Atkin JD, Monk PN, Taylor SM, and Noakes PG (2008) The complement factor C5a contributes to pathology in a rat model of amyotrophic lateral sclerosis. J Immunol 181:8727-8734.
Woodruff TM, Crane JW, Proctor LM, Buller KM, Shek AB, de Vos K, Pollitt S, Williams HM, Shiels IA, Monk PN, and Taylor SM (2006) Therapeutic activity of C5a receptor antagonists in a rat model of neurodegeneration. FASEB $J \mathbf{2 0}$ 1407-1417.

Woodruff TM, Nandakumar KS, and Tedesco F (2011) Inhibiting the C5-C5a receptor axis. Mol Immunol 48:1631-1642.

Wright AJ, Higginbottom A, Philippe D, Upadhyay A, Bagby S, Read RC, Monk PN, and Partridge LJ (2007) Characterisation of receptor binding by the chemotaxis inhibitory protein of Staphylococcus aureus and the effects of the host immune response. Mol Immunol 44:2507-2517.

Wu Y, Zhang J, Wen Y, Wang H, Zhang M, and Cianflone K (2009) Increased acylation-stimulating protein, C-reactive protein, and lipid levels in young women with polycystic ovary syndrome. Fertil Steril 91:213-219.

Wysoczynski M, Kucia M, Ratajczak J, and Ratajczak MZ (2007) Cleavage fragments of the third complement component (C3) enhance stromal derived factor-1 (SDF-1)mediated platelet production during reactive postbleeding thrombocytosis. Leukemia 21:973-982.

Xia Z, Sniderman AD, and Cianflone K (2002) Acylation-stimulating protein (ASP) deficiency induces obesity resistance and increased energy expenditure in ob/ob mice. J Biol Chem 277:45874-45879.

Xia Z, Stanhope KL, Digitale E, Simion OM, Chen L, Havel P, and Cianflone K (2004) Acylation-stimulating protein (ASP)/complement C3adesArg deficiency results in increased energy expenditure in mice. J Biol Chem 279:4051-4057.

Xiao H, Jennette JC, Dairaghi DJ, Ertl L, Baumgart T, Miao S, Powers JP, Seitz LC, Wang Y, Hu P, et al. (2010) The novel C5aR antagonist CCX168 displays great efficacy in a mouse model of ANCA-induced glomerulonephritis (abstract 2048). Arthritis Rheum 62:S856. Annual Meeting of the American College of Rheumatology; 2010 Nov 3; Atlanta, GA.

Xie L, Cheng SL, Li YZ, Liu LR, Han P, Chen N, Wei Q, and Zhou Q (2011) The relationship between anaphylatoxin C3a and benign prostatic hyperplasia with inflammation [article in Chinese]. Sichuan Da Xue Xue Bao Yi Xue Ban 42:642-645.

Xie P, Nishiura H, Semba U, Chen J, Zhao R, Kuniyasu A, and Yamamoto T (2012) Inhibitory effects of $\mathrm{C} 4 \mathrm{a}$ on chemoattractant and secretagogue functions of the other anaphylatoxins via $\mathrm{Gi}$ protein-adenylyl cyclase inhibition pathway in mast cells. Int Immunopharmacol 12:158-168.

Xu R, Wang R, Han G, Wang J, Chen G, Wang L, Li X, Guo R, Shen B, and Li Y (2010a) Complement C5a regulates IL-17 by affecting the crosstalk between DC and gammadelta T cells in CLP-induced sepsis. Eur J Immunol 40:1079-1088.

Xu XH, Peng HS, Sun MQ, Hu M, Zhang R, Wang WH, He XY, and Xiao XR (2010b) C-terminal peptide of anaphylatoxin C3a enhances hepatic function after steatotic liver transplantation: a study in a rat model. Transplant Proc 42:737-740.

Yamamoto T (2000) Molecular mechanism of monocyte predominant infiltration in chronic inflammation: mediation by a novel monocyte chemotactic factor, S19 ribosomal protein dimer. Pathol Int 50:863-871.

Yanamadala V and Friedlander RM (2010) Complement in neuroprotection and neurodegeneration. Trends $\mathrm{Mol} \mathrm{Med}$ 16:69-76.

Zarbock J, Gennaro R, Romeo D, Clore GM, and Gronenborn AM (1988) A proton nuclear magnetic resonance study of the conformation of bovine anaphylatoxin C5a in solution. FEBS Lett 238:289-294.

Zarkadis IK, Mastellos D, and Lambris JD (2001) Phylogenetic aspects of the complement system. Dev Comp Immunol 25:745-762.

Zhang J, Yao WZ, and Chen YH (2011) Change in airway anaphylatoxin-complement factors $\mathrm{C} 3 \mathrm{a}$ of sputum in patients with chronic obstructive pulmonary disease [article in Chinese]. Beijing Da Xue Xue Bao 43:446-449.

Zhang L, Mallik B, and Morikis D (2008) Structural study of Ac-Phe-[Orn-Pro-dChaTrp-Arg], a potent C5a receptor antagonist, by NMR. Biopolymers 90:803-815.

Zhang X, Boyar W, Galakatos N, and Gonnella NC (1997a) Solution structure of a unique C5a semi-synthetic antagonist: implications in receptor binding. Protein Sci 6:65-72.

Zhang X, Boyar W, Toth MJ, Wennogle L, and Gonnella NC (1997b) Structural definition of the $\mathrm{C} 5 \mathrm{a} \mathrm{C}$ terminus by two-dimensional nuclear magnetic resonance spectroscopy. Proteins 28:261-267.

Zhang X, Lewkowich IP, Köhl G, Clark JR, Wills-Karp M, and Köhl J (2009) A protective role for $\mathrm{C} 5 \mathrm{a}$ in the development of allergic asthma associated with al tered levels of B7-H1 and B7-DC on plasmacytoid dendritic cells. J Immunol 182 $5123-5130$

Zhang X, Schmudde I, Laumonnier Y, Pandey MK, Clark JR, König P, Gerard NP, Gerard C, Wills-Karp M, and Köhl J (2010) A critical role for C5L2 in the pathogenesis of experimental allergic asthma. J Immunol 185:6741-6752.

Zheng YY, Xie X, Ma YT, Yang YN, Fu ZY, Li XM, Liu F, Yang SJ, Ma X, and Chen BD (2011a) S323I polymorphism of the C5L2 gene was not identified in a Chinese population with familial combined hyperlipidemia or with type 2 diabetes. Genet Mol Res 10:3256-3266.

Zheng YY, Xie X, Ma YT, Yang YN, Fu ZY, Li XM, Ma X, Chen BD, and Liu F (2011b) Relationship between a novel polymorphism of the C5L2 gene and coronary artery disease. PLoS ONE 6:e20984.

Zheng YY, Xie X, Ma YT, Yang YN, Fu ZY, Li XM, Ma X, Chen BD, and Liu F (2012) Relationship between type 2 diabetes mellitus and a novel polymorphism C698T in C5L2 in the Chinese Han population. Endocrine 41:296-301.

Zuiderweg ER, Mollison KW, Henkin J, and Carter GW (1988) Sequence-specific assignments in the $1 \mathrm{H}$ NMR spectrum of the human inflammatory protein C5a. Biochemistry 27:3568-3580.

Zuiderweg ER, Nettesheim DG, Mollison KW, and Carter GW (1989) Tertiary structure of human complement component C5a in solution from nuclear magnetic resonance data. Biochemistry 28:172-185.

Zwirner J, Götze O, Begemann G, Kapp A, Kirchhoff K, and Werfel T (1999) Evaluation of C3a receptor expression on human leucocytes by the use of novel monoclonal antibodies. Immunology 97:166-172. 


\section{Correction to "International Union of Pharmacology. LXXXVII. Complement Peptide C5a, C4a, and C3a Receptors"}

In the above article [Klos A, Wende E, Wareham KJ, and Monk PN (2013) Pharmacol Rev 65:500-543], the title is listed incorrectly. The correct name is "International Union of Basic and Clinical Pharmacology."

The printer regrets this error and any inconvenience it may have caused. 